\title{
Tolerance to the Behavioural and Neurochemical Effects of MDMA Following Repeated Exposure
}

by

Karen Jones

A thesis submitted to Victoria University of Wellington

in fulfilment of the

requirements for the degree of

Doctor of Philosophy

In Psychology

Victoria University of Wellington

2009 


\begin{abstract}
Rationale: Following repeated +/-3,4-methylenedioxymethamphetamine (MDMA) administration there is tolerance to many behavioural effects and deficits in serotonergic neurotransmission.

Objectives: The present studies had three main objectives. 1. To develop a behavioural assay to examine the effects of acute and repeated MDMA exposure. 2. To use this behavioural assay to determine whether functional changes in serotonin $(5-\mathrm{HT})_{2 \mathrm{a}}$ or $5-\mathrm{HT}_{2 \mathrm{c}}$ receptors accompany tolerance to the effects of MDMA. 3. To attempt to reverse behavioural tolerance and 5-HT deficits by administering a treatment that has been shown to desensitise the 5-HT $1 \mathrm{a}$ autoreceptor.
\end{abstract}

Methods: In separate groups of rats the dose effect curves for MDMAproduced hyperactivity were determined $(0.0,1.0,3.3,10.0 \mathrm{mg} / \mathrm{kg})$. In additional groups the effect of MDMA pretreatment (4 X 10mg/kg MDMA injections at 2 hour intervals) or saline vehicle on MDMA-produced hyperactivity was assessed. To determine the experimental parameters for MDMA effects in the Emergence Test (ET) separate groups of rats received MDMA $(0.0,3.3 \mathrm{mg} / \mathrm{kg})$ and were either habituated to a hide box for various periods $(15,30,45 \mathrm{mins})$ or exposed to the test arena 3 times over a period of days (day $1,5,9$ ) or injected daily in the home cage with MDMA $(0.0,3.3 \mathrm{mg} / \mathrm{kg})$ for 3 days. Emergence latency following injections of MDMA (0.0, $3.3 \mathrm{mg} / \mathrm{kg})$, the $5-\mathrm{HT}_{2 \mathrm{a} / \mathrm{c}}$ agonist $\mathrm{m}-\mathrm{CPP}(0.0,0.3,0.6$ or $1.25 \mathrm{~m} / \mathrm{kg})$, the $5-\mathrm{HT}$ releasing stimulant, fenfluramine $(0.0,1.0,2.0 \mathrm{mg} / \mathrm{kg})$, and the $5-\mathrm{HT}_{2 \mathrm{a}}$ agonist DOI $(0.0,1.0,2.0 \mathrm{mg} / \mathrm{kg})$ was measured. The role of $5-\mathrm{HT}_{2 \mathrm{c}}$ receptors was assessed by determining the effect of the 5- $\mathrm{HT}_{2 \mathrm{c}}$ antagonist, $\mathrm{RS} 102221(0.0,0.25,0.5,1.0 \mathrm{mg} / \mathrm{kg})$. The effect of MDMA pretreatment on MDMA $(0.0,3.3 \mathrm{mg} / \mathrm{kg}), \mathrm{m}-\mathrm{CPP}(1.25 \mathrm{mg} / \mathrm{kg})$, or fenfluramine $(2.0 \mathrm{mg} / \mathrm{kg})$ induced increases in emergence latency was also assessed.

The functional status of the 5- $\mathrm{HT}_{1 \mathrm{a}}$ autoreceptor following MDMA pretreatment was determined by measuring the effect of the 5-HT $1 \mathrm{a}$ agonist, 8OHDPAT $(0.0,0.315,0.0625,0.125,0.25,0.5 \mathrm{mg} / \mathrm{kg}, \mathrm{SC})$, on body temperature. The ability of the 5-HT $1 \mathrm{a}$ antagonist, WAY100635 (0.0, 0.01, 0.1, 1.0mg/kg, SC, 1 X daily for 7 days or by local injection of 0.0 or $500 \mathrm{ng}$ into the dorsal raphe) to reverse the attenuation of MDMA-induced hyperactivity following MDMA pretreatment was 
examined. Effects of various treatments on tissue levels of 5-HT and 5-HIAA were also measured using HPLC with EC. Results: MDMA produced dose-dependent hyperactivity and tolerance was produced by MDMA pretreatment. MDMA $(3.3 \mathrm{mg} / \mathrm{kg})$ increased emergence latency following a 30 minute habituation period and this effect was reduced in MDMA-pretreated rats. Fenfluramine and m-CPP but not DOI also increased emergence latency in a dose-dependent manner. RS102221 dose dependently blocked the acute effects of MDMA and m-CPP. Two weeks following MDMA pretreatment rats were tolerant to the effects of MDMA and fenfluramine, but not m-CPP. MDMA pretreatment also produced significant reductions in tissue levels of 5-HT and 5-HIAA.

Subcutaneous WAY100635 administration failed to reverse the behavioural and neurochemical deficits produced by MDMA pretreatment but local administration increased MDMA-produced hyperactivity in saline and MDMA pretreated rats and reversed MDMA-produced 5-HT tissue depletions.

Conclusion: The Emergence Test is a behavioural assay sensitive to the effects of acute and repeated MDMA exposure. Following MDMA pretreatment behavioural tolerance as measured by the ET is likely to be due to impaired 5-HT release rather than changes in $5-\mathrm{HT}_{2 \mathrm{a}}$ or $5-\mathrm{HT}_{2 \mathrm{c}}$ receptor responses. Because partial reversal of tolerance and 5-HT deficits following repeated MDMA administration was achieved through local DRN 5-HT 1 antagonist administration the 5-HT $1 \mathrm{a}$ autoreceptor may prove to be a clinical target for the reversal of MDMA produced deficits. 


\section{Acknowledgements}

I would like to acknowledge the many people who have supported me through my study and research.

Firstly, thank you to my husband, Peter, and children Jessica, Rebekah and Henry. You have always believed in me, given me unwavering support and stepped up on the home front when needed.

Secondly, to my Mum who regularly provided me with sound advice, all of which was listened to and some even taken. To my Dad who I miss very much. Thank you both for so much.

To my supervisor, Prof Susan Schenk, thank you for all your guidance and encouragement, it's been an amazing journey. I have really enjoyed being part of the lab team and wish to thank everyone especially Richard, Katie, Dave, and Joyce.

To my friends who were always there for me even when I didn't return their calls. A special thanks to Sarah and Wendy.

Thank you to Victoria University for providing funding through my $\mathrm{PhD}$ Scholarship and research funding grants. 


ACKNOWLEDGEMENTS

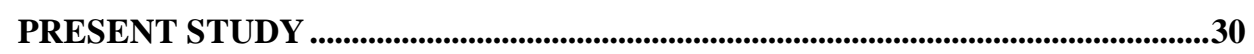

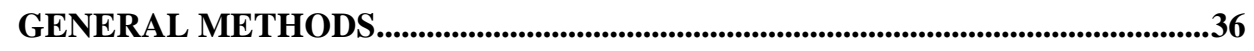

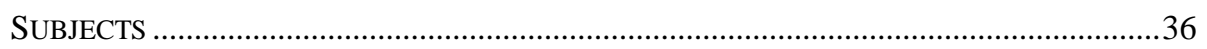

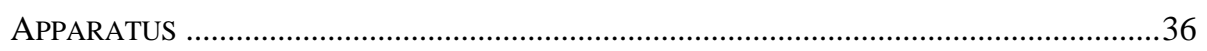

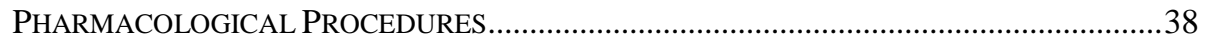

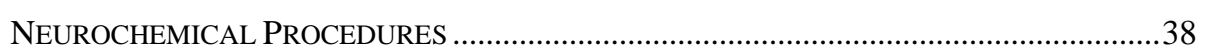

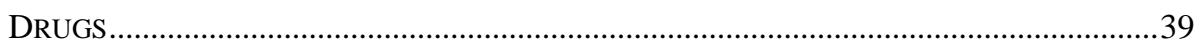

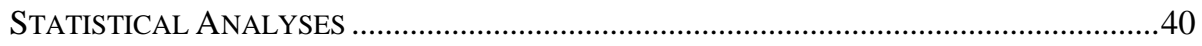

SECTION ONE: EMERGENCE TEST ...............................................................41

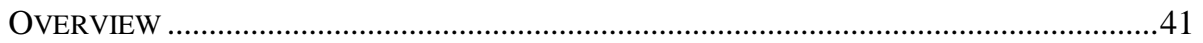

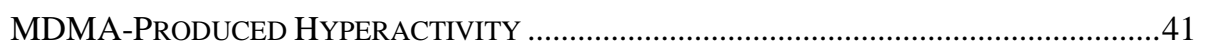

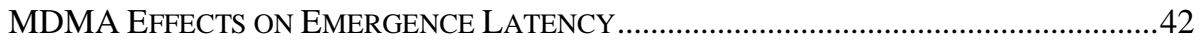

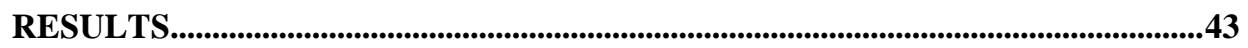

MDMA-PRODUCED HYPERACTIVITY ..................................................................... 43

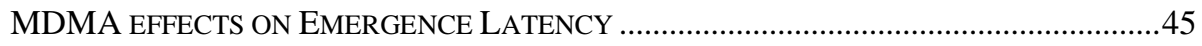

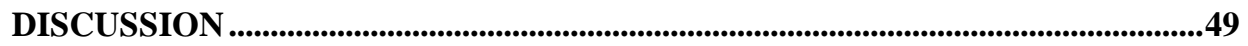

SECTION TWO: EMERGENCE LATENCY (EL) FOLLOWING MDMA

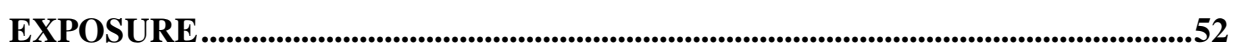

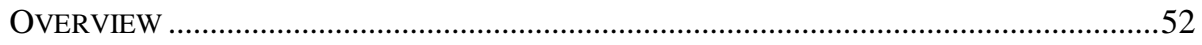

EFFECTS OF MDMA, M-CPP, DOI AND FENFLURAMINE ON EL ..................................52

EFFECTS OF 5-HT 2 RECEPTOR ANTAGONIST PRETREATMENT ON MDMA, M-CPP AND

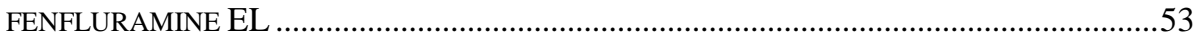

EFFECTS OF MDMA PRE-TREATMENT ON MDMA, M-CPP AND FENFLURAMINE EL 53

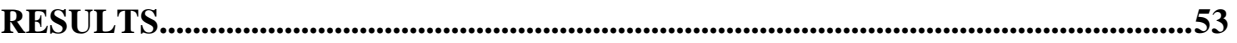

EFFECTS OF MDMA, M-CPP, DOI AND FENFLURAMINE ON EL ....................................53 
EFFECTS OF 5-HT 2 RECEPTOR ANTAGONIST PRETREATMENT ON MDMA, M-CPP AND

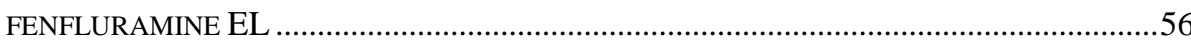

EFFECTS OF MDMA PRE-TREATMENT ON MDMA, M-CPP AND FENFLURAMINE EL 57 EFFECTS OF MDMA PRE-TREATMENT ON BRAIN 5-HT AND5-HIAA TISSUE

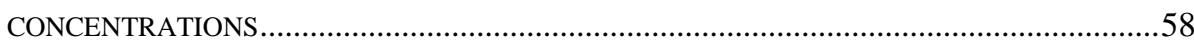

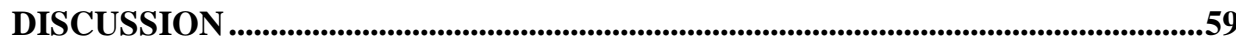

SECTION 3: 5-HT ${ }_{1 \mathrm{~A}}$ FUNCTIONAL STATUS FOLLOWING MDMA

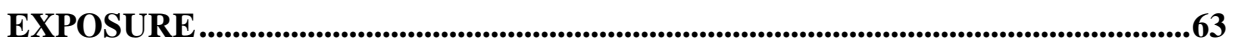

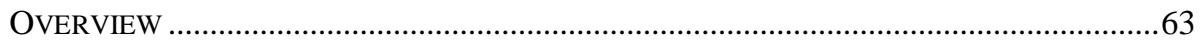

EFFECTS OF MDMA PRETREATMENT ON RECTAL TEMPERATURE.................................64

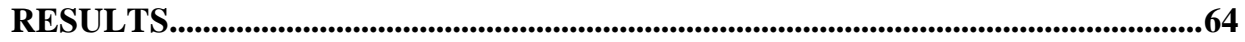

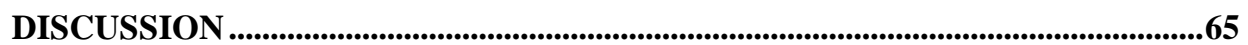

SECTION 4. REVERSAL OF TOLERANCE TO MDMA EFFECTS: SYSTEMIC STUDIES

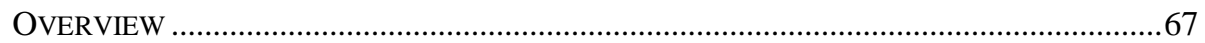

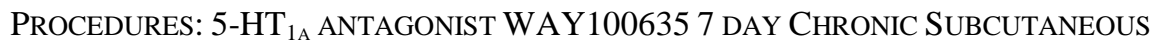

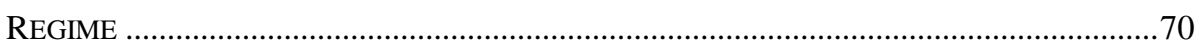

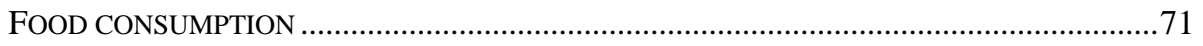

EFFECTS OF MDMA PRETREATMENT ON MDMA -INDUCED HYPERACTIVITY ............71

EFFECTS OF WAY100635 PRETREATMENT ON MDMA-INDUCED HYPERACTIVITY ...72

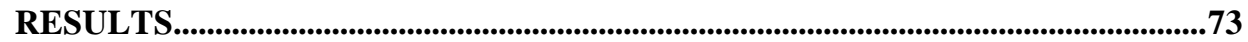

FOOD CONSUMPTION FOLLOWING WAY100635 ADMINISTRATION .............................73

EFFECT OF MDMA PRE-TREATMENT ON MDMA-PRODUCED HYPERACTIVITY ..........73

EFFECTS OF WAY100635 ADMINISTRATION ON MDMA-INDUCED HYPERACTIVITY FOLLOWING SALINE AND MDMA PRETREATMENT .76

EFFECT OF WAY100635 AND MDMA PRE-TREATMENT ON BRAIN 5-HT AND 5-HIAA TISSUE CONCENTRATION . .80

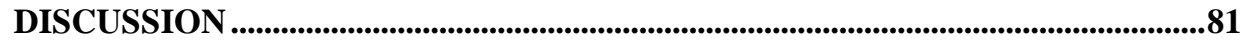

SECTION 5: REVERSAL OF TOLERANCE TO MDMA EFFECTS:

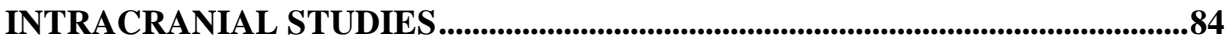

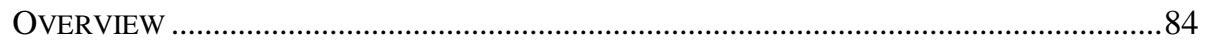

PROCEDURES: WAY100635 4 DAY CHRONIC INTRACRANIAL-DRN REGIME ..............84

EFFECTS OF MDMA PRE-TREATMENT ON MDMA-INDUCED HYPERACTIVITY ............87

EFFECTS OF WAY100635 ON MDMA-INDUCED HYPERACTIVITY ................................87 
EFFECT OF MDMA PRETREATMENT AND WAY100635 4 DAY INTRA-DRN ADMINISTRATION ON BRAIN 5-HT AND 5-HIAA TISSUE CONCENTRATIONS

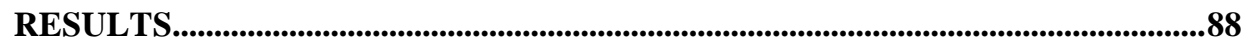

EFFECTS OF MDMA PRE-TREATMENT ON MDMA-INDUCED HYPERACTIVITY 88

EFFECTS OF WAY100635 ON MDMA-PRODUCED HYPERACTIVITY FOLLOWING MDMA PRETREATMENT 90

EFFECT OF MDMA AND WAY100635 PRETREATMENT ON BRAIN 5-HT AND 5-HIAA TISSUE CONCENTRATION.

DISCUSSION

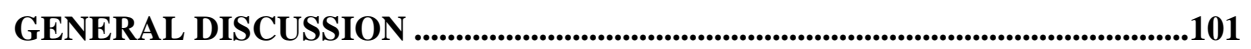

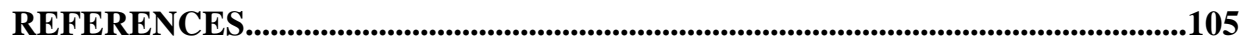




\section{Introduction}

\section{MDMA "Ecstasy"}

Brief History

3,4-Methylenedioxymethamphetamine (MDMA) is a ring substituted amphetamine derivative structurally related to the stimulant methamphetamine and the hallucinogen mescaline (Green, Cross, \& Goodwin, 1995; White, Obradovic, Imel, \& Wheaton, 1996). MDMA's unique psychoactive effects, which include stimulant and hallucinogenic actions, coupled with an ability to produce subjective effects such as empathy and interpersonal understanding has made MDMA an increasingly popular recreational drug of choice (Nichols \& Oberlender, 1990; Parrott, 2001).

First patented in 1914 by Merck Pharmaceuticals (Lyles \& Cadet, 2003) MDMA remained largely unstudied until the early 1970s. In 1977, due to its lack of therapeutic efficacy, the United Kingdom scheduled MDMA as a Class A drug. In the Unites States, however, it had become a popular psychotherapeutic tool sometimes known as "penicillin for the soul" (Parrott, 2001). Following an increase in the prevalence of its abuse, and evidence of adverse physiological and psychological effects, MDMA was placed on the list of Schedule 1 drugs by the U.S. Drug Enforcement Administration (DEA) in 1985 (Cole \& Sumnall, 2003a).

Despite MDMA's illegal status it continues to be a popular drug likely due to its subjective affects which include feelings of euphoria, increased energy and sensory and sexual pleasure. However, it is MDMA's adverse effects that have prompted ongoing research into its short and long term effects (Cohen, 1995; Liechti, Baumann, Gamma, \& Vollenweider, 2000a; Parrott, 2002; Peroutka, Newman, \& Harris, 1988; Verheyden, Henry, \& Curran, 2003; Vollenweider, Gamma, Liechti, \& Huber, 1998).

\section{Epidemiology and Patterns of Use}

There is substantial evidence that global MDMA consumption, manufacture and trafficking has increased over the past decade (United Nations Office on Drugs 
and Crime, 2004). In the early 1990's MDMA trafficking was almost exclusively restricted to Europe however, by 2002, MDMA use had spread worldwide. The highest levels of MDMA use were found in the Oceania region with Australia and New Zealand reporting increases in trafficking and consumption above the global average. Recent reports indicate that, in contrast to other drugs such as cocaine and cannabis, MDMA use in New Zealand continues to increase. In 2006, the New Zealand National Household survey data found that the population prevalence of MDMA consumption increased compared to 2004 (7.5\% versus 5.2\%) (SHORE, 2006).

MDMA use originally centred around parties often held at large dance clubs over weekends (Cole \& Sumnall, 2003a). However, studies indicated a trend towards more widespread use across increasingly diverse populations and situations (Wilkins, Bhatta, Pledger, \& Casswell, 2003; Wilkins, Sweetsur, \& Casswell, 2006). Distinct patterns of MDMA use have been reported with increased MDMA experience associated with both increases in dose and frequency of use (Fox, Parrott, \& Turner, 2001; Parrott, 2002; Scholey et al., 2004; Verheyden et al., 2003; Verkes et al., 2001). Novice users (1-9 lifetime occasions) reported consuming on average 1.2 tablets per session while moderate users (10-99 occasions) increased the dose to 1.8 tablets (Scholey et al., 2004; Verheyden et al., 2003). Heavy users, those who taken MDMA on more than 100 occasions, reported a mean of 3.7 tablets per occasion with $35 \%$ indicating a maximum average of 10.7 tablets (Scholey et al., 2004). Additionally, patterns of binging were reported in heavy MDMA users with over one third reported to binge over a $48 \mathrm{hr}$ period on a regular basis (Parrott, 2005; Topp, Hando, Dillon, Roche, \& Solowij, 1999). The increase in MDMA dose and frequency of use has been associated with the development of tolerance. Tolerance can be defined as a progressively decreasing response to a drug (Merrill, 1996; Parrott, Milani, Parmar, \& Turner, 2001; Peroutka et al., 1988; Scholey et al., 2004). A study revealed that DSM criteria for abuse and dependence were met by $25 \%$ of the sample with the most commonly reported criteria being the development of tolerance (65\%) (EACD, 2004) Additionally, animal studies have shown that, compared to other drugs of addiction, maintenance of MDMA self-administration is facilitated by prolonged exposure to, and higher doses of, MDMA (Schenk et al., 2007). 
Effects of MDMA Use

As MDMA use has increased so have the reports of serious adverse physiological and psychological effects. Acute MDMA has been associated with hypertension, hyperthermia and cardiac arrhythmias as well as transient depression and anxiety (Parrott, 2002; Vollenweider et al., 1998).

Evidence indicates that long term and heavy MDMA use is associated with insomnia, energy loss, irritability, persistent cognitive impairments and mood disturbances (Dalley et al., 2007; Fox et al., 2001; Morgan, 2000; Parrott, 2002; Reneman, Booij, Majoie, Van Den Brink, \& Den Heeten, 2001; Topp et al., 1999; Verheyden et al., 2003; Verkes et al., 2001).

There are numerous studies showing that MDMA exposure produces major changes to brain neurochemical systems that may be persistent (Green, Mechan, Elliott, O'Shea, \& Colado, 2003). Furthermore, some studies indicate that MDMA can produce neurotoxicity (O'Hearn, Battaglia, De Souza, Kuhar, \& Molliver 1988; Schmidt, 1987; Steele, McCann, \& Ricaurte, 1994). These neurochemical changes may underlie the cognitive and behavioural deficits reported by MDMA users (Cole \& Sumnall, 2003a; Liechti et al., 2000a; Liechti, Saur, Gamma, Hell, \& Vollenweider, 2000b; Verheyden et al., 2003).

\section{Pharmacokinetics of MDMA}

MDMA contains a racemic mixture of $(+)$ and (-) isomers each different in their metabolism, elimination and effects on neurotransmitter release. The $(+)$ isomer is metabolised and cleared faster (Fallon et al., 1999; Fitzgerald \& Reid, 1990), is a more potent releaser of neurotransmitters and, in particular, is a more effective dopamine (DA) releaser than the (-) isomer (Johnson, Hoffman, \& Nichols, 1986). The MDMA isomers also vary in contribution to changes in the 5-HT function and neurotoxicity (Johnson et al., 1986). When compared to other amphetamines MDMA is a potent 5-HT releaser. For example, (+)-MDMA-induced 5-HT release is ten times greater than (+)-methamphetamine (White et al., 1996). It is these neurochemical differences that make MDMA a distinctive drug in its subjective and neurochemical effects. 
"Ecstasy" tablets most commonly ingested contain a racemic mixture of $(+)$ and (-) isomers of MDMA. MDMA serum levels are detectable within 15 minutes and reach peak concentration about 2 hours after oral ingestion. MDMA is metabolised mainly in the liver by the enzyme, CYP2D6. However, other enzymes are also involved some of which become saturated at relatively low concentrations of the drug. Therefore, as the dose is increased, disproportionately large increases in plasma and brain concentrations occur. Consequently, small increases in dosage may markedly increase the risk of neurotoxicity especially in heavy MDMA users (de la Torre et al., 2000a). Elimination of MDMA from the body is relatively slow with a half life of approximately 8 hours in humans (de la Torre et al., 2000b; Mas et al., 1999).

Pharmacology and Mechanisms of MDMA

MDMA initially produces a rapid increase in extracellular levels of serotonin (5-HT), dopamine (DA), and norepinephrine (NE) with predominant effects on 5-HT (Green et al., 2003; Gudelsky \& Nash, 1996; Lyles \& Cadet, 2003; Yamamoto, Nash, \& Gudelsky, 1995). MDMA interacts with the 5-HT transporter (SERT) blocking 5-HT reuptake and inducing a calcium-independent carrier mediated 5-HT release (Gudelsky \& Nash, 1996; Johnson, Conarty, \& Nichols, 1991; White et al., 1996). Additionally, MDMA directly depletes vesicular 5-HT (Mlinar \& Corradetti, 2003) and disrupts vesicle repackaging of cytosolic 5-HT (Rudnick \& Wall, 1992).

MDMA also increases synaptic levels of 5-HT by inhibiting monoamine oxidase (MAO) activity leading to a reduction in metabolic breakdown. Conversely, MDMA inhibits tryptophan hydroxylase, the rate limiting enzyme for 5-HT synthesis, resulting in a reduction of 5-HT availability (Schmidt, 1987; Stone, Johnson, Hanson, \& Gibb, 1989b; Stone, Stahl, Hanson, \& Gibb, 1986).

MDMA has affinity for a range of pre and postsynaptic 5-HT receptors (Battaglia, Brooks, Kulsakdinun, \& De Souza, 1988). Activation of the 5-HT receptors following MDMA administration is thought to underlie many of the subjective, neurochemical and behavioural responses following MDMA use including hyperactivity(Callaway, Rempel, Peng, \& Geyer, 1992; Fletcher, Korth, Robinson, \& Baker, 2002; Kehne et al., 1996), hyperthermia (Aguirre, Ballaz, Lasheras, \& Del Rio, 1998; Dafters, 1994; Green et al., 2004) and exploratory 
behaviour (Bull, Hutson, \& Fone, 2004; McGregor et al., 2003; Sumnall, O'Shea, Marsden, \& Cole, 2004).

MDMA acts preferentially at the SERT with a lesser affinity at the norepinephrine (NE) and dopamine transporters (DAT) (Shankaran \& Gudelsky, 1999; White, Duffy, \& Kalivas, 1994). MDMA is a substrate releaser, which is transported into the nerve terminals and causes a rapid release of serotonin via a reverse transport mediated and vesicle dependant mechanism (Howell \& Kimmel, 2008; Seiden et al., 1993). MDMA interacts to a lesser extent with the DA system increasing synaptic levels directly via DAT inhibition and indirectly via 5-HT release and activation of 5-HT receptors (Cole \& Sumnall, 2003b; Gudelsky, Yamamoto, \& Nash, 1994; Rudnick \& Wall, 1992; White et al., 1996). The interactions between 5HT and DA are complex, dependent on the brain region and on the state of DA activity (Meltzer \& Nash, 1991). DA has been shown to be an important contributor to MDMA-induced behaviours, however, MDMA's ability to evoke significant 5-HT release due to its affinity for the SERT, and to indirectly stimulate 5-HT receptors, have been shown to be important components of its ability to increase DA neurotransmission.

\section{Effects of MDMA on Humans}

\section{Acute MDMA effects in Humans}

There is extensive research outlining the physiological and psychological effects following acute MDMA ingestion. At recreational doses MDMA produces acute sympathomimetic effects such as increase in blood pressure and heart rate, increased activation of the hypothalamic pituitary adrenal axis and changes in cerebral blood flow (Gamma, Buck, Berthold, Liechti, \& Vollenweider, 2000; Green et al., 2003; Lester et al., 2000; Vollenweider et al., 1998). Additional aversive effects include jaw clenching, lack of appetite, agitation, insomnia and a lack of concentration (Cohen, 1995; McCann, Mertl, Eligulashvili, \& Ricaurte, 1999; Vollenweider et al., 1998). The most commonly reported adverse physiological response to MDMA is hyperthermia. Core body temperatures as high as $44^{\circ} \mathrm{C}$ have been reported usually proving fatal due to complications such as multiple organ failure and rhabdomyolysis (Chadwick, Curry, Linsley, Freemont, \& Doran, 1991; 
Cohen, 1995; Liechti et al., 2000b).Experimental studies in humans have attributed psychological effects to 5-HT function since reduced inhibition, perceptual changes and heightened sensory effects are all attenuated by blockade of the SERT and/or antagonism of 5- $\mathrm{HT}_{2}$ receptors (Cole \& Sumnall, 2003a; Liechti et al., 2000a; Liechti et al., 2000b; Verheyden et al., 2003).

\section{Effects of Repeated MDMA exposure in Humans}

There is evidence that repeated MDMA alters the integrity of the 5-HT system in humans. Imaging studies revealed decreases in some structural components of 5-HT neurons including a reduction of 5-HT transporter sites (McCann, Szabo, Scheffel, Dannals, \& Ricaurte, 1998; Semple, Ebmeier, Glabus, O'Carroll, \& Johnstone, 1999) and 5- $\mathrm{HT}_{2}$ receptor binding sites (Reneman et al., 2001; Reneman et al., 2002). The extent of alterations was positively correlated with past MDMA use with heavy or repeated MDMA users more at risk of immediate and long term 5-HT deficits (McCann et al., 1998). Additionally, responses in 5-HT function were blunted in MDMA users. For example, neuroendocrine studies showed that cortisol and prolactin secretion were reduced in MDMA users (Gerra et al., 1998; Price, Ricaurte, Krystal, \& Heninger, 1989). As these responses involve the activation of 5$\mathrm{HT}_{2}$ receptors it suggests a reduction in sensitivity and/or binding densities of these receptor subtypes.

There is evidence that repeated MDMA use results in a range of cognitive deficits and emotional dysregulation. A battery of neuropsychological tests revealed that working, short-term and long term memory were all compromised in regular and heavy MDMA users (Fox et al., 2001; McCann et al., 1999; McCardle, Luebbers, Carter, Croft, \& Stough, 2004; Reneman, Booij, Schmand, van den Brink, \& Gunning, 2000). Furthermore, heavy MDMA use was associated with more pronounced and long lasting performance deficits (Bolla, McCann, \& Ricaurte, 1998; McCardle et al., 2004; Verkes et al., 2001). Cognitive/memory deficits have also been shown to be persistent (Fox et al., 2001; Morgan, McFie, Fleetwood, \& Robinson, 2002). Several studies found that emotional dysregulation such as depression, anxiety, panic disorder, paranoia and increased impulsivity persisted long after drug abstinence. Again, more extensive deficits and longer persistence was 
found in heavy MDMA users (Fox et al., 2001; Morgan et al., 2002; Parrott et al., 2002). As many of these disorders are closely linked to 5-HT impairments (Griebel, 1995; Pineyro \& Blier, 1999) these studies indicate a relationship between the extent of MDMA exposure and the severity of psychological impairments with heavier use possibly linked to more severe and longer lasting 5-HT impairments.

Tolerance is one of the most commonly reported effects of repeated MDMA use. Up to $85-90 \%$ of participants reported tolerance to the effects of MDMA (Merrill, 1996; Verheyden et al., 2003) with many users reporting a reduction in the positive effects of MDMA within the first few occasions of use (Merrill, 1996; Parrott \& Lasky, 1998; Peroutka et al., 1988; Scholey et al., 2004; Topp et al., 1999; Verheyden et al., 2003). Further, many participants reported that as the positive effects declined the negative effects, such as paranoia, increased (Merrill, 1996; Solowij, Hall, \& Lee, 1992).

As a result of tolerance MDMA users often changed their pattern of drug use. Drug dose and frequency of consumption increased in an attempt to generate the lost "positive on-drug experience" (Fox et al., 2001; Scholey et al., 2004; Verheyden et al., 2003). Patterns of binging such as boosting (multiple tablets over an extended period), or stacking (multiple tablets at one time) are common in users who reported tolerance. Furthermore, binging was related to heavy MDMA use with experienced users reporting significantly more binges than light users (Parrott, 2005; Scholey et al., 2004). In some instances a change in the method of ingestion was reported with snorting or intravenous injections becoming more common (Carlson, Falck, McCaughan, \& Siegal, 2004). These findings raise the concern that as tolerance develops MDMA users are more at risk of administering doses high enough to exert lasting change or damage to brain neurochemical systems.

Studies have attempted to investigate the consequences of MDMA use in humans as the patterns of binging have both immediate and long term physiological effects. However, as well as ethical constraints, human studies are confounded by a range of factors. The patterns of MDMA use and doses consumed often rely on self reports and retrospective surveys. Reliability of these reports is likely to be compromised due MDMA's illegal status, poor recall of doses consumed and functional deficits experienced following MDMA use (Parrott, 2005; Topp et al., 1999). Furthermore, the method of consumption may alter users' experiences. 
MDMA is commonly taken in tablet form however alternatives included intravenous injection, intranasal snorting and smoking (Topp et al., 1999). It has been estimated that each tablet contains between 80 and $150 \mathrm{mg}$ of MDMA with approximately 8590\% of tablets seized containing MDMA as the active ingredient (Cole, Bailey, Sumnall, Wagstaff, \& King, 2002; Parrott, 2004a). However, due to MDMA being illicitly manufactured, the dose and purity are known to vary greatly (Green et al., 2003; Parrott, 2004b). Additionally, other psychoactive drugs are commonly mixed with MDMA including amphetamine and LSD. Forensic analysis of seized MDMA has found amphetamine-like substances as well as unrelated compounds (WHO, 2001). Polydrug use in MDMA users is often reported (Scholey et al., 2004). Therefore, it is hard to ascertain whether any long term physiological or psychological impairments are due to MDMA consumption alone or are a consequence of the combination of drugs used. Due to these restraints the effects of repeated MDMA exposure and the mechanisms underlying tolerance in humans remain elusive.

Animal models provide an alternative method for investigating the behavioural responses to, and mechanisms responsible for tolerance resulting from repeated MDMA exposure. These models provide the advantages of flexibility, precision and reproducibility which allow conclusions to be drawn with control of extraneous variables that human studies do not afford.

\section{MDMA effects in Animals}

\section{Acute MDMA}

In rats acute exposure to MDMA induces a unique profile of behavioural and physiological responses compared to its parent derivative, amphetamine. MDMA induces increased forward locomotion (hyperactivity) (Callaway, Wing, \& Geyer, 1990; Colado, Murray, \& Green, 1993; Ross, Herin, Frankel, Thomas, \& Cunningham, 2006; Spanos \& Yamamoto, 1989), elements of the 5-HT behavioural syndrome such as flattened body posture, fore-paw treading and repetitive movements known as stereotypy (Marston, Reid, Lawrence, Olverman, \& Butcher, 1999; Piper, Fraiman, \& Meyer, 2005; Shankaran \& Gudelsky, 1999; Spanos \& 
Yamamoto, 1989). Alterations in exploratory behaviours have also been reported following acute MDMA exposure (Ho, Pawlak, Guo, \& Schwarting, 2004; Lin, Burden, Christie, \& Johnston, 1999; Morley \& McGregor, 2000; Sumnall et al., 2004). For example, decreased exploration of the elevated plus maze (EPM) was found following low dose MDMA while higher doses increased exploration (Lin et al., 1999). Additionally, MDMA consistently induces a dose dependent increase in body temperature (Baumann, Clark, Franken, Rutter, \& Rothman, 2008; Dafters, 1995; Mechan, O'Shea, Elliott, Colado, \& Green, 2001; Shankaran \& Gudelsky, 1999).

\section{Repeated MDMA Exposure}

Under some circumstances tolerance following repeated MDMA exposure has been demonstrated. Repeated high dose MDMA administered in a single day ( $4 \mathrm{x}$ $2 \mathrm{hrly} 10 \mathrm{mg} / \mathrm{kg}$ ) reduced MDMA-induced hyperactivity, components of the MDMAinduced 5-HT syndrome, and MDMA-produced hyperthermia (Brennan \& Schenk, 2006; Callaway \& Geyer, 1992; Piper \& Meyer, 2006; Shankaran \& Gudelsky, 1999; Slikker et al., 1989; Wallace, Gudelsky, \& Vorhees, 2001). Further, MDMA exposure produced tolerance to MDMA-induced hypophagia (Zacny, Virus, \& Woolverton, 1990) reduced drug discrimination sensitivity (Schechter, 1991), and blunted MDMA-produced hormonal responses (Baumann et al., 2008). MDMAinduced tolerance in non-human primates is also well established (Fantegrossi, 2007; Fantegrossi et al., 2004; Frederick \& Paule, 1997).

The mechanisms responsible for MDMA-induced behaviours are clearly multifaceted often involving complex interactions between 5-HT and DA mechanisms. However, as MDMA has been shown to exert its effects predominately via the 5-HT system, tolerance to those effects are likely to be due to MDMA's ability to alter the 5-HT system following repeated MDMA exposure. 


\section{$\underline{\text { Serotonin (5-HT) System }}$}

\section{Overview}

Serotonin is a biogenic amine which acts as a neurotransmitter extensively throughout the central (CNS) and peripheral nervous systems. The cell bodies of 5HT neurons are located within nine raphe nuclei (RN) localised along the rostrocaudal midline of the brain stem where they project to almost all brain regions and the spinal cord. The dorsal (DRN) and median raphe (MRN) are the two major nuclei of the ascending serotonergic projections containing approximately $85 \%$ of the 5-HT neurons found within the brain. The DRN projects predominately to the ventral hippocampus, amygdala, lateral septum, striatum, prefrontal and cerebral cortex (McQuade \& Sharp, 1995; O'Hearn et al., 1988; Underwood, Arango, Bakalian, Ruggiero, \& Mann, 1999). The MRN innervates the hypothalamus, medial septum, dorsal hippocampus and cerebral cortex (Barnes \& Sharp, 1999; Hornung, 2003; Hoyer et al., 1994).

Serotonin exerts its effects on neuronal activity through the excitatory or inhibitory activation of at least 14 genetically, pharmacologically and functionally distinct 5-HT receptor subtypes (Barnes \& Sharp, 1999; Hoyer et al., 1994; Peroutka, Lebovitz, \& Snyder, 1981). The 5-HT receptor subtypes belong to seven transmembrane domain G-protein coupled metabotropic families with one exception, the $5-\mathrm{HT}_{3}$ receptor group, which is a ligand-gated ion channel. Some receptors such as the $5-\mathrm{HT}_{1 \mathrm{a}}, 5-\mathrm{HT}_{2 \mathrm{a}}$ and $5-\mathrm{HT}_{2 \mathrm{c}}$ undergo adaptive changes such as changes in sensitivity and/or number following prolonged stimulation or following treatments that increased 5-HT availability (Aguirre, Frechilla, Garcia-Osta, Lasheras, and Del Rio, 1997; Peroutka \& Snyder, 1980). As these receptors have been shown to play major roles in MDMA-produced effects they will be discussed in more detail below.

\section{$\underline{5-\mathrm{HT}_{1}} \underline{\text { Receptors }}$}

\section{Overview}

A wealth of studies including ligand binding and more recently PET studies, have demonstrated that the $5-\mathrm{HT}_{1}$ receptor is expressed extensively throughout the 
mammalian CNS (Baker, Halliday, \& Tork, 1990; Barnes \& Sharp, 1999). The 5$\mathrm{HT}_{1}$ receptor family presently includes five subtypes; the 5-HT $\mathrm{Ha}, 5-\mathrm{HT}_{1 \mathrm{~b}}, 5-\mathrm{HT}_{1 \mathrm{~d}}, 5-$ $\mathrm{HT}_{1 \mathrm{e}}$, and 5-HT $\mathrm{Hf}_{1 \mathrm{f}}$ (Barnes \& Sharp, 1999; Hoyer et al., 1994). The subtypes are similar in their molecular structure, are negatively coupled to adenylate cyclase via $G$ proteins and show a high affinity for 5-HT. Activation inhibits adenyl cyclase thereby reducing cellular levels of cyclic AMP (cAMP). Additionally, activation initiates a G-protein-activated potassium channel independent of cAMP (Albert, Lembo, Storring, Charest, \& Saucier, 1996; Pucadyil, Kalipatnapu, \& Chattopadhyay, 2005). Therefore, $5-\mathrm{HT}_{1}$ receptors are predominately inhibitory.

\section{5-HT $1 \mathrm{a}$ Receptor}

\section{Distribution}

Two types of 5-HT $1 \mathrm{a}$ receptor have been identified; the inhibitory 5- $\mathrm{HT}_{1 \mathrm{a}}$ autoreceptor and the 5-HT $\mathrm{Ha}_{1 \mathrm{a}}$ postsynaptic receptor. High density $5-\mathrm{HT}_{1 \mathrm{a}}$ labelling and high levels of 5-HT $\mathrm{Ha}_{1 \mathrm{a}}$ mRNA expression are found in a number of CNS regions, including the dorsal raphe nucleus (DRN), hippocampal pyramidal cell layer and cerebral cortex (Chalmers \& Watson, 1991; Pazos \& Palacios, 1985; Pedigo, Yamamura, \& Nelson, 1981).

Within the raphe nuclei (RN) and particularly in the DRN and nucleus raphe magnus, the 5-HT $1 \mathrm{a}$ receptor has been located predominately on the cell body and dendrites of 5-HT neurons (Gozlan, El Mestikawy, Pichat, Glowinski, \& Hamon, 1983; Riad et al., 2000; Verge et al., 1986) identifying this receptor as a somatodendritic autoreceptor. Further, DRN 5-HT $1 \mathrm{a}$ autoreceptors are predominately extrasynaptic at the plasma membrane suggesting activation is reliant on the concentration of synaptic 5-HT (Hoyer et al., 1994).

Post-synaptic 5- $\mathrm{HT}_{1 \mathrm{a}}$ receptors are predominately located in forebrain terminal regions with ascending projections from the DRN and MRN. These include limbic brain areas such as the hippocampus, lateral septum and limbic cortical areas where they are located in principal cells and predominately glutamate pyramidal neurons. Medium binding has been detected in the thalamus, hypothalamus and 
olfactory bulb with lower levels found in the basal ganglia and cerebellum (Gozlan et al., 1983; Riad et al., 2000; Verge et al., 1986).

\section{Mechanism}

The $5-\mathrm{HT}_{1 \mathrm{a}}$ autoreceptor is activated by $5-\mathrm{HT}$ released through exocytosis from 5-HT neurons or alternately from a non-vesicular pool (Adell, Celada, Abellan, \& Artigas, 2002; Gozlan et al., 1983). Activation results in an inhibitory action on cell firing and 5-HT synthesis in the RN and reduction of 5-HT release in the RN and forebrain projection areas of the DRN and MRN (Hervas, Bel, Fernandez, Palacios, \& Artigas, 1998; Sharp, Umbers, \& Hjorth, 1996; Sprouse, Bradberry, Roth, \& Aghajanian, 1989). In vitro agonists with 5-HT 1 a selectivity, such as 8-OHDPAT, mimic this activity by inhibiting raphe cell firing causing a dose dependent decrease in 5-HT release. These effects can be reversed by various $5-\mathrm{HT}_{1 \mathrm{a}}$ antagonists including WAY100635 (Bosker, Donker, Klompmakers, Kurata, \& Westenberg, 1994; Davidson \& Stamford, 1995; Forster et al., 1995; Gartside, Umbers, Hajos, \& Sharp, 1995; Gozlan et al., 1983; Penington, Kelly, \& Fox, 1993a, 1993b).

Activation of the 5-HT 1 a autoreceptor not only has a major impact on 5-HT release in the raphe nuclei but also in the forebrain projection areas by modulating 5HT activity (Stamford, Davidson, McLaughlin, \& Hopwood, 2000). Microdialysis and electrophysiological studies showed that the 5-HT 1 agonist, 8-OHDPAT, infused into the DRN resulted in a decrease of 5-HT release in the striatum, an effect blocked by selective 5-HT $1 \mathrm{a}$ antagonists (Bonvento, Scatton, Claustre, \& Rouquier, 1992; Kreiss \& Lucki, 1994).

Long term stimulation of the 5- $\mathrm{HT}_{1 \mathrm{a}}$ autoreceptor led to alterations in sensitivity and an internalisation of the receptor. This consequently may allow an increase of neuronal firing and 5-HT release in postsynaptic target areas (Blier \& de Montigny, 1998; Blier, Pineyro, el Mansari, Bergeron, \& de Montigny, 1998; Dong, de Montigny, \& Blier, 1997; Riad et al., 2000; Riad, Watkins, Doucet, Hamon, \& Descarries, 2001). In contrast, postsynaptic 5-HT $1 \mathrm{a}$ receptors remain unchanged following continued activity. However, it is suggested that activation of these postsynaptic receptors would be increased due to the desensitisation of the autoreceptor and result in increased 5-HT release in projection areas (Dong et al., 1997; Godbout, Chaput, Blier, \& de Montigny, 1991) again highlighting the different 
properties of the $5-\mathrm{HT}_{1 \mathrm{a}}$ autoreceptor and the 5-HT $\mathrm{Ha}_{1 \mathrm{a}}$ postsynaptic receptor. These studies highlight the high degree and importance of the plasticity of 5- $\mathrm{HT}_{1 \mathrm{a}}$ receptors, and especially the 5- $\mathrm{HT}_{1 \mathrm{a}}$ autoreceptor, to 5-HT transmission.

\section{$\underline{5-\mathrm{HT}_{2}} \underline{\text { receptors }}$}

Overview

Three 5- $\mathrm{HT}_{2}$ receptor subtypes have been identified within the mammalian CNS; the 5-HT $2 \mathrm{a}, 5-\mathrm{HT}_{2 \mathrm{~b}}$, and 5- $\mathrm{HT}_{2 \mathrm{c}}$ (Hoyer et al., 1994; Ikemoto et al., 2000; Nocjar, Roth, \& Pehek, 2002). All three subtypes are G-protein coupled-receptors that have low affinity for 5-HT have similar structural, pharmacological and signal transduction pathway characteristics (Barnes \& Sharp, 1999; Hoyer et al., 1994). The $5-\mathrm{HT}_{2 \mathrm{a}}$ and $5-\mathrm{HT}_{2 \mathrm{c}}$ are the most extensively studied of the subtypes as they are widely distributed throughout the CNS while the $5-\mathrm{HT}_{2 \mathrm{~b}}$ receptor is restricted to a few brain regions in both humans and rodents (Barnes \& Sharp, 1999). The recent development of selective 5-HT 2 antagonists has enabled some of the functional responses of the 5- $\mathrm{HT}_{2 \mathrm{a}}$ and $5-\mathrm{HT}_{2 \mathrm{c}}$ receptors to be distinguished.

\section{5-HT $2 \mathrm{a}$ Receptor}

\section{Distribution}

The 5- $\mathrm{HT}_{2 \mathrm{a}}$ binding sites in the human and rodent CNS show high levels of expression in the neocortex, olfactory tubercle, striatum, substantia nigra, hippocampus, entorhinal and pyriform cortex, caudate nucleus, nucleus accumbens (NAcc), and some brain stem nuclei such as the rostral dorsal raphe (LopezGimenez, Mengod, Palacios, \& Vilaro, 1997; Nocjar et al., 2002; Pazos, Cortes, \& Palacios, 1985; Pompeiano, Palacios, \& Mengod, 1994). The 5- $\mathrm{HT}_{2 \mathrm{a}}$ binding sites have been found to map onto the distribution of 5-HT axons arriving from the DRN in specific regions such as the frontal cortex, suggesting that they receive selective activation by innervations from the DRN (Blue, Yagaloff, Mamounas, Hartig, \& Molliver, 1988). Studies have also indicated that the 5- $\mathrm{HT}_{2 \mathrm{a}}$ receptor is postsynaptic (Lopez-Gimenez et al., 1997). Because these receptors have been detected on DA neurons in the rat and human midbrain that project to forebrain regions (Doherty \& 
Pickel, 2000; Ikemoto et al., 2000; Nocjar et al., 2002), they might modulate DA neurotransmission.

\section{Mechanism}

The 5- $\mathrm{HT}_{2 \mathrm{a}}$ receptor modulates the release of several neurotransmitters including glutamate, GABA, and DA (Barnes \& Sharp, 1999). Microdialysis studies revealed that 5- $\mathrm{HT}_{2 \mathrm{a}}$ agonists enhanced DA release in the striatum while 5- $\mathrm{HT}_{2 \mathrm{a}}$ antagonism attenuated dopamine release in the ventral tegmental area (VTA) and striatum (De Deurwaerdere \& Spaminato, 1999; Lucas \& Spampinato, 2000). As 5$\mathrm{HT}_{2 \mathrm{a}}$ selective agonists are not readily available the behavioural effects of 5- $\mathrm{HT}_{2 \mathrm{a}}$ receptor activation have been difficult to determine. The use of selective $5-\mathrm{HT}_{2 \mathrm{a}}$ antagonists in conjunction with 5-HT agonists has, however, permitted some 5-HT2a mediated behaviours to be identified. For example, the 5-HT 2 agonist, DOI produced head twitches in the rat, and this effect was attenuated by $5-\mathrm{HT}_{2 \mathrm{a} / \mathrm{c}}$ antagonists, ketanserin and ritanserin (Kleven, Assie, \& Koek, 1997).

\section{5-HT $2 \mathrm{c}$ Receptor}

\section{Distribution}

The 5- $\mathrm{HT}_{2 \mathrm{c}}$ receptor is widely distributed throughout the CNS (LopezGimenez, Mengod, Palacios, \& Vilaro, 2001; Pompeiano et al., 1994) and is localised in the neocortical areas, hippocampus, NAcc, amygdala, striatum, amygdala and substantia nigra, olfactory tubercle and DRN. As with the 5-HT2a receptor, the $5-\mathrm{HT}_{2 \mathrm{c}}$ receptor has been identified predominately as postsynaptic (Barnes \& Sharp, 1999; Lopez-Gimenez et al., 2001).

\section{Mechanism}

Evidence suggests that activation of the $5-\mathrm{HT}_{2 \mathrm{c}}$ receptor mediates some of the effects of 5-HT in several brain regions and receptor activation modulates dopamine transmission. Activation of DA neurons in the rat substantia nigra reticulata by $5-\mathrm{HT}$ was blocked by the non-selective 5- $\mathrm{HT}_{2 \mathrm{c}}$ antagonist, ketanserin (Giorgetti \& Tecott, 2004). Systemic administration of 5- $\mathrm{HT}_{2 \mathrm{c}}$ receptor antagonists dose dependently increased firing of DA neurons in the VTA. The 5-HT2c antagonist, SB-242084, 
increased dopamine overflow in the nucleus accumbens and prefrontal cortex as measured by microdialysis. Conversely, the 5-HT 2 agonist, Ro 60-0175, reduced the firing rate of mesolimbic DA neurons resulting in a reduction of DA release in the frontal cortex and nucleus accumbens (De Deurwaerdere, Navailles, Berg, Clarke, \& Spampinato, 2004; Di Matteo, Di Giovanni, Di Mascio, \& Esposito, 1999; Gobert et al., 2000).

Several behaviours have been attributed to the activation of $5-\mathrm{HT}_{2 \mathrm{c}}$ receptors including hypolocomotion, hypophagia (Barnes \& Sharp, 1999; Kennett et al., 1997) and anxiety (Bagdy, Graf, Anheur, Modos, \& Kantor, 2001). Many of these responses have been obtained following administration of non-selective $5-\mathrm{HT}_{2 \mathrm{c}}$ agonists such as m-CPP (Barnes \& Sharp, 1999; Fone, Austin, Topham, Kennett, \& Punhani, 1998; Kennett et al., 1997). The availability of highly selective 5-HT 2 c antagonists, such as RS102221 (Bonhaus et al., 1997; Conductier, Crosson, Hen, Bockaert, \& Compan, 2005), has allowed the contribution of the 5- $\mathrm{HT}_{2 \mathrm{c}}$ receptor to be determined.

\section{$\underline{\text { Role of 5-HT receptors in the behavioural effects of MDMA }}$}

\section{Acute MDMA}

There is evidence that the 5- $\mathrm{HT}_{2 \mathrm{a}}$ and 5- $\mathrm{HT}_{2 \mathrm{c}}$ receptors contribute to MDMAinduced hyperactivity (Fletcher et al., 2002; Halberstadt et al., 2009; Kehne et al., 1996; Ross et al., 2006). Pre-treatment with a range of 5-HT $2 \mathrm{a}$ antagonists, such as ritanserin, ketanserin, SR-46349B, and the highly selective 5- $\mathrm{HT}_{2 \mathrm{a}}$ antagonist, MDL 100,907, dose dependently attenuated locomotor activity in rats (Ball \& Rebec, 2005; Herin, Liu, Ullrich, Rice, \& Cunningham, 2005; Kehne et al., 1996). In contrast the $5-\mathrm{HT}_{2 \mathrm{c}}$ receptor exerts an inhibitory influence on hyperactivity induced by MDMA. Antagonists at the 5- $\mathrm{HT}_{2 \mathrm{c}}$ receptor, including SB242084 and SB 206553, dose dependently potentiated MDMA-induced hyperactivity (Bankson \& Cunningham, 2002; Fletcher et al., 2002; Fletcher, Sinyard, \& Higgins, 2006). These data suggest that activation of the $5-\mathrm{HT}_{2 \mathrm{a}}$ receptor is involved in the generation of MDMA 
produced hyperactivity while activation of the $5-\mathrm{HT}_{2 \mathrm{c}}$ receptor attenuates its expression. The involvement of the 5- $\mathrm{HT}_{1 \mathrm{a}}$ receptor in MDMA-induced locomotor effects remains equivocal as both inhibitory and limited effects have been found when 5-HT $1 \mathrm{a}$ antagonists were administered (Bankson \& Cunningham, 2001; Kehne et al., 1996; McCreary, Bankson, \& Cunningham, 1999).

It has been suggested that MDMA-induced hyperthermia is mediated by activation of 5- $\mathrm{HT}_{2 \mathrm{a}}, 5-\mathrm{HT}_{2 \mathrm{c}}$ and 5- $\mathrm{HT}_{1 \mathrm{a}}$ receptors. Selective and non-selective 5$\mathrm{HT}_{2 \mathrm{a}}$ and 5- $\mathrm{HT}_{2 \mathrm{c}}$ antagonists such as MDL 100,907, ketanserin, ritanserin, and R96544 blocked MDMA-induced hyperthermia (Fantegrossi et al., 2003; Herin et al., 2005; Mechan et al., 2002a; Schmidt, Abbate, Black, \& Taylor, 1990). However, 5$\mathrm{HT}_{2 \mathrm{~b} / \mathrm{c}}$ antagonists and 5-HT $1 \mathrm{a}$ antagonists failed to attenuate MDMA-produced hyperthermia (Shioda et al., 2008) suggesting a limited role of these receptor subtypes. Additionally, the hypothermic response induced by the 5-HT $1 \mathrm{a}$ agonist, 8OHDPAT, was potentiated following single and repeated MDMA exposure, an effect correlated with increased 5- $\mathrm{HT}_{1 \mathrm{a}}$ receptor density in the frontal cortex following MDMA exposure (Aguirre et al., 1997; Aguirre et al., 1998). It may be suggested that 5- $\mathrm{HT}_{1 \mathrm{a}}$ antagonists, through their ability to increase 5-HT release, activate 5$\mathrm{HT}_{2 \mathrm{a}}$ receptors and result in a potentiated hypothermic response.

Alterations in exploratory behaviour induced by MDMA have also been shown to involve 5- $\mathrm{HT}_{2}$ and $5-\mathrm{HT}_{1 \mathrm{a}}$ receptor activation (Bhattacharya, Bhattacharya, \& Ghosal, 1998; Morley \& McGregor, 2000). Decreased exploration of the elevated plus maze (EPM) was found following low dose MDMA while higher doses increased exploration (Lin et al., 1999). It was suggested that, as 5- $\mathrm{HT}_{1 \mathrm{a}}$ receptors have a higher affinity for $5-\mathrm{HT}$ than $5-\mathrm{HT}_{2}$ receptors, the low dose administration activated the $5-\mathrm{HT}_{1 \mathrm{a}}$ while the higher doses activated $5-\mathrm{HT}_{2}$ receptors. These studies highlight a complex interaction between MDMA and the 5- $\mathrm{HT}_{1 \mathrm{a}}$ and 5-HT receptors.

\section{Repeated MDMA Exposure}

Adaptations in several 5-HT receptor mechanisms have been reported following repeated MDMA exposure (McGregor et al., 2003; Reneman et al., 2002; Scheffel, Lever, Stathis, \& Ricaurte, 1992). Because repeated MDMA exposure 
produced tolerance to the effects of MDMA as well as to other 5-HT agonists, tolerance may reflect these receptor changes.

There have been few investigations into the effects of MDMA pre-treatment on the binding of 5- $\mathrm{HT}_{1 \mathrm{a}}$ and 5- $\mathrm{HT}_{2}$ receptors. Reneman et al. (2002) examined the effect of MDMA exposure on 5- $\mathrm{HT}_{2 \mathrm{a}}$ receptor binding densities in several brain regions in humans and rats. Rats exposed to MDMA (10mg/kg x2 per day for 4 days a total of $80 \mathrm{mg} / \mathrm{kg}$ ) showed significant decreases in $5-\mathrm{HT}_{2 \mathrm{a}}$ binding densities in the frontal, parietal and occipital cortex 6 hours post MDMA with decreased densities persisting at 3 days. Thirty days post MDMA an upregulation of 5-HT $2 \mathrm{a}$ binding sites was observed in the frontal cortex while the parietal and occipital cortex returned to control levels. Depletions of 5HT were produced in all regions at 6 hours and 3 days with the greatest reductions observed at 30 days. Brain imaging also revealed reduced 5- $\mathrm{HT}_{2 \mathrm{a}}$ binding in current MDMA users but abstinent users showed 5- $\mathrm{HT}_{2 \mathrm{a}}$ upregulation. Because 5- $\mathrm{HT}_{2}$ receptors adapt to synaptic 5-HT levels, it was suggested that these alterations resulted from increases in synaptic 5-HT produced by MDMA. In another study 5-HT $2 \mathrm{a} / \mathrm{c}$ receptor binding was measured in rats 10 weeks following MDMA exposure ( $5 \mathrm{mg} / \mathrm{kg}$ hourly $\mathrm{x} 4$ for 2 days, total $40 \mathrm{mg} / \mathrm{kg}$ ). In contrast to Reneman et al. (2002), it was found that DOI binding was reduced in most brain regions suggesting a more persistent downregulation of the $5-\mathrm{HT}_{2 \mathrm{a} / \mathrm{c}}$ receptors (Bull et al., 2004).The conflicting results may reflect the difference in MDMA dose or the methods of measurement, however, together the results confirm that repeated MDMA exposure produced adaptations in the 5- $\mathrm{HT}_{2}$ receptor mechanism.

Effects of repeated MDMA exposure on 5- $\mathrm{HT}_{1 \mathrm{a}}$ receptor densities have also been demonstrated. One week following both single $(30 \mathrm{mg} / \mathrm{kg})$ and daily high dose MDMA (30mg/kg daily for 4 consecutive days) administration increased 5-HT receptor binding density was observed in the frontal cortex and hypothalamus. In contrast, decreased densities were observed in the hippocampus and brain stem, including the DRN (Aguirre et al., 1998; Aguirre et al., 1997; Aguirre et al., 1995). It was suggested that MDMA's ability to damage fine 5-HT terminals but not cell bodies may account for the opposite results. The increase in the $5-\mathrm{HT}_{1 \mathrm{a}}$ receptors in the frontal cortex was seen as compensation for the regional loss of 5-HT nerve terminals and therefore 5-HT synthesis. It is also possible that pre and postsynaptic 
activation may account for these differences. The DRN has a high density of 5-HT $1 \mathrm{a}$ autoreceptors relative to postsynaptic receptors (Gozlan et al., 1983; Riad et al., 2000; Verge et al., 1985). Therefore, differential effects may reflect the direct response of the $5-\mathrm{HT}_{1 \mathrm{a}}$ autoreceptors to $5-\mathrm{HT}$ release while adaptations in the terminal regions reflect a response to the 5-HT1a autoreceptor activity. In contrast, no change in 5-HT $1 \mathrm{a}$ binding was reported 3 months following MDMA exposure $(4 \mathrm{x}$ $5 \mathrm{mg} / \mathrm{kg}$ over $4 \mathrm{~h}$ over 2 days) (McGregor et al., 2003). The varying results may be due to the time differences of measurement and MDMA doses.

Behavioural studies more consistently suggest that 5-HT receptors undergo neuroadaptations following repeated MDMA exposure. However, studies examining the consequences of repeated MDMA exposure on 5-HT $1 \mathrm{a}$ and 5- $\mathrm{HT}_{2}$ receptor function and expression are limited. A few studies have attempted to identify functional changes by using specific pharmacological challenges in selected behavioural tests.

Bull, Hutson, \& Fone (2003) investigated the effect of MDMA pre-treatment in Lister Hooded rats. Rats received MDMA $(15 \mathrm{mg} / \mathrm{kg})$ twice daily for 3 days. Effects of the 5- $\mathrm{HT}_{2}$ agonist, $\mathrm{m}-\mathrm{CPP}$, were examined in the elevated plus maze (EPM), social interaction and locomotor activity tests. As has been reported in another study (McGregor et al., 2003), MDMA pre-treated rats showed reduced social interaction three weeks following MDMA exposure. Two days later the effects of $\mathrm{m}-\mathrm{CPP}(2.5 \mathrm{mg} / \mathrm{kg})$ were determined. Hypolocomotion induced by $\mathrm{m}-\mathrm{CPP}$ was unaltered by MDMA pre-treatment. Four days later m-CPP $(1.0 \mathrm{mg} / \mathrm{kg})$ produced a reduction in open arm exploration on the EPM but there was no effect of MDMA pre-treatment. Because these behaviours have been attributed to activation of $5-\mathrm{HT}_{2 \mathrm{c}}$ receptors (but see File, 1992; Griebel, Perrault, \& Sanger, 1997), it was suggested that repeated MDMA did not modify these receptors. The use of only a single dose of m-CPP, however, limits the interpretation. In follow-up study Bull et al. (2004) pre-treated rats with MDMA (5mg/kg hourly for 4 hours on 2 consecutive days) and eight weeks later administered the 5-HT $2 \mathrm{a} / \mathrm{c}$ agonist, DOI. DOI reduced exploration in saline but not MDMA pretreated rats suggesting a desensitised 5- $\mathrm{HT}_{2 \mathrm{a}}$ receptor.

Altered 5- $\mathrm{HT}_{2 \mathrm{a}}$ sensitivity following MDMA pre-exposure has also been found in the absence of changes in receptor density. Sprague Dawley rats were administered MDMA (10mg/kg $2 x$ daily $4 x$ every $5^{\text {th }}$ day) and challenged with DOI. 
Repeated MDMA potentiated DOI-induced head twitches and back muscle contractions suggesting that MDMA exposure enhanced sensitivity of 5- $\mathrm{HT} 2 \mathrm{a} / 2 \mathrm{c}$ receptors (Biezonski, Courtemanche, Hong, Piper, \& Meyer, 2009) even though binding densities remained unchanged. The lack of change in $5-\mathrm{HT}_{2 \mathrm{a} / \mathrm{c}}$ binding suggests that differing pre-treatment regimens can alter receptor function without increasing receptor expression (Richtand et al., 2003; Shuto, Seeman, Kuroiwa, \& Nishi, 2008).

The effect of repeated MDMA exposure on the behavioural responses of 5$\mathrm{HT}_{1 \mathrm{a}}$ receptor ligands has also been investigated. MDMA pre-treatment produced tolerance to behaviours induced by the 5-HT la $_{\text {a }}$ agonist, 8-OHDPAT, including components of the 5-HT syndrome such as flat body posture and forepaw treading. Conversely, tolerance to the hypothermic or locomotor activating effects of 8OHDPAT were not produced (Granoff \& Ashby, 2001). As the various brain regions involved in 8-OHDPAT mediated behaviours remain to be elucidated these findings may indicate region specific alterations in $5-\mathrm{HT}_{1 \mathrm{a}}$ function. Furthermore, pre or postsynaptic $5-\mathrm{HT}_{1 \mathrm{a}}$ activation may lead to varying results. Flat body posture has been reported following 8-OHDPAT application into the DRN suggesting the contribution of 5-HT $\mathrm{HT}_{1 \mathrm{a}}$ autoreceptors (Higgins \& Elliott, 1991) however, as 5-HT $1 \mathrm{a}$ heteroreceptors are also present within the DRN albeit at a low ratio to presynaptic, specific contributions of the two receptor types can be difficult to dissociate.

Enhanced MDMA-produced behavioural responses mediated by $5-\mathrm{HT}_{1 \mathrm{a}}$ receptor activation have also been found following repeated neonatal MDMA exposure. Enhanced MDMA-produced serotonin syndrome behaviours, including head weaving and forepaw treading, and hyperthermic response were produced in adults following neonatal exposure (Piper \& Meyer, 2004; Piper et al., 2005). These changes in sensitivity to MDMA may reflect an alteration in receptor number or supersensitivity of the 5- $\mathrm{HT}_{1 \mathrm{a}}$ receptor population that mediate each behaviour. While this is yet to be elucidated these studies highlight the adaptability of the 5$\mathrm{HT}_{1 \mathrm{a}}$ receptors, both pre and postsynaptic, following MDMA exposure.

A consistent observation has been that repeated MDMA produces deficits in tissue levels of 5-HT and its primary metabolite 5-Hydroxyindoleacetic acid (5HIAA) as well as reductions in SERT binding following high dose MDMA pretreatment. Reductions in 5-HT and 5-HIAA tissue concentrations were evident in the 
striatum, frontal cortex, hippocampus, amygdala, nucleus accumbens, olfactory tubercle and caudate one to four weeks following repeated MDMA exposure (Aguirre et al., 1998; Battaglia et al., 1987; Granoff \& Ashby, 2001) and decreased SERT binding in cortical, hippocampal, thalamic, and hypothalamic sites was reported (Battaglia et al., 1987; McGregor et al., 2003). Several of these studies suggested that these deficits mediated behavioural tolerance (Callaway \& Geyer, 1992; Scanzello, Hatzidimitriou, Martello, Katz, \& Ricaurte, 1993; Shankaran \& Gudelsky, 1999).

Microdialysis studies have reported blunted synaptic 5-HT overflow in response to MDMA following repeated high dose MDMA administration. Prior MDMA exposure reduced 5-HT release in the frontal cortex and striatum in response to MDMA or the 5-HT releasing stimulant, fenfluramine (Gartside, McQuade, \& Sharp, 1996; Matuszewich, Filon, Finn, \& Yamamoto, 2002; Series, Cowen, \& Sharp, 1994; Shankaran \& Gudelsky, 1999). Reduced striatal release was accompanied by attenuated hyperthermic and 5-HT syndrome responses (Shankaran \& Gudelsky, 1999). Other studies have reported impaired 5-HT release following high dose MDMA pre-treatment in response to physiological or stressful stimuli (Gartside et al., 1996; Matuszewich et al., 2002). Together, these studies suggest that tolerance to the effects of MDMA may reflect impairments in 5-HT transmission under circumstances in which the 5-HT system is challenged. However, there is an ongoing debate as to whether MDMA-induced impairments reflect neuroadaptive changes or neurotoxicity (Baumann, Wang, \& Rothman, 2007).

\section{Neurotoxicity vs. Neuroadaptations}

There is extensive evidence that across a variety of species including rats (Commins et al., 1987), guinea pigs (Colado, O'Shea, \& Green, 2004) and nonhuman primates (Fantegrossi, Ullrich, Rice, Woods, \& Winger, 2002; Ricaurte et al., 1988) MDMA produces changes in neuronal markers which may indicate degeneration in 5-HT mechanisms. Following acute administration of MDMA there is an acute rapid release of 5-HT, a subsequent depletion of 5-HT and an inactivation of tryptophan hydroxylase. The 5-HT tissue deficits recover within 24 hours but tryptophan hydroxylase inactivation persists (Schmidt, Levin, \& Lovenberg, 1987; Stone et al., 1989b). 
Neurotoxic type effects appear in the second phase, occurring between 24 hours and 1 week following MDMA administration. These effects include long term inhibition of tryptophan hydroxylase activity, a reduction in reuptake sites and reduced 5-HT and 5-HIAA tissue levels (Battaglia et al., 1988; Commins et al., 1987; Scanzello et al., 1993). While it is unequivocal that repeated MDMA exposure produces 5-HT deficits, few studies have shown other established markers of neurotoxicity, such as degeneration of nerve terminals and reactive gliosis. Administration of $80 \mathrm{mg} / \mathrm{kg}$ of MDMA twice a day for 2 days to rats was followed by a degeneration of 5-HT axons in the striatum and somatosensory cortex as determined by silver staining (Commins et al., 1987). In another study rats were injected twice daily with 75-150mg/kg MDMA for two days (Jensen et al., 1993). The levels of glial fibrillary acidic protein (GFAP) which, if expression is enhanced is a marker of reactive gliosis(O'Callaghan \& Miller, 1993), was markedly elevated in several brain regions (Commins et al., 1987; Molliver et al., 1990; O'Hearn et al., 1988).

However, as these pre-treatment regimes used extremely high dose exposures it is questionable as to whether they are meaningful. With lower dose administrations that produced 5-HT depletions nerve degeneration or gliosis was not observed. For example, administration of MDMA (7.5 mg/kg, IPQ $2 \mathrm{~h}$ x 3 doses) markedly decreased levels of 5-HT in the cortex and hippocampus but there was no effect on the expression of GFAP (Wang, Baumann, Xu, Morales, \& Rothman, 2005; Wang, Baumann, Xu, \& Rothman, 2004). Further, rats administered twice daily injections of $20 \mathrm{mg} / \mathrm{kg}$ MDMA for 4 days showed decreased SERT binding but no reactive gliosis (Pubill et al., 2003). While MDMA-induced 5-HT depletions can last for several months to years there is evidence of recovery (Brennan \& Schenk, 2006; Scanzello et al., 1993). One year post MDMA pre-treatment recovery of 5-HT markers was found in all brain regions. Brain 5-HT and 5-HIAA levels also showed recovery with time in rats. One year post MDMA treatment (10mg/kg 4x 2 hourly) in most rats there was complete recovery in all brain regions examined (Scanzello et al., 1993). Additionally, paroxetine binding studies following MDMA administration have shown time dependent recovery (Lew et al., 1996).

MDMA-induced behavioural effects have also shown to recover following repeated MDMA exposure. Two weeks following an MDMA pre-treatment regimen 
rats were tolerant to the locomotor activating effects of MDMA. There was, however, recovery 12 weeks following treatment (Brennan \& Schenk, 2006).These studies suggest that, while some individuals may be more susceptible to permanent deficits, the majority may recover following abstinence.

\section{Summary}

MDMA produces long term changes in 5-HT neurochemistry. However, studies suggest that these deficits are not associated with toxicity markers such as cell death and reactive gliosis and therefore do not reflect neuronal damage equivalent to toxicity. Tolerance to the behavioural effects of MDMA has been observed following doses that act on the 5-HT system yet do not induce other markers of toxicity such as reactive gliosis. Therefore, the underlying mechanisms of MDMA-induced tolerance are most likely due to neuroadaptations in response to repeated MDMA.

Following repeated MDMA tolerance to many of the effects produced by MDMA is evident. Additionally, MDMA depletes 5-HT and 5-HIAA levels, and produces 5-HT receptor adaptations. Of these the 5- $\mathrm{HT}_{1 \mathrm{a}}, 5-\mathrm{HT}_{2 \mathrm{a} / \mathrm{c}}$ receptors have been shown to undergo adaptations following repeated MDMA exposure. Together, these findings suggest that these alterations to the 5-HT system play a role in MDMA-induced behavioural tolerance, although the underlying mechanisms remain unclear. 


\section{Present Study}

There are three aims of this thesis. The first was to develop a behavioural paradigm that was sensitive to 5-HT probes in order to assess the effects of MDMA exposure on receptor function. The second was, to measure changes in specific receptor function as a result of MDMA pretreatment. The third was to use selective ligands and exposure in an attempt to reverse tolerance

\section{$\underline{\text { Section } 1}$}

\section{Behavioural Assay Development}

The driving hypothesis was that there was altered 5-HT receptor function underlying behavioural tolerance. Section 1 describes the development of a behavioural assay in which the effects of MDMA administration could be observed. This assay makes use of a variation of an Emergence Test (ET). The ET was chosen as it has been shown to be sensitive to effects attributed to 5-HT and specifically 5$\mathrm{HT}_{2}$ receptors (Griebel, 1995). Additionally, effects of MDMA have been documented using the paradigm (Morley, Gallate, Hunt, Mallet, \& McGregor, 2001; Morley \& McGregor, 2000). Furthermore, this model is advantageous as it does not require conditioning, punishment, or reward thereby limiting the type of response evoked.

\section{The Emergence Test}

The principle known as "Neotic" preference, first described by Fehrer in 1956 , is based on an animal's natural preference to readily explore a novel environment over a familiar one (Fehrer, 1956; Hughes, 2007). The emergence test, based on this principle, is a behavioural assay that measures the animal's latency to move freely between a familiar area (the hide box) and an area not previously encountered (the test arena) (Crawley \& Goodwin, 1980; Hascoet, Bourin, \& Dhonnchadha, 2001; Pare, Tejani-Butt, \& Kluczynski, 2001). The procedure requires the rat to be placed in a fully enclosed hide box situated within an open arena. Following a habituation period the experimenter opens a slide door along one side of the hide box allowing the rat to emerge into the test arena. The latency to emerge 
from the hide box into the open arena is then measured. Figure 1 below shows the ET apparatus. In the top panel the hide box is placed in the test arena and kept closed during the habituation period. The panel below shows the animal emerging from the hide box into the novel test arena once the hide box has been opened by the experimenter.

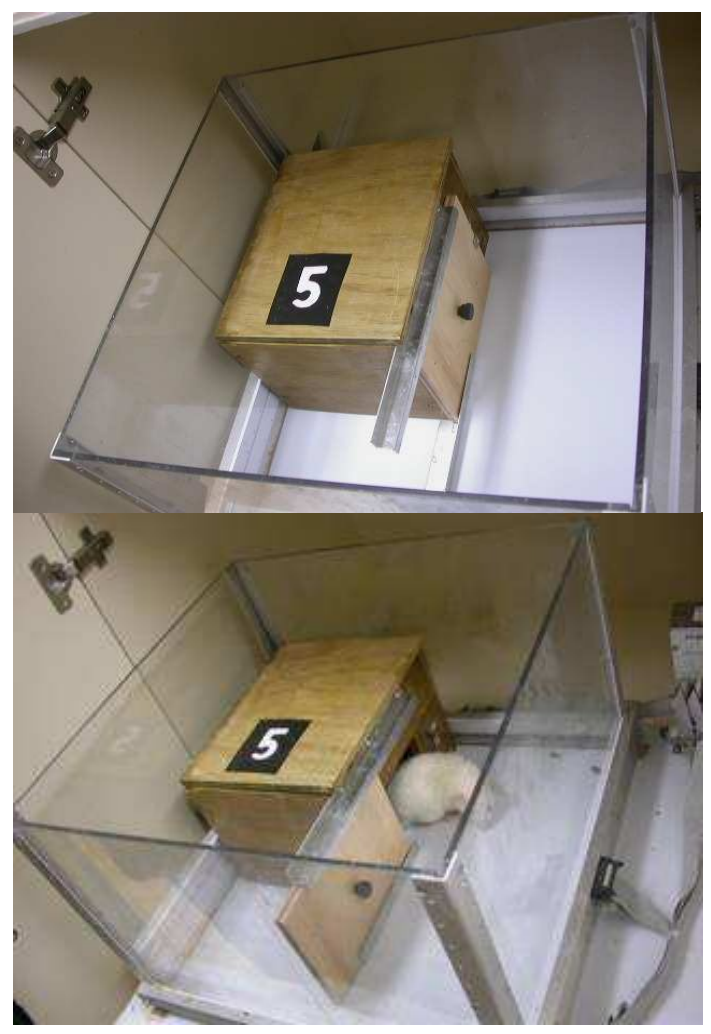

Figure 1 The Emergence Test.

MDMA typically produced decreased exploratory behaviour in the emergence test (ET) (Morley et al., 2001; Morley \& McGregor, 2000). It is well established that several experimental factors can impact on baseline responses as well as pharmacologically-induced behaviours in animals. These include handling, exposure to the environment, drug and drug doses, pretreatment times, administration routes, species and strain (Griebel et al., 1997; Schmitt \& Hiemke, 1998; van Driel \& Talling, 2005).Therefore, the present study investigated the effects of prior test exposure, handling, and drug exposure on MDMA responses in the ET and adopted particular methods based on these results.

MDMA administration produces an acute dose dependent hyperactivity response (Callaway et al., 1990; Kehne et al., 1996; McCreary et al., 1999; Spanos \& 
Yamamoto, 1989). Therefore, when developing a procedure in which locomotor activity may influence the measured behaviour, it is necessary to demonstrate dissociation between these two behavioural responses. In the ET this hyperactivity may reduce or increase emergence latency thereby confounding the results. Hence, the first experiment established a dose response curve for MDMA-produced hyperactivity. Following this, MDMA doses were chosen for testing in the ET that did not affect locomotor activity.

In order for the ET to reflect a behavioural paradigm based on "Neotic" preference the concept of novelty was addressed within the test itself and through repeated exposure to the test. Firstly, within the ET two environments were required; one familiar and one novel (Hughes, 2007). The present study provided a habituation period in the hide box, in which the animal was initially placed, to establish a familiar environment. The test arena, to which the animal was exposed once the slide door was opened, was then considered the novel environment. Secondly, it has been reported that the novelty of an environment depends on the animal's previous experience with that environment (Hughes, 2007). Studies have shown a reduction in responses such as the number of punished crossings in the four plates test and decreased open arm exploration in the EPM, on second and subsequent trials (File, 1990; File, Mabbutt, \& Hitchcott, 1990; File, Zangrossi, Viana, \& Graeff, 1993). Additionally, drug response was altered following test re-exposure. For example, the response to diazepam was eliminated following prior test exposure (Hascoet, Bourin, $\&$ Couetoux du Tertre, 1997). In order to determine if the animals could be repeatedly tested, thereby minimising the number required, rats were re-exposed to the test over a number of days and baseline and MDMA-induced behavioural responses were measured. Whether or not re-exposure to the test arena altered subsequent baseline and MDMA responses would determine if experiments were to be between or within subjects.

It has been reported that the extent of handling can also influence responses in the ET. Studies show that following one week of daily handling rats displayed higher levels of activity compared to those handled only on test days (Schmitt \& Hiemke, 1998). Accordingly, this variable was investigated in order to assess the effects on baseline and MDMA-produced changes in EL. EL of animals with no prior handling were compared to those that received handling on days 1, 5 and 9. 


\section{$\underline{\text { Section } 2}$}

Section 2 utilises the ET in conjunction with pharmacological agents to assess changes in receptor function as a result of MDMA exposure. The effects of MDMA and the 5-HT agonists, $\mathrm{m}-\mathrm{CPP}$ and fenfluramine, were examined in the ET. m-CPP was chosen as it has been shown to act preferentially as a $5-\mathrm{HT}_{2 \mathrm{c}}$ agonist (Fiorella, Rabin, \& Winter, 1995; Hamik \& Peroutka, 1989; Kennett \& Curzon, 1988; Kennett et al., 1994) and to release 5-HT via the 5-HT transporter (Baumann, Mash, \& Staley, 1995; Pettibone \& Williams, 1984). m-CPP decreased exploratory behaviour has been attributed to activation of $5-\mathrm{HT}_{2 \mathrm{c}}$ receptors (Bilkei-Gorzo, Gyertyan, \& Levay, 1998; Griebel et al., 1997). Fenfluramine is a 5-HT transporter substrate and potent 5-HT releaser (Berger, Gu, \& Azmitia, 1992; Rothman \& Baumann, 2002). DOI is a preferential 5-HT $2 \mathrm{a}$ agonist that produces a range of behavioural responses including wet dog shakes and head twitches (Kleven et al., 1997; Willins \& Meltzer, 1997). In addition, DOI altered exploratory behaviour on the elevated plus maze (Bull et al., 2004; Kennett et al., 1994). These effects have been attributed to 5-HT2a receptor activation because they were attenuated by the $5-\mathrm{HT}_{2 \mathrm{a}}$ but not $5-\mathrm{HT}_{2 \mathrm{c}}$ antagonists (Kennett et al., 1994; Willins \& Meltzer, 1997). In addition to MDMA these pharmacological probes would help to elucidate the contribution of specific receptors in emergence latency in the ET. The highly selective 5-HT $2 \mathrm{c}$ antagonist, RS102221 (Bonhaus et al., 1997), was administered to determine the contribution of this receptor subtype. All drug pretreatment times were established by reviewing previous literature in combination with peak effect times established in our laboratory.

\section{MDMA Pre-treatment Regimen}

In order to investigate the effects of repeated MDMA exposure in the ET the MDMA pre-treatment regimen (10mg/kg, 4x 2hr, IP) and 2 week withdrawal period were chosen for the present study as 5-HT deficits and behavioural tolerance following this procedure are well established (Brennan \& Schenk, 2006; Nair \& Gudelsky, 2006; Scanzello et al., 1993; Shankaran \& Gudelsky, 1999; Sumnall et al., 2004). This time frame was also chosen because deficits in tissue 5-HT and 5-HIAA concentrations, dialysate 5-HT, and alterations to 5-HT receptors have been 
demonstrated (Renman et al., 2002; Shankaran \& Gudelsky, 1999). In order to verify that the dosing regimen used produced 5-HT deficits, 5-HT and 5-HIAA tissue levels were measured using HPLC analysis, as described in the method section.

It has previously been reported that following high dose MDMA administration tissue 5-HT and 5-HIAA levels are depleted and 5-HT release impaired. Further, MDMA-induced behaviours were attenuated suggesting tolerance. However, baseline dialysate 5-HT levels were unaltered (Granoff \& Ashby, 2001).These results suggest that despite significant depletions the 5-HT system is able to maintain a baseline concentration of synaptic 5-HT. While reductions in the SERT binding sites and decreased MAO activity following high dose MDMA exposure may contribute to maintaining the synaptic 5-HT levels through limiting reuptake and degradation, the reduced ability to release 5-HT is evident when the system is challenged. In order to detect any effect of intervention the current study investigated both baseline and challenged groups.

\section{$\underline{\text { Section } 3}$}

Section 3 investigates the functional status of the $5-\mathrm{HT}_{1 \mathrm{a}}$ receptor by determining the response to a 5- $\mathrm{HT}_{1 \mathrm{a}}$ agonist following MDMA pretreatment.The 5$\mathrm{HT}_{1 \mathrm{a}}$ agonist, 8-OHDPAT, has been extensively used to investigate the functional status of the 5-HT $1 \mathrm{a}$ receptors (Hillegaart, 1991; Hjorth, 1985). 8-OHDPAT has consistently been shown to induce a hypothermic response in rats (Hillegaart, 1991; Hjorth, 1985; Renoir et al., 2008) with low dose (<.05mg/kg) preferentially targeting the presynaptic 5-HT $1 \mathrm{a}$ autoreceptor (Hoyer, Hannon, \& Martin, 2002). In the present study, rectal temperature was measured fifteen minutes prior to 8-OHDPAT administration and again 15, 30 and 45 minutes post injection. In line with previous studies (Hjorth, 1985) it was established that a peak hypothermic effect was achieved 30 min post injection in drug naïve rats. Dose-response curves for 8-OHDPAT produced hypothermia were then compared for MDMA and saline pretreated groups.

\section{$\underline{\text { Sections } 4 \text { and } 5}$}

In order to determine the ability of the 5- $\mathrm{HT}_{1 \mathrm{a}}$ antagonists to reverse tolerance to MDMA-induced hyperactivity two approaches were used; 1) systemic application and 2) local antagonist application targeting the 5- $\mathrm{HT}_{1 \mathrm{a}}$ receptor in the DRN. In order 
to measure the functional response following 5-HT $1 \mathrm{a}$ antagonist administration locomotor activity was chosen because of the ability for time-course measurements that are not easily obtained in the ET. 5- $\mathrm{HT}_{1 \mathrm{a}}$ receptors have also been implicated in feeding (Dourish et al., 1985; Fletcher et al., 1996) and so food consumption following $5-\mathrm{HT}_{1 \mathrm{a}}$ antagonist administration was measured. 


\section{General Methods}

$\underline{\text { Subjects }}$

The subjects were male Sprague-Dawley rats weighing between 200-250gm. The animals were bred in the vivarium at Victoria University of Wellington, New Zealand. The humidity $(74 \%)$ and temperature $\left(21^{\circ} \mathrm{C}\right)$ controlled colony was maintained under a 12:12 hr light/dark cycle with lights on at 0700. Food and water were available ad libitum except during testing. All experimental protocols were consistent with OLAW regulations and approved by the Animal Ethics Committee of Victoria University.

\section{$\underline{\text { Apparatus }}$}

\section{Locomotor Activity}

Forward locomotion activity was measured using the Activity Monitor Version 5 program (Med Associates Inc.). This system consisted of a perspex-lined open-field chamber $(50 \times 50 \times 20 \mathrm{~cm})$. Each sound attenuated chamber was equipped with 16 infrared sources and sensors evenly distributed around the periphery of the chamber, a system power supply, an environmental data source controller, connecting cables, PC/ environment interface card and data analysis software. The chambers were interfaced with a computer that recorded each beam interruption by the subject as a forward locomotion count. The program achieved this by dividing the chamber into zones. The zone size was able to be predetermined and was, for these experiments, set to be the approximate dimensions of a $250 \mathrm{gm}$ rat. When the animal travelled distance and crossed the zone perimeters into the adjacent zone, the program registered this as an ambulatory (activity) count.

\section{Emergence Latency}

Emergence latency was measured using a method developed by Pare et al. (2001). For the emergence test a wooden hide box $(25 \times 17 \times 20.5 \mathrm{~cm})$ was placed in 
the top left corner of the open-field chamber. The hide box was designed with a hinged lid, through which the rat could initially be placed. Following a predetermined habituation period the sliding door was opened to allow emergence. Full body emergence from the hide box was determined when the distance travelled by the rat was equivalent to the length of the rat as measured by Med Associates software.

Infrared videos cameras located above the test chambers recorded and monitored activity continuously without disruption. These were used to verify emergence and to observe qualitative behaviours as required. The temperature $\left(21^{\circ} \mathrm{C}\right)$ and humidity (53\%) controlled testing room was illuminated with red light (50W), and subject to white noise $(80 \mathrm{~dB})$. Before and after each test the arenas, hide boxes, and maze arms were wiped with Virkon 'S' disinfectant (Southern Veterinary Supplies, Palmerston North). Tests were conducted in the dark between 0800 and $1700 \mathrm{hr}$. Experimenters remained outside the test room during experiments.

\section{Temperature}

Rectal temperature was obtained using a lubricated digital thermometer probe (Surgipack Digital Thermometer, Code 6344) inserted $4 \mathrm{~cm}$ into the rectum. The rat was lightly restrained by hand until the temperature stabilised, (no longer than $30 \mathrm{sec}$ at any time), a method adopted from Ho et al. (2004). All readings were taken in the temperature controlled $\left(21^{\circ} \mathrm{C}\right)$ home room.

\section{Food Consumption}

In section 4 food consumption was recorded on day 1 and 8 following the administration of WAY100635. A measured amount of food was placed inside the home cage on a daily basis, weighed the following day and the difference calculated as the amount consumed. The home cage was searched for any food being placed in the area by the animal and taken into account. 


\section{$\underline{\text { Pharmacological Procedures }}$}

\section{MDMA Pre-treatment Regimen}

On day 1 rats were placed in individual cages and administered a regimen of 4 injections of either MDMA (10mg/kg per injection, I.P) or the saline vehicle at 2 hourly intervals (total MDMA exposure $=40 \mathrm{mg} / \mathrm{kg}$ over 6 hours). This regimen was chosen because of its reported ability to produce serotonin deficits two weeks following treatment (Scanzello et al., 1993; Shankaran \& Gudelsky, 1999; Sumnall et al., 2004) and to produce tolerance to MDMA-induced hyperactivity (Shankaran \& Gudelsky, 1999).

On day 2 rats were housed in pairs for a two week period before behavioural tests commenced. Rats were closely monitored during and following the pretreatment regimen. When of interest, temperature was recorded $15 \mathrm{~min}$ prior to and 30 min following the last MDMA pre-treatment injection. Overall, the drug regimen was well tolerated.

\section{$\underline{\text { Neurochemical Procedures }}$}

\section{Brain Dissection}

In order to determine brain 5-HT and 5-HIAA concentrations rats were asphyxiated by $\mathrm{C}^{2}$, decapitated and brains rapidly removed. In line with the methods developed by Heffner, Hartman, \& Seiden (1980) the brains were then placed in a stainless steel brain block for dissection into $1 \mathrm{~mm}$ coronal slices. Slices were placed onto an inverted petrie dish chilled by ice. The frontal cortex, striatum, nucleus accumbens, hippocampus, hypothalamus and dorsal raphe were dissected out, placed in vials, weighed, and tissue weights recorded. All samples were stored at $-80^{\circ} \mathrm{C}$ until analysed. 


\section{HPLC analysis}

For the determination of tissue neurotransmitter concentrations High Performance Liquid Chromatography (HPLC) with electrochemical detection was used. Tissues were removed from the freezer, homogenised in $0.1 \mathrm{~N}$ perchloric acid and centrifuged at $10000 \mathrm{~g}$ for $30 \mathrm{~min}$ at $4^{\circ} \mathrm{C}$. The supernatant was filtered and injected into a high-performance liquid chromatography system (Agilent 1100 series) with electrochemical detection. The injection volume was $10 \mu \mathrm{L}$ for the striatum and $20 \mu \mathrm{l}$ for the other regions. 5-HT and 5-HIAA were separated using a C18 reversed phase column $(150 \times 4.6 \mathrm{~mm}, 5 \mu \mathrm{m}$ particle size; Eclipse XDB-C18, Agilent, USA). The mobile phase consisted of $\mathrm{NaH}_{2} \mathrm{PO}_{4}(75 \mathrm{mM})$, octane-1-sulphonic acid $(1.7 \mathrm{mM})$, EDTA $(0.25 \mathrm{mM})$, triethylamine $(100 \mu \mathrm{L} / \mathrm{L})$ and methanol $(10 \%)$, and was adjusted to $\mathrm{pH} 3$ with phosphoric acid. The flow rate was $1 \mathrm{ml} / \mathrm{min}$. Detection was performed using a coulometric detector (Coulochem III, ESA, USA). The guard cell potential was set at $450 \mathrm{mV}$ and the analytical cell potential at $400 \mathrm{mV}$. Chromatograms were acquired with ChemStation software. Concentrations are expressed as ng per mg of tissue. Working external standards (500 $-15.125 \mathrm{ng} / \mathrm{ml}$ in $0.1 \mathrm{~N}$ perchloric acid) were prepared daily from external standard stock solutions.

\section{$\underline{\text { Drugs }}$}

- +/- 3,4- Methylenedioxymethamphetamine hydrochloride (MDMA, ESR, Porirua, New Zealand), dissolved in a solution of $0.9 \%$ saline

- 1-(3-chlorophenyl) piperazine hydrochloride (m-CPP, Tocris), dissolved in a solution of $0.9 \%$ saline

- +/-2,5-dimethoxy-4-iodo-phenylisopropylamine (DOI, Sigma Aldrich), dissolved in a solution of $0.9 \%$ saline

- (+) - Fenfluramine hydrochloride (fenfluramine, Sigma Aldrich) dissolved in a solution of $0.9 \%$ saline.

- 8-[5-(2,4-dimethoxy-5-(4trifluoromethylphenylsulphonamido)phenyl-5-oxopentyl]-1,3,8- 
triazaspiro[4.5]decane-2,4-dione hydrochloride (RS102221, Tocris), suspended in a solution of $1 \%$ polysorbate 80 (Tween $80 \AA$ ).

- \pm 8 -hydroxy-2-(di- $n$ - propylamino) tetralin (8-OHDPAT, Tocris), dissolved in sterile distilled water.

- $\quad N$-[2-[4-(2-methoxyphenyl)-1-piperazinyl]ethyl]- $N-2-$ pyridinylcyclohexanecarboxamide maleate (WAY100635, Sigma Aldrich), dissolved in a solution of $0.9 \%$ saline

Injections were intraperitoneally (IP) or subcutaneously (SC) administered as noted, in a volume of $1.0 \mathrm{ml} / \mathrm{kg}$ with intracranial injections (IC) at a concentration of $0.5 \mu \mathrm{g} / 0.5 \mu \mathrm{l}$ (500ng). All drugs were prepared immediately prior to administration and drug weights refer to the salt.

\section{$\underline{\text { Statistical Analyses }}$}

All analyses were conducted using SPSS statistical package (SPSS Inc) version16.0 for Windows 2005. All experimental sample sizes are located on relative figures. 


\section{Section 1: Emergence Test}

\section{Overview}

The aim of Section 1 was to develop a behavioural assay that was a reliable, consistent and sensitive measure of the effects of acute MDMA. This was achieved by determining effective doses of MDMA, pretreatment times and procedural parameters that were required to elicit optimal MDMA effects.

In the first experiment a dose effect curve for MDMA-induced locomotor activity was determined. In the second experiment separate groups of rats were tested following three habituation periods (15, 30, and 45min) in the Emergence Test (ET). These times were chosen as it has previously been shown in our laboratory that when rats are first placed in an activity box there are initially high levels of activity which abate over the first 15minutes. Therefore, prior to MDMA exposure, the rats were habituated to the hide box to reduce activity to baseline levels. Secondly, this would allow the animals to become familiar with the hide box creating a contrast to the test arena which remains novel as required in the ET. Thirdly, as MDMA effects are known to peak around 30 min post administration these habitation times would provide a window for MDMA-induced behaviours.

The third experiment examined the effect of repeated exposure to the ET. Rats were repeatedly run in the ET over 3 days (day1, 5, and 9). The number of days between tests days was chosen as MDMA is known to have a relatively long half life of 8 hours and is fully eliminated within 48 hours following administration (McCreary et al., 1999).

Finally, the fourth experiment examined the effect of repeated MDMA exposure on emergence latency and experiment 5 examined the effect of repeated handling.

\section{MDMA-Produced Hyperactivity}

Separate groups of drug naïve rats were placed in the activity chambers, habituated for 30 minutes then administered MDMA $(0.0,1.0,3.3,10.0 \mathrm{mg} / \mathrm{kg}$, IP). Locomotor activity was recorded for a further 60 minutes. 


\section{MDMA Effects on Emergence Latency}

\section{Effects of MDMA on Emergence Latency as a function of Habituation Time}

The effect of acute MDMA $(0.0,1.0,3.3 \mathrm{mg} / \mathrm{kg}, \mathrm{IP})$ administration on emergence latency was assessed following three habituation periods $(15,30,45 \mathrm{~min})$ in separate groups of drug naïve rats. Rats were placed in the hide box and given a 15,30 , or 45 mintue habituation period, the slide door was then opened and testing continued until either the rat emerged or $30 \mathrm{~min}$ had elapsed.

\section{Effects of Repeated Exposure to Emergence Test on Emergence Latency}

MDMA doses and habituation period were based on results from preliminary work (see Experiment 1 and 2). Experiment 1 demonstrated that MDMA doses 0.0, 1.0 and $3.3 \mathrm{mg} / \mathrm{kg}$ failed to increase locomotor activity above baseline. Experiment 2 revealed that the dose of $3.3 \mathrm{mg} / \mathrm{kg}$, following a $30 \mathrm{~min}$ habituation period, produced a significant increase in emergence latency. Hence, the effect of repeated exposure to the test arena on emergence latency was investigated utilizing a $30 \mathrm{~min}$ habituation period with MDMA doses of 0.0 and $3.3 \mathrm{mg} / \mathrm{kg}$.

On test day 1 separate groups of drug naïve rats were injected with MDMA $(0.0,3.3 \mathrm{mg} / \mathrm{kg}, \mathrm{IP})$ and placed into the hide box for a 30 minute habituation period. Following habituation, the slide door was opened and testing continued for a further $30 \mathrm{~min}$. At the end of the test period the animals were returned in a group cage until the next testing day. Testing was conducted on days 1,5 , and 9 .

\section{Effects of Repeated MDMA exposure on Emergence Latency}

The effect of repeated MDMA $(0.0,3.3 \mathrm{mg} / \mathrm{kg}$, IP) exposure was assessed in four groups of drug naïve rats. On days 1 and 5 rats were weighed then injected with MDMA $(0.0$ or $3.3 \mathrm{mg} / \mathrm{kg}$, IP) in the home cage. On day 9 rats were weighed, taken to the test room in a group cage, then injected with MDMA $(0.0$ or $3.3 \mathrm{mg} / \mathrm{kg}$, IP $)$ and placed in the hide box. Following a 30 min habituation period, the slide door was opened and testing continued for 30minutes.

\section{Effects of Handling on Emergence Latency}

The effect of handling was examined in drug naïve rats. On day 1 and 5 rats were either handled or left unhandled in their home cages. On day 9 rats were 
injected with MDMA $(0.0$ or $3.3 \mathrm{mg} / \mathrm{kg})$, placed in the ET and emergence latency measured as above.

\section{Results}

\section{MDMA-produced Hyperactivity}

\section{Dose Effects of MDMA administration on Locomotor Activity}

Figure 2 shows the effect of MDMA $(0.0,1.0,3.3,10.0 \mathrm{mg} / \mathrm{kg})$ on locomotor activity. Figure $2 \mathrm{~A}$ shows the time course for the effects of MDMA (0.0, 1.0, 3.3, $10 \mathrm{mg} / \mathrm{kg}$ ) on locomotor activity. A 2-Way ANOVA (time X MDMA dose), with time as a repeated measure, revealed a significant interaction between these factors $(\mathrm{F}(33,352)=7.292, \mathrm{p}<.01)$ and a main effect of dose $(\mathrm{F}(3,32)=36.34, \mathrm{p}<.01)$. Post hoc analyses revealed that the MDMA dose $10.0 \mathrm{mg} / \mathrm{kg}$ significantly increased locomotor activity above baseline while 1.0 and $3.3 \mathrm{mg} / \mathrm{kg}$ doses were ineffective. Figure 2B shows the total activity counts post MDMA $(0.0,1.0,3.3,10 \mathrm{mg} / \mathrm{kg})$ administration. A 1-Way ANOVA revealed a significant main effect of MDMA dose $(\mathrm{F}(3,35)=60.74, \mathrm{p}<.01)$. Post hoc tests showed that MDMA $10.0 \mathrm{mg} / \mathrm{kg}$ significantly increased locomotor activity while $0.0,1.0$, and $3.3 \mathrm{mg} / \mathrm{kg}$ doses had no effect. Therefore, a maximum dose of $3.3 \mathrm{mg} / \mathrm{kg}$ MDMA will be utilised for future experiments measuring emergence latency. 

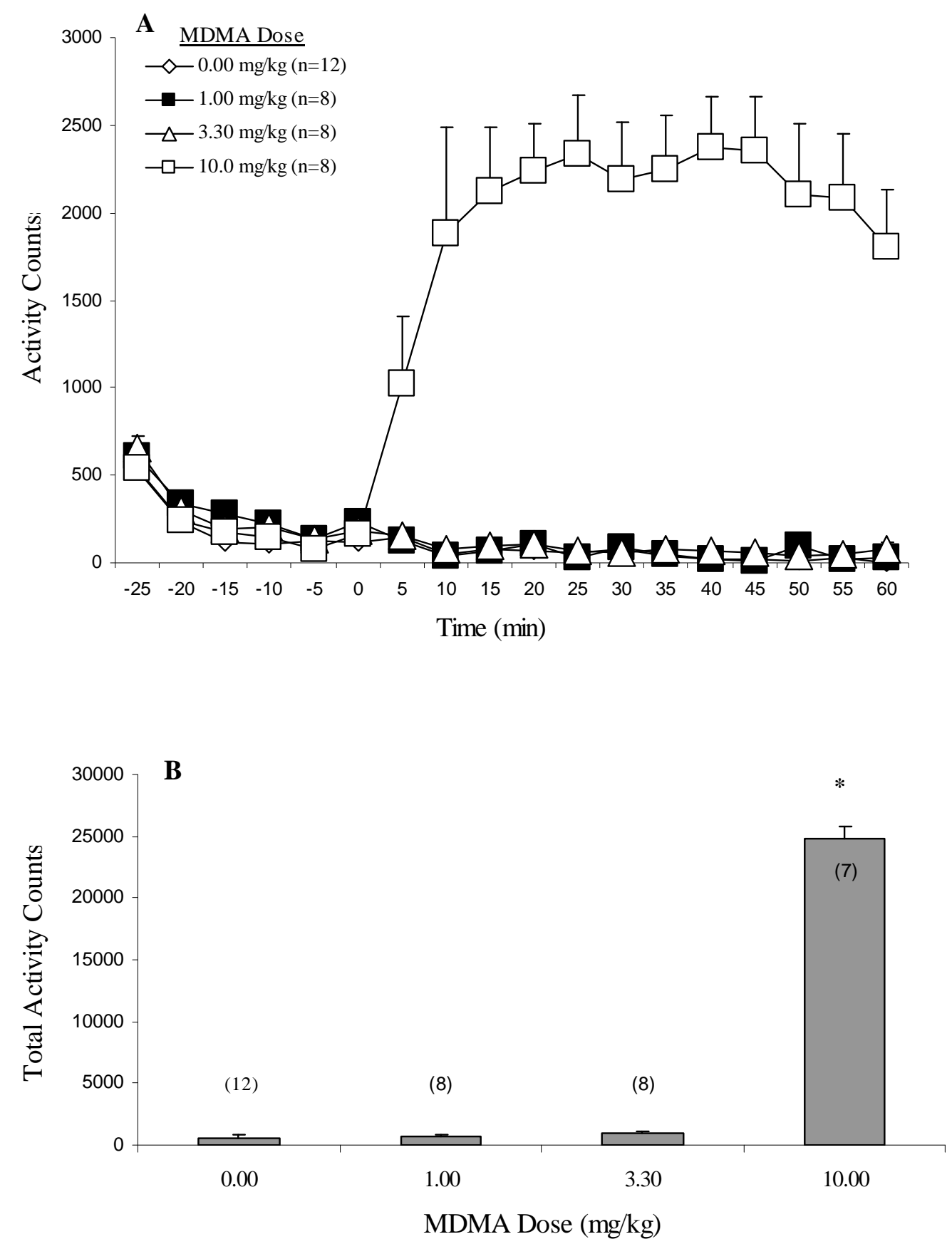

Figure 2 Activity counts produced following MDMA (0.0, 1.0, 3.3, 10.0mg/kg, IP) administration (+SEM). The top panel shows the time course of the mean activity counts where MDMA was administered at time=0 (Figure 2A). The bottom panel shows the total activity counts produced for the 60 minute period post MDMA injection (+SEM) (Figure 2B). Significant difference relative to vehicle group $* \mathbf{p}<.05$. 


\section{MDMA effects on Emergence Latency}

Effects of Acute MDMA administration on Emergence Latency over Three Habituation Periods

Figure 3 shows the effect of MDMA doses $(0.0,1.0,3.3 \mathrm{mg} / \mathrm{kg})$ after a 15 (Figure 3A), 30 (Figure 3B), and 45 min (Figure 3C) habituation period, on mean emergence latency. Separate 1-Way ANOVAs on emergence latency as a function of MDMA dose revealed that, following the 15 min habituation $(\mathrm{F}(2,37)=1.211, \mathrm{p}>$ $.05)$, and $45 \mathrm{~min}$ habituation period $(\mathrm{F}(2,40)=2.904, \mathrm{p}>.05)$, MDMA failed to produce an effect on emergence latency. It was found that a $30 \mathrm{~min}$ habituation period $(\mathrm{F}(2,40)=10.764, \mathrm{p}<.01)$ was required in order to observe increased latency effects of MDMA administration. Post hoc Tukey analyses revealed that the MDMA $3.3 \mathrm{mg} / \mathrm{kg}$ dose significantly increased emergence latency compared to controls, while MDMA 1.0 was ineffective. 

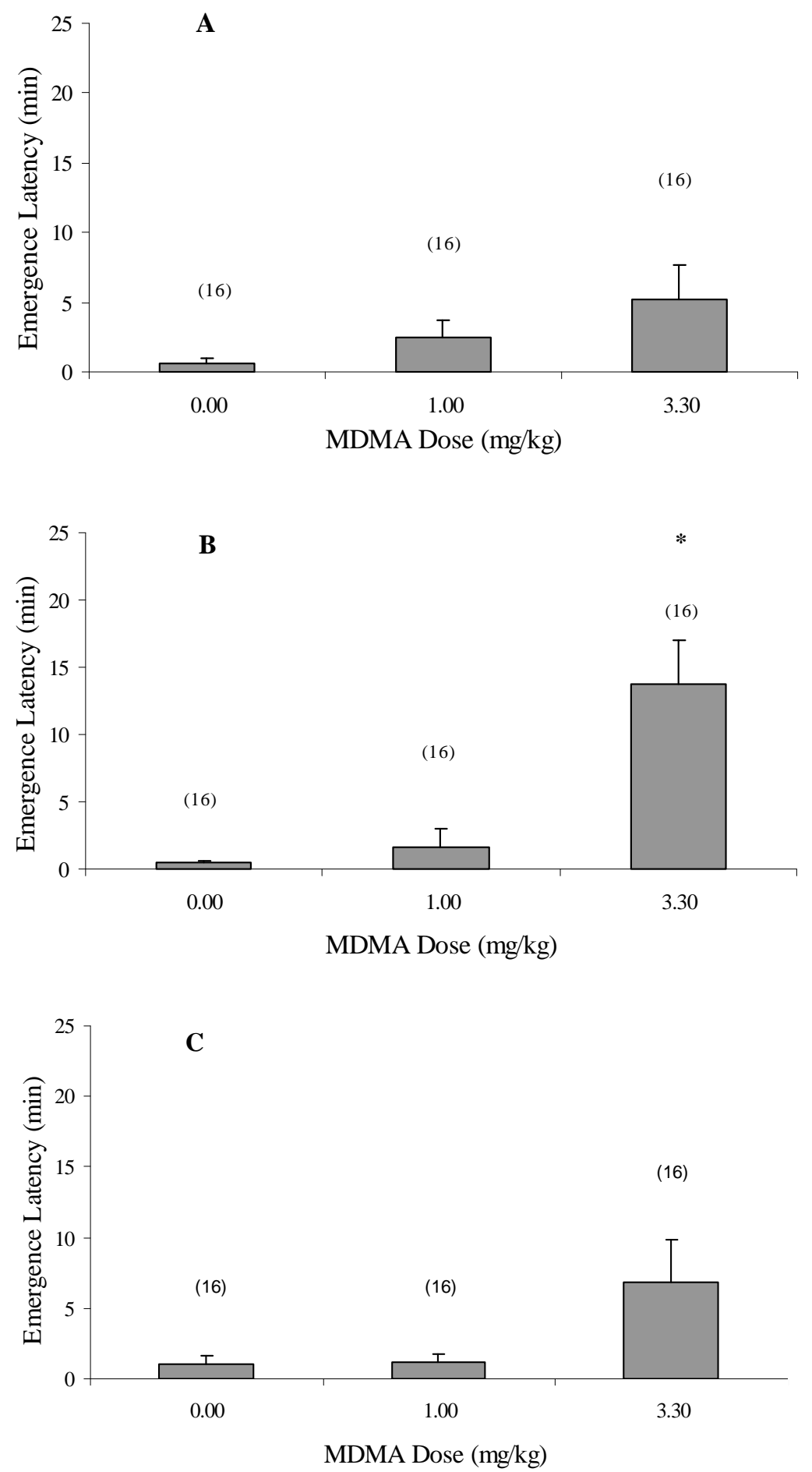

Figure 3 Effect of various MDMA $(0.0,1.0,3.3 \mathrm{mg} / \mathrm{kg}$, IP) doses on emergence latency (min) following a $15 \mathrm{~min}$ (Figure 3A), $30 \mathrm{~min}$ (Figure 3B) and 45min (Figure 3C) habituation period (+SEM). Significant difference relative to vehicle group $* \mathbf{p}<.05$. 
Effects of Repeated Exposure to the Emergence Test following acute MDMA on Emergence Latency.

Figure 4 shows the effect of repeated exposure to the emergence test following MDMA exposure on mean emergence latency. A 2-Way ANOVA revealed an interaction between day and MDMA dose $(F(2,28)=7.96, p<0.01)$ indicating that repeated exposure to the novel environment significantly decreases the MDMA effect. A 1-Way ANOVA revealed a significant main effect of day with MDMA dose 3.3mg/kg $(\mathrm{F}(2,21)=7.00, \mathrm{p}<.01)$ but not saline $(\mathrm{F}(2,21)=1.21$, p>.05). Post hoc tests showed a significant decrease in emergence latency from day 1 to day 9 with MDMA $(3.3 \mathrm{mg} / \mathrm{kg})$ dose.

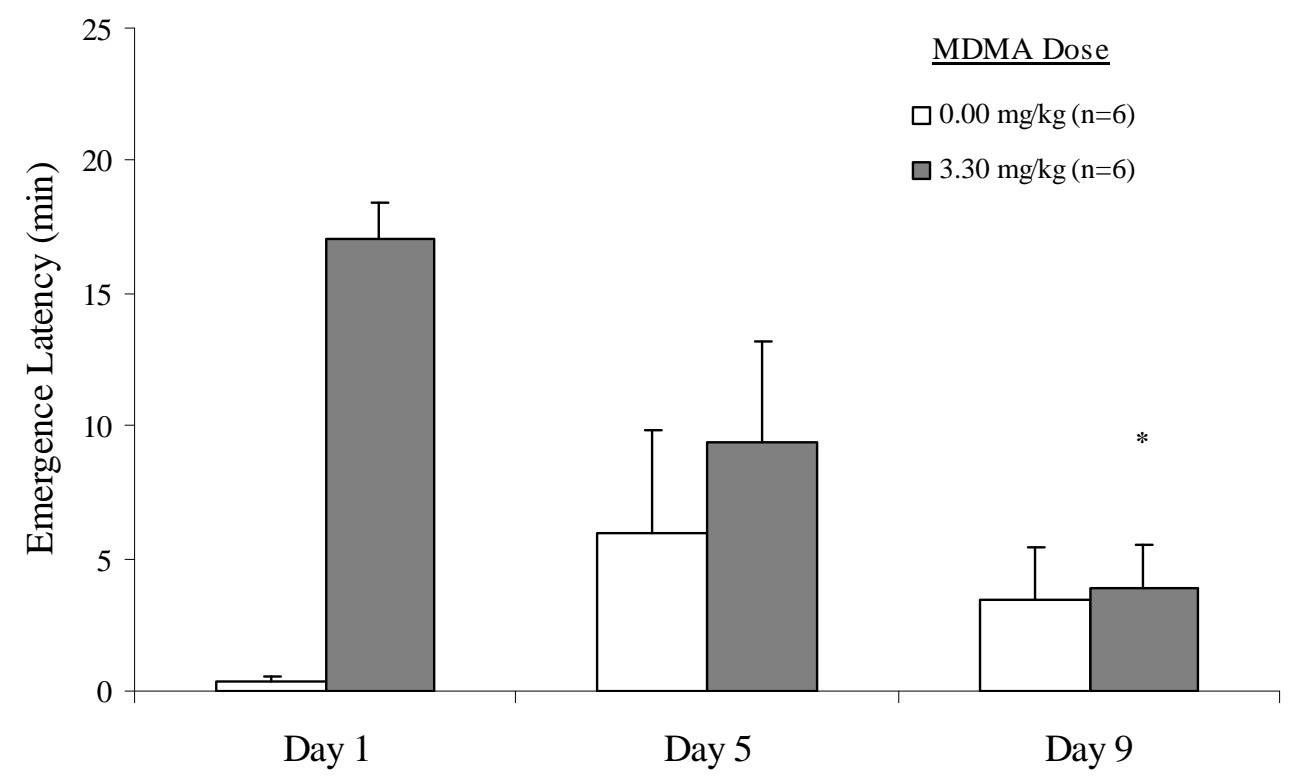

Figure 4 Effect of repeated exposure to the emergence test on days 1, 5 and 9 on emergence latency (min) following MDMA $(0.0,3.3 \mathrm{mg} / \mathrm{kg}$, IP) administration (+SEM). Significant difference relative to MDMA $(3.3 \mathrm{mg} / \mathrm{kg})$ day $1 * p<.05$. 
Effects of Repeated MDMA Exposure on Emergence Latency

Figure 5 shows the effect of repeated MDMA $(0.0,3.3 \mathrm{mg} / \mathrm{kg})$ exposure on day 1 , and 5 in home cages on emergence latency following MDMA (0.0, $3.3 \mathrm{mg} / \mathrm{kg}$ ) administration on day 9. A 1-Way ANOVA revealed no significant effect of repeated exposure to daily MDMA $(3.3 \mathrm{mg} / \mathrm{kg})$ injections on emergence latency following MDMA $(0.0,3.3 \mathrm{mg} / \mathrm{kg})$ administration $(\mathrm{F}(1,22)=.416, \mathrm{p}>$ $.05)$.

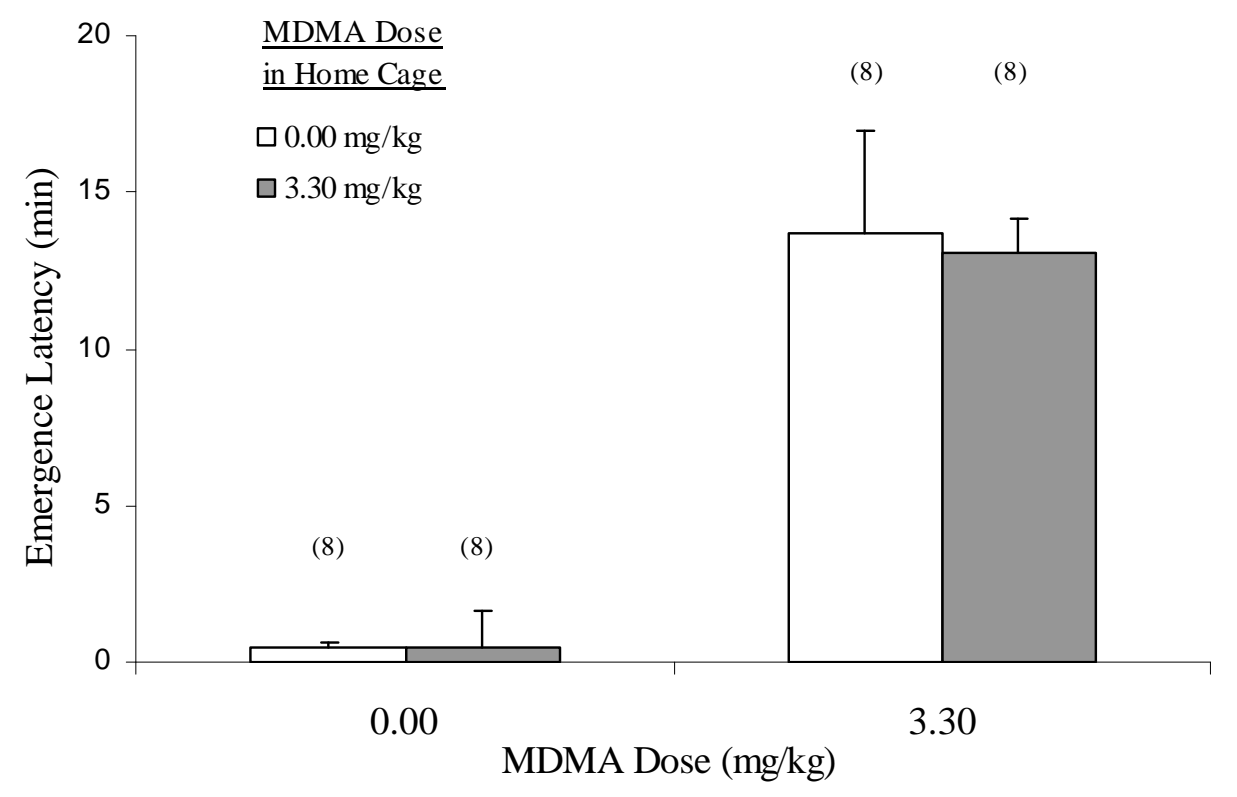

Figure 5 Effect of repeated exposure to MDMA $(0.0,3.3 \mathrm{mg} / \mathrm{kg}$, IP) on Day 1 and 5 in home cages on emergence latency (min) following MDMA (0.0, $3.3 \mathrm{mg} / \mathrm{kg}$ ) administration on Day 9.

\section{Effects of Handling on Emergence Latency}

Figure 6 shows the effect of repeated handling on emergence latency following MDMA $(0.0,3.3 \mathrm{mg} / \mathrm{kg})$ administration. A 2-Way ANOVA (handling X MDMA dose) revealed no significant interaction of repeated handling on emergence latency following MDMA $(0.0,3.3 \mathrm{mg} / \mathrm{kg})$ administration $(\mathrm{F}(1,39)=.02, \mathrm{p}>.05)$. 


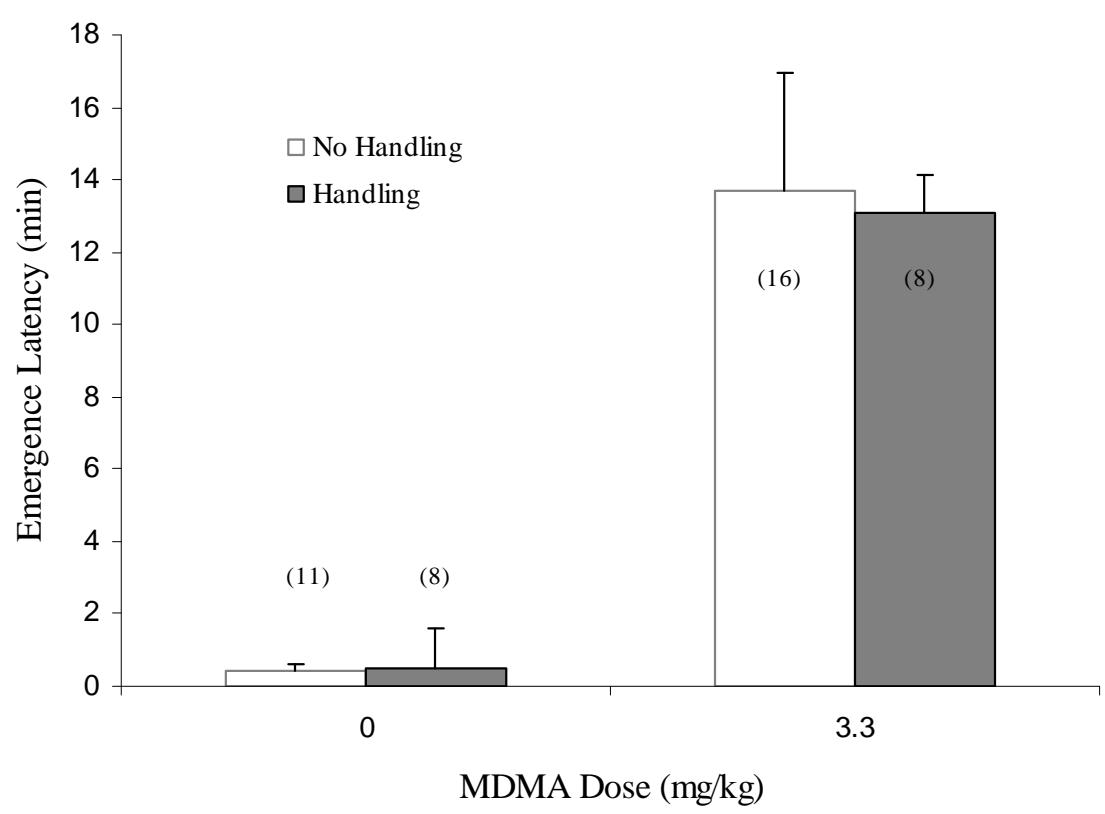

Figure 6 Effect of repeated handling on Day 1 and 5 in home cages on emergence latency $(\mathrm{min})$ following MDMA $(0.0,3.3 \mathrm{mg} / \mathrm{kg})$ administration on Day 9.

\section{Discussion}

The present study determined some parameters for use of the Emergence Test (ET) as a behavioural assay to examine the acute effects of MDMA. In line with similar studies (Callaway et al., 1990; Kehne et al., 1996; McCreary et al., 1999; Spanos \& Yamamoto, 1989) MDMA produced a dose dependent increase in locomotor activity (Figure 2). To ensure that behaviour in the ET following MDMA administration was not a reflection of hyperactivity, the highest dose of MDMA $(3.3 \mathrm{mg} / \mathrm{kg})$ that had no effect on locomotion was used for establishing further protocols in the ET. Some previous studies report an increase in locomotor activity following an MDMA dose 3.0mg/kg (McCreary et al., 1999). In the current experiment, however, no increase in activity following MDMA $3.3 \mathrm{mg} / \mathrm{kg}$ dose was found. The discrepancy between studies may be due to varying methodological procedures. Habituation periods have been shown to alter subsequent levels of activity in response to drugs. In well habituated animals locomotor activity increases compared to less well habituated animals (Evenden 
\& Angeby-Moller, 1990). McCreary et al. (1999) habituated rats for 3 hours on the two days preceding the test in addition to $60 \mathrm{~min}$ on the day of the test. In the present study habituation was substantially less with only 30minutes on the test day. The reduced level of habituation in the present study may therefore account for the lack of hyperactivity produced by MDMA $(3.3 \mathrm{mg} / \mathrm{kg})$. Additionally, the use of different MDMA isomers may have contributed to the varying results. The (+) MDMA isomer, as used by McCreary et al. (1999), increases synaptic DA to a greater extent than the (+/-) isomer used in the present study (Johnson et al., 1986; Hiramatsu \& Cho, 1990) and is therefore likely to increase activity to a greater extent (Paulus \& Geyer, 1992; Fantegrossi et al., 2003).

Following various habituation periods increases in emergence latency were found. A 30minute habituation produced maximal effects of MDMA, significantly increasing latencies, and so this habituation period was utilised for further ET development.

Once the MDMA dose $(3.3 \mathrm{mg} / \mathrm{kg}$ ) and habituation period (30min) were established the effect of repeated exposure to the test environment was measured in order to determine whether animals previously exposed to the environment were able to be retested. Emergence latency induced by the novel environment (the open test arena) was influenced by repeated exposure. Once the animals had been exposed to the test arena the tendency to explore was reduced, as has previously been demonstrated (File, 1990; File et al., 1990; File et al., 1993). Whether this was a response to the loss of novelty of the test or a reflection of repeated drug exposure or handling was also explored. When animals were repeatedly injected with either MDMA $(3.3 \mathrm{mg} / \mathrm{kg})$ or saline in home cages, but not exposed to the test environment, emergence latencies were unaltered. Additionally, handling over several days failed to alter latencies. This suggests that in the ET the novelty of the environment is not affected by handling or repeated MDMA administration as carried out in this study but, by prior test exposure. Accordingly, in the ET future experiments in this thesis will administer MDMA $(3.3 \mathrm{mg} / \mathrm{kg})$ following a 30minute habituation period using a betweensubjects procedure. 
The emergence latencies of the saline pretreated animals in these experiments indicated that, in line with the concept of "neotic" behaviour the animals readily explored a novel environment following a period of habituation. 


\section{Section 2: Emergence Latency (EL) following MDMA Exposure}

\section{$\underline{\text { Overview }}$}

The aim of the present study was to establish whether tolerance to MDMA is associated with changes in $5-\mathrm{HT}_{2 \mathrm{c}}$ or $5-\mathrm{HT}_{2 \mathrm{a}}$ receptor responses and /or alternatively, an impaired ability of MDMA to evoke SERT-mediated 5-HT release. Effects of MDMA, m-CPP, DOI, and fenfluramine were measured using an emergence test as in section 1 (Pare et al., 2001).

DOI is a preferential 5- $\mathrm{HT}_{2 \mathrm{a}}$ receptor agonist (Kleven et al., 1997;

Schreiber et al., 1995; Willins \& Meltzer, 1997) and was therefore used to assess the contribution of this receptor subtype to the emergence response. Additional testing with the preferential $5-\mathrm{HT}_{2 \mathrm{C}}$ receptor agonist, $\mathrm{m}-\mathrm{CPP}$, and with MDMA were also conducted and the specific role of the $5-\mathrm{HT}_{2 \mathrm{C}}$ receptor in the response to MDMA and m-CPP(Bilkei-Gorzo et al., 1998) was determined by measuring the effect of the selective receptor antagonist, RS102221 (Bonhaus et al., 1997). Fenfluramine was used as a 5HT releasing stimulant (Fuxe, Farnebo, Hamberger, \& Ogren, 1975; Garattini, Buczko, Jori, \& Samanin, 1975) to determine the effect of alterations in this mechanism on emergence latency. Finally, the effect of a regimen consisting of repeated exposure to MDMA that decreased brain tissue levels of 5-HT on the behavioural response to MDMA, m-CPP and fenfluramine was measured (Shankaran \& Gudelsky, 1999).

\section{Effects of MDMA, m-CPP, DOI and fenfluramine on EL}

The effect of m-CPP $(0.0,0.3,0.6$ or $1.25 \mathrm{mg} / \mathrm{kg}$, IP), MDMA $(0.0,1.0$ or $3.3 \mathrm{mg} / \mathrm{kg}$, IP), fenfluramine $(0.0,1.0$, or $2.0 \mathrm{mg} / \mathrm{kg}$, IP), and DOI $(0.0,1.0,2.0$ $\mathrm{mg} / \mathrm{kg}$, IP) on EL was assessed in separate groups of randomly assigned rats. Immediately following administration of the drugs the rats were placed into the hide box for 30 (MDMA), 15 (m-CPP, fenfluramine) or 10 (DOI) minutes. These treatment times were chosen based on preliminary studies that examined the time course of the effect of the four drugs. Following the habituation period, the slide 
door was opened and latency to emerge was measured. Rats that failed to emerge within 30 minutes were removed and a score of 30 min was assigned.

Effects of 5- $\mathrm{HT}_{2 \mathrm{C}}$ receptor antagonist pretreatment on MDMA, m-CPP and fenfluramine EL

The effect of the selective 5- $\mathrm{HT}_{2 \mathrm{C}}$ receptor antagonist, $\mathrm{RS} 102221(0.0$, $0.25,0.5$ or $1.0 \mathrm{mg} / \mathrm{kg}$, IP) on m-CPP- (1.25 mg/kg) and MDMA-(3.3 mg/kg, IP) produced increases in EL was subsequently assessed in separate groups of randomly assigned rats. These doses of MDMA and m-CPP were chosen because they produced increased EL without significant changes in locomotor activity (Brennan \& Schenk, 2006). Preliminary studies indicated that maximal effects of RS102221 were produced 15 min following injection. Therefore, the hide box was opened 15 min following the injection of RS102221. To allow peak times of agonist and antagonist to coincide, m-CPP and RS102221 were administered simultaneously, whilst MDMA was administered 15 min prior to RS102221.

\section{Effects of MDMA pre-treatment on MDMA, m-CPP and fenfluramine EL}

Two weeks prior to testing separate groups of rats received MDMA (10.0 $\mathrm{mg} / \mathrm{kg}$ per injection, IP) pretreatment or the saline vehicle, as inidicated in General Methods. On test day, effects of m-CPP (0.0 or $1.25 \mathrm{mg})$, MDMA (0.0 or $3.3 \mathrm{mg} / \mathrm{kg}$ ), and fenfluramine ( 0.0 or $2.0 \mathrm{mg} / \mathrm{kg}$ ) on EL was measured as above. The doses of MDMA, m-CPP and fenfluramine were chosen as preliminary studies found that they produced increased EL without alterations to locomotor activity. Other groups of rats were treated with saline or MDMA as above and two weeks later brain 5-HT and 5-HIAA tissue levels were measured.

\section{Results}

\section{Effects of MDMA, m-CPP, DOI and fenfluramine on EL}

All drugs increased EL except for DOI (m-CPP: $(F(3,28)=8.73, p<0.05$, Figure 7); MDMA: $(\mathrm{F}(2,45)=67.17, \mathrm{p}<0.05$, Figure 8); fenfluramine: $(\mathrm{F}(2,23)=$ 7.35, $\mathrm{p}<0.05$, Figure 9$)$; DOI: $(\mathrm{F}(2,15)=1.09$, NS, Figure 10). 


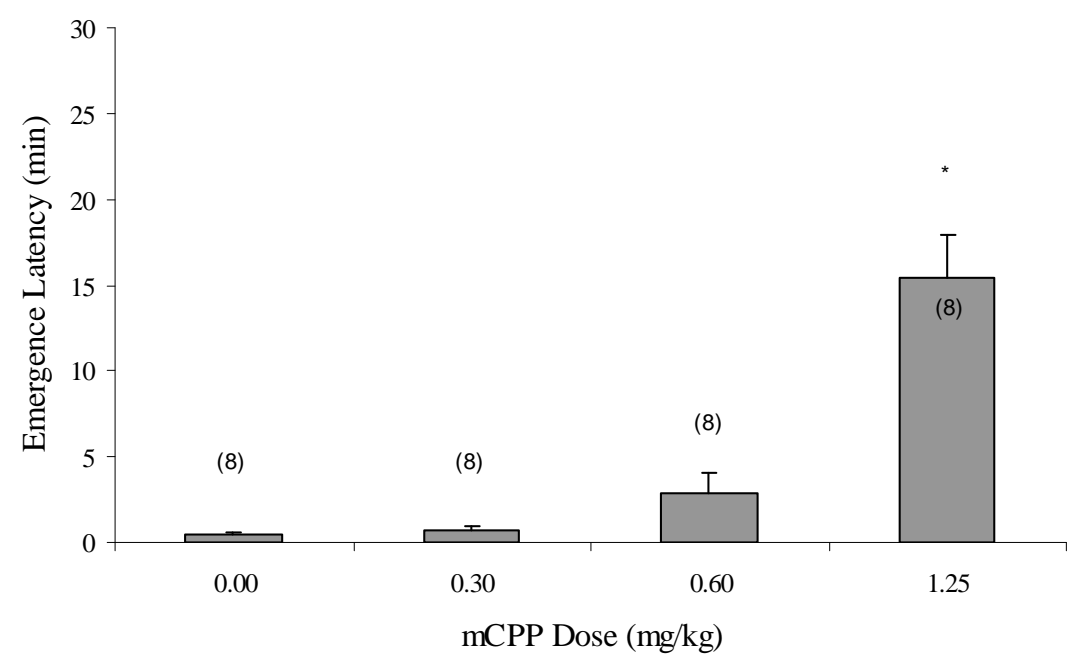

Figure 7 Effect of $\mathrm{m}-\mathrm{CPP}(0.00,0.30,0.60,1.25 \mathrm{mg} / \mathrm{kg}$, IP) on emergence latency (+SEM). Significant difference relative to control group $* \mathbf{p}<.05$.

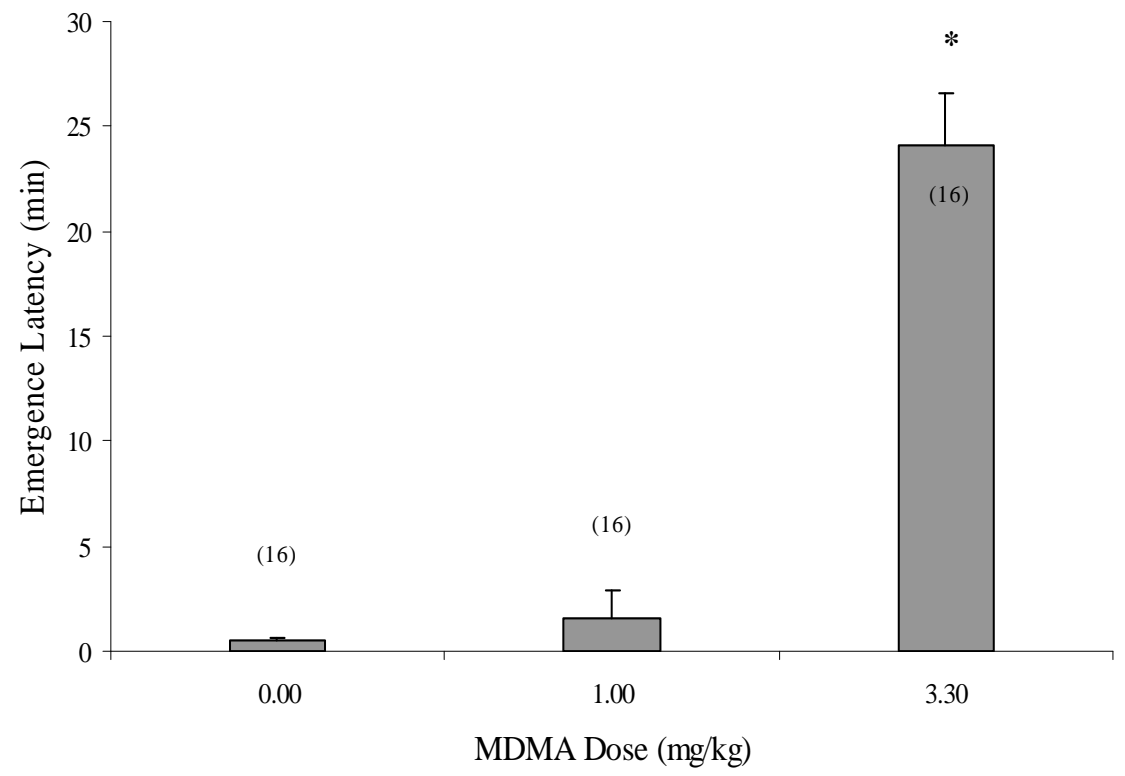

Figure 8 Effect of MDMA $(0.0,1.00,3.30 \mathrm{mg} / \mathrm{kg}$, IP) on emergence latency (+SEM). Significant difference relative to control group * $\mathbf{p}<.05$. 


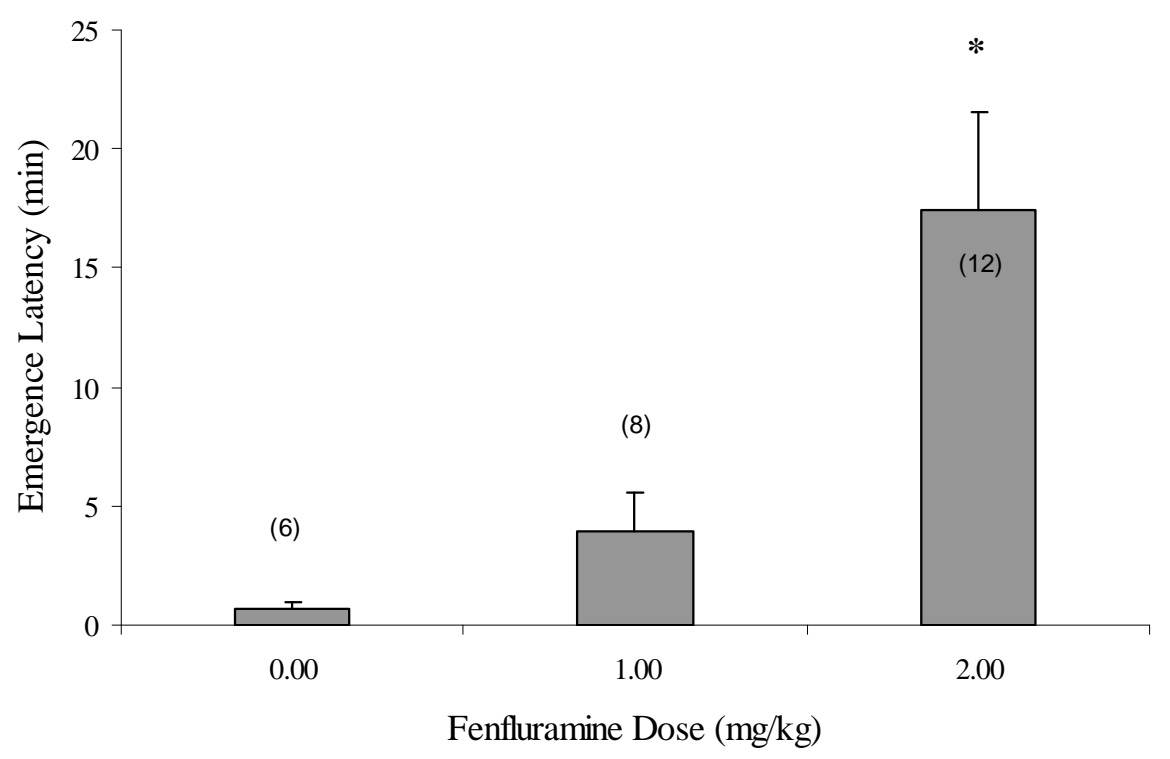

Figure 9 Effect of fenfluramine $(0.0,1.00,2.00 \mathrm{mg} / \mathrm{kg}$, IP) on emergence latency $(+$ SEM). Significant difference relative to control group $*$ p $<.05$.

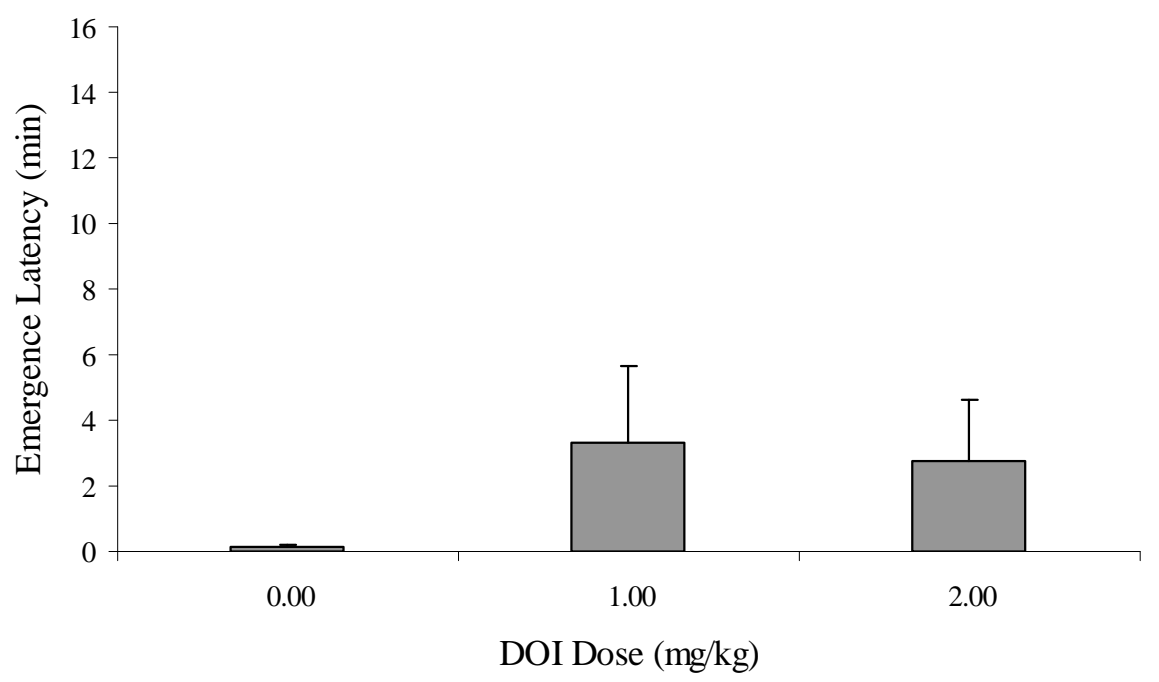

Figure 10 Effect of DOI $(0.0,1.00,2.00 \mathrm{mg} / \mathrm{kg}$, IP) on emergence latency (+SEM). 
Effects of 5- $\mathrm{HT}_{2 \mathrm{C}}$ receptor antagonist pretreatment on MDMA and m-CPP EL

Figure 11 shows the effect of the 5-HT 2 C receptor antagonist, RS102221, on m-CPP- (Figure 11A) and MDMA- (Figure 11B) produced increased EL. RS102221 dose-dependently attenuated the increased EL produced by both m$\mathrm{CPP}(\mathrm{F}(3,60)=4.116, \mathrm{p}<0.05)$ and MDMA $(\mathrm{F}(3,28)=5.427, \mathrm{p}<0.01)$. Post-hoc tests indicated that the highest dose of RS102221 significantly reduced the effect of both $\mathrm{m}-\mathrm{CPP}$ and MDMA. The lower dose of $0.5 \mathrm{mg} / \mathrm{kg}$ also attenuated the MDMA-produced effect $(\mathrm{p}<0.05)$. 

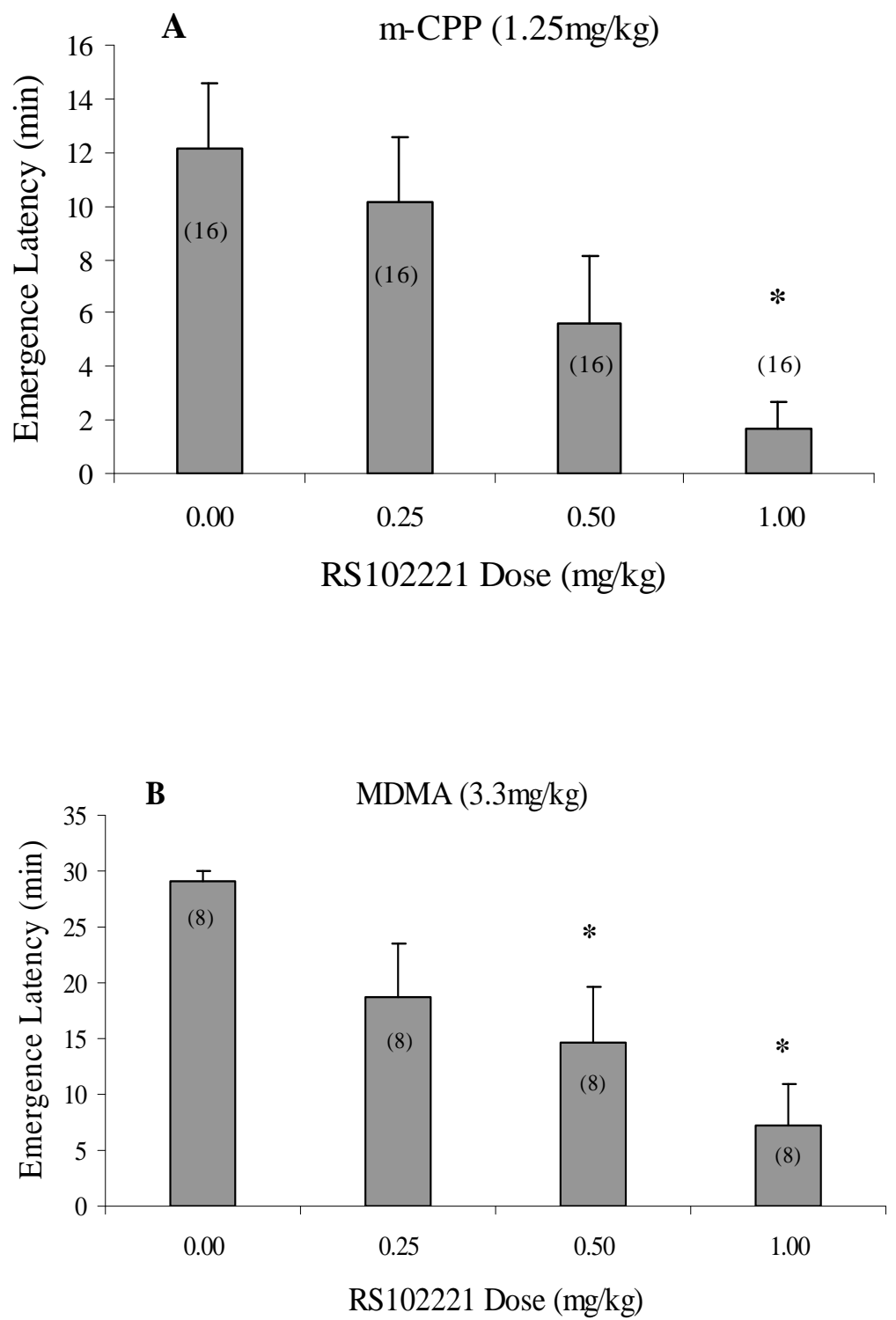

Figure 11 Effect of RS102221 pretreatment on m-CPP $(1.25 \mathrm{mg} / \mathrm{kg}$, IP) (Figure 11A) and MDMA (3.3mg/kg, IP) (Figure 11B) increased emergence latency (+SEM). Significant difference relative to control group * $\mathbf{p}<.05$.

Effects of MDMA pre-treatment on MDMA, m-CPP and fenfluramine EL

Figure 12 shows the effect of MDMA pre-treatment on the increase in EL produced by m-CPP, MDMA, and fenfluramine. MDMA pre-treatment failed to alter the acute effect of $\mathrm{m}-\mathrm{CPP}(\mathrm{F}(1,14)=.328, \mathrm{p}>0.05)$ but significantly 
attenuated MDMA $(\mathrm{F}(1,25)=33.452, \mathrm{p}<0.01)$ and fenfluramine $(\mathrm{F}(1,17)=16.26$, $\mathrm{p}<0.05)$ produced increases in EL.

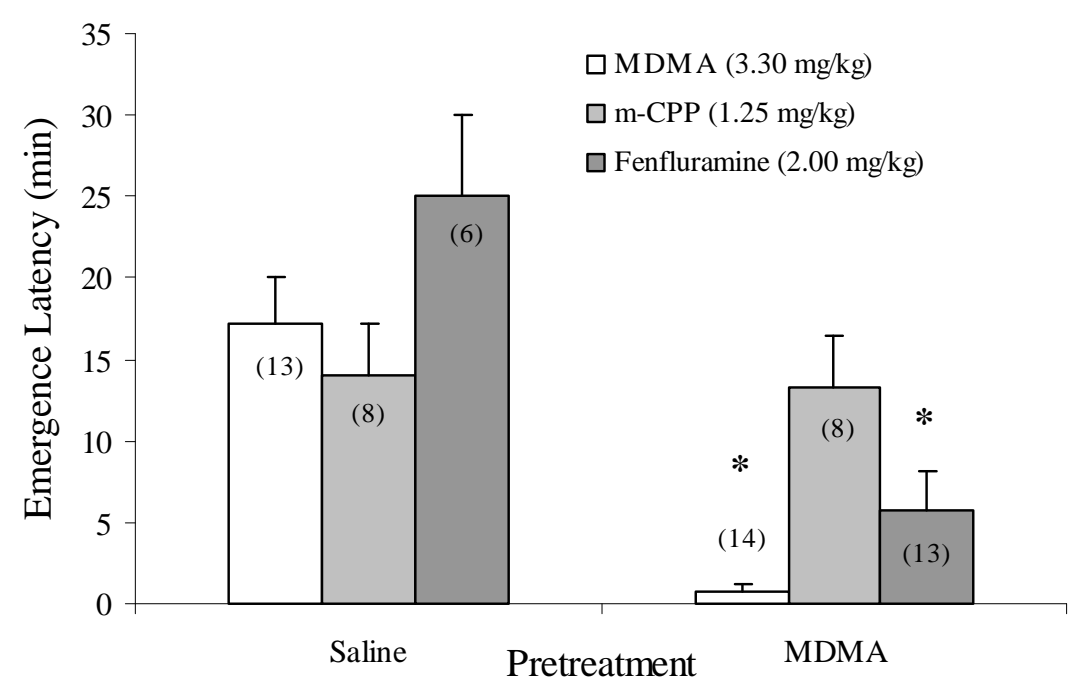

Figure 12 Effect of saline or MDMA pretreatment on m-CPP $(1.25 \mathrm{mg} / \mathrm{kg}, \mathrm{IP})$, MDMA $(3.3 \mathrm{mg} / \mathrm{kg}$, IP) and fenfluramine $(2.00 \mathrm{mg} / \mathrm{kg}$, IP) produced increases in emergence latency. Significant difference relative to control group * ${ }^{*}<.05$.

Effects of MDMA pre-treatment on brain 5-HT and5-HIAA tissue concentrations

Effects of MDMA pre-treatment on tissue levels of 5-HT and 5-HIAA are shown in Table 1. 5-HT and 5-HIAA levels were significantly lower in MDMA pre-treated rats in all brain regions assayed (striatum: 5-HT $(\mathrm{F}(1,9)=5.249$, $\mathrm{p}<0.05), 5$-HIAA $(\mathrm{F}(1,9)=7.03, \mathrm{p}<0.05)$; frontal cortex 5-HT $(\mathrm{F}(1,9)=13.98, \mathrm{p}<$ 0.01), 5-HIAA $(\mathrm{F}(1,9)=10.78, \mathrm{p}<0.01)$; hypothalamus 5-HT $(\mathrm{F}(1,9)=25.14, \mathrm{p}<$ 0.01), 5-HIAA $(\mathrm{F}(1,9)=7.92, \mathrm{p}<0.05)$; and hippocampus 5-HT $(\mathrm{F}(1,9)=6.49, \mathrm{p}<$ $0.05)$, 5-HIAA $(\mathrm{F}(1,9)=45.06, \mathrm{p}<0.01)$. 
Table 1 Tissue levels (ng/mg) of 5-HT and 5-HIAA 2 weeks following MDMA or vehicle pre-treatment $(n=6$ per group) $(+\mathrm{SEM})$. Significance relative to control groups $* \mathbf{p}<0.05$ or $* * \mathbf{p}<0.01$.

\begin{tabular}{lllll}
\hline & 5-HT & & 5-HIAA & \\
& Control & MDMA & Control & MDMA \\
Brain Region & & & & \\
Frontal Cortex & $.344 \pm .02$ & $.233 \pm .01^{* *}$ & $.302 \pm .01$ & $.232 \pm .01^{* *}$ \\
Striatum & $.403 \pm .03$ & $.302 \pm .02^{*}$ & $.630 \pm .01$ & $.569 \pm .01^{*}$ \\
Hippocampus & $.563 \pm .04$ & $.435 \pm .02^{*}$ & $.564 \pm .02$ & $.377 \pm .01^{* *}$ \\
Hypothalamus & $1.15 \pm .03$ & $.917 \pm .03^{* *}$ & $.829 \pm .07$ & $.600 \pm .04^{*}$ \\
\hline
\end{tabular}

\section{Discussion}

Acute exposure to m-CPP, MDMA, and fenfluramine increased the latency to emerge into a novel environment, as has previously been reported (Bilkei-Gorzo et al., 1998; Morley, Arnold, \& McGregor, 2005) but DOI failed to alter EL. The lack of a DOI-produced effect on EL is in contrast to the decrease in open arm exploration on the elevated plus maze found by Bull and colleagues (Morley et al., 2005). The doses of DOI used in the present study produced 5$\mathrm{HT}_{2 \mathrm{a}}$ receptor-mediated behaviours such as wet dog shakes (Kleven et al., 1997; Schreiber et al., 1995; Willins \& Meltzer, 1997) supporting the idea that they were behaviourally relevant. The failure of DOI to produce an effect on EL suggests a limited role of the 5- $\mathrm{HT}_{2 \mathrm{a}}$ receptor subtype in this behaviour. The increased EL produced by $\mathrm{m}-\mathrm{CPP}$ and MDMA was, however, attenuated by the selective 5$\mathrm{HT}_{2 \mathrm{c}}$ receptor antagonist, $\mathrm{RS} 102221$, suggesting an important role of this receptor subtype in these drug-produced responses.

The 5- $\mathrm{HT}_{2 \mathrm{c}}$ receptor was previously reported to play a minimal role in MDMA produced increase in EL. Specifically, pre-treatment with the 5- $\mathrm{HT}_{2 \mathrm{c} / \mathrm{b}}$ receptor antagonist, SB 206553 (2 mg/kg), failed to block the increase in EL 
produced by MDMA (Morley et al., 2005). The long antagonist pre-treatment time employed and use of only a single dose of SB 206553 might have precluded observation of an effect. Alternatively, the non-selectivity of SB 206553 for the 5$\mathrm{HT}_{2 \mathrm{c}}$ receptor might also have limited observation of an effect (Grignaschi et al., 1998; Kennett et al., 1996).

A concern with this type of study is that EL can be confounded by drugproduced alterations in locomotor activity. Because the EL requires movement from one location to another, drugs that alter baseline locomotor activity might produce a non-specific change in EL. Accordingly, the increased EL produced following m-CPP, fenfluramine or MDMA administration might reflect the well documented decrease in locomotor activity produced by serotonergic agonists (Gleason, Lucaites, Shannon, Nelson, \& Leander, 2001; Lucki, Ward, \& Frazer, 1989; Martin et al., 1998). In the present study, however, doses of all three compounds that increased EL were less than those required to produce a generalised decrease in motor activity (unpublished findings). Therefore, the increased EL cannot easily be attributed to non specific effects.

In contrast to results of other studies, MDMA pre-treatment did not alter baseline exploratory behaviour in the present study. Other studies have shown increased basal levels of exploratory behaviour in an open field (Mechan et al., 2002b) or elevated plus maze (Mechan et al., 2002b; Piper \& Meyer, 2004) in MDMA pre-exposed rats. Importantly, a previous study suggested that MDMA pre-treatment decreased basal levels of exploratory behaviour in the emergence test (McGregor et al., 2003). The discrepancy between the present findings and those of McGregor et al. (2003) might be due to methodological differences between the two studies as well as rat strain. Indeed, there is evidence to show that Sprague Dawley rats might be more resilient to MDMA exposure than the Wistar strain used in the McGregor study (Pare et al., 2001).

Two weeks following an MDMA pretreatment regimen that significantly reduced 5-HT and 5-HIAA levels, m-CPP produced increased EL was unaltered. In contrast, tolerance to the effect of MDMA was produced. Because of the important role of 5- $\mathrm{HT}_{2 \mathrm{C}}$ receptors in the acute effects of both drugs, the differential response to repeated MDMA exposure suggests that tolerance to this 
behavioural effect of MDMA is not mediated by altered sensitivity of 5- $\mathrm{HT}_{2 \mathrm{c}}$ receptors. Rather, the present data are consistent with the idea that decreased 5HT release underlies tolerance to the effect of MDMA (Baumann et al., 2008; Shankaran \& Gudelsky, 1999).

Tolerance to MDMA and fenfluramine but not m-CPP might be explained by the differential pharmacology of these compounds. MDMA (Green et al., 2003), m-CPP (Pettibone \& Williams, 1984), and fenfluramine (Berger et al., 1992) are all 5-HT releasing stimulants that elevate synaptic levels via a SERTdependent mechanism (Berger et al., 1992; Rudnick \& Wall, 1992), and therefore indirectly activate 5-HT receptors that have relatively low affinity for 5-HT, including the $5-\mathrm{HT}_{2 \mathrm{c}}$ receptor (Zifa \& Fillion, 1992). Repeated exposure to MDMA decreased tissue levels of 5-HT (Table 1), reduced SERT binding densities (Schenk et al., 2007) and reduced MDMA-produced increases in synaptic levels of 5-HT (Shankaran \& Gudelsky, 1999). Since SERT-mediated 5HT release is the predominant mechanism underlying the response to both MDMA and fenfluramine, decreased ability of MDMA and fenfluramine to enhance synaptic 5-HT after MDMA pre-treatment would have led to decreased activation of the low affinity $5-\mathrm{HT}_{2 \mathrm{c}}$ receptors. However, $\mathrm{m}-\mathrm{CPP}$ is also a direct $5-\mathrm{HT}_{2 \mathrm{c}}$ receptor agonist. Therefore, repeated exposure to MDMA would not be expected to impact on the ability of this drug to exert its effects in the absence of SERT-mediated 5-HT release. Thus, effects of $\mathrm{m}-\mathrm{CPP}$ are not altered by prior exposure to MDMA because of its direct agonist activity at the $5-\mathrm{HT}_{2 \mathrm{c}}$ receptor. Taken together, the data suggest that MDMA-produced tolerance in the emergence test is due to impaired 5-HT release.

The present results indicate that the $5-\mathrm{HT}_{2 \mathrm{c}}$ receptors associated with exploratory behaviour do not become desensitised following MDMA pretreatment, as previously suggested (Bull et al., 2003). They extend those findings by showing that tolerance to this behavioural effect of MDMA cannot be explained by $5-\mathrm{HT}_{2 \mathrm{c}}$ receptor desensitisation. Rather, the data are consistent with the idea that tolerance to MDMA reflects impaired 5-HT release.

Just as the ET was identified as the most reliable behavioural assay to assess the contribution of the 5- $\mathrm{HT}_{2 \mathrm{a} / \mathrm{c}}$ receptors in MDMA-induced behaviours 
future studies will utilise a combination of physiological and behavioural assays thought to best elucidate the functional status of 5-HT receptors identified to be involved in 5-HT transmission. 


\section{Section 3: 5-HT $1 \mathrm{a}$ functional status following MDMA Exposure}

\section{$\underline{\text { Overview }}$}

Previous experiments have suggested that tolerance to the effects of acute MDMA following MDMA pretreatment may be attributed to impaired 5-HT release. As the 5- $\mathrm{HT}_{1 \mathrm{a}}$ autoreceptor is known to play a major role in 5-HT release in both the DRN and terminal regions of the DRN projections (Blier et al., 1998), the functional status of the 5- $\mathrm{HT}_{1 \mathrm{a}}$ receptor following MDMA pre-treatment was investigated.

Central 5- $\mathrm{HT}_{1 \mathrm{a}}$ receptors are located both within the raphe nuclei of the brain stem and terminal regions (Verge et al., 1986). Within the raphe nuclei the $5-\mathrm{HT}_{1 \mathrm{a}}$ receptor is an inhibitory somadendritic autoreceptor while is predominantly post synaptic in 5-HT terminal fields such as the hippocampus and frontal cortex (Aguirre et al., 1998). One function of the 5- $\mathrm{HT}_{1 \mathrm{a}}$ receptor is modulation of temperature. Indeed, hypothermia is a common consequence of agonist administration (Hedlund et al., 2004; Hillegaart, 1991; Kitamura et al., 2007). Therefore, the hypothermic response to MDMA following repeated MDMA exposure was identified as a reliable measure of 5- $\mathrm{HT}_{1 \mathrm{a}}$ receptor status and was utilised to this end.

The location of the receptors involved in the hypothermic response to 8OHDPAT in rats remains equivocal. Some studies suggest that the response is mediated by postsynaptic activation (Aguirre et al., 1998; Blier, Seletti, Gilbert, Young, \& Benkelfat, 2002). For example, one week after a single administration of MDMA (30 mg/kg, IP) the hypothermic response to 8-OHDPAT (1 mg/kg, SC) was potentiated. This was associated with increased 5-HT Ha $_{1}$ density in the hypothalamus suggesting a postsynaptic contribution (Aguirre et al., 1998). Other studies suggest that the response is mediated by a presynaptic mechanism (Cowen, Power, Ware, \& Anderson, 1994; Young, MacDonald, St John, Dick, \& Goodwin, 1992) as direct application of 8-OHDPAT into the DRN produced hypothermia that was blocked by selective $5-\mathrm{HT}_{1 \mathrm{a}}$ antagonists (Higgins, Bradbury, Jones, \& Oakley, 1988; Hillegaart, 1991). These discrepancies may be partly due to variations in the dose of the agonist used. Low doses of 8-OHDPAT 
$(\leq 0.05 \mathrm{mg} / \mathrm{kg}, \mathrm{IP})$ preferentially activate the autoreceptor while higher doses stimulate both pre and postsynaptic receptors (Barnes \& Sharp, 1999; Hoyer et al., 2002).

The 5-HT $1 \mathrm{a}$ agonist, 8-OHDPAT, has been extensively used to investigate the functional status of the 5- $\mathrm{HT}_{1 \mathrm{a}}$ receptor. 8-OHDPAT is a potent selective 5$\mathrm{HT}_{1 \mathrm{a}}$ agonist that induces hypothermia in mice and rats (Hillegaart, 1991; Hjorth, 1985; Moser, 1991; Renoir et al., 2008). Behavioural, neurochemical, electrophysiological and radioligand studies confirm that 8-OHDPAT binds dose dependently to both pre and post synaptic $5-\mathrm{HT}_{1 \mathrm{a}}$ brain sites and can be used to investigate the behavioural and pharmacological properties of these receptors (Gozlan et al., 1983; Hjorth, 1985; Kennett, Marcou, Dourish, \& Curzon, 1987). Accordingly, the hypothermic response induced by 8-OHDPAT, was used to assess the sensitivity of the 5-HT $1 \mathrm{a}$ autoreceptor following MDMA pretreatment.

\section{Effects of MDMA Pretreatment on Rectal Temperature}

Separate groups of rats were administered the MDMA pre-treatment regime. Two weeks later baseline core body temperatures were recorded. Fifteen minutes later various doses of 8-OHDPAT $(0.0,0.0315,0.0625,0.125,0.25$, $0.5 \mathrm{mg} / \mathrm{kg}, \mathrm{SC}$ ) were administered and temperatures were recorded $30 \mathrm{~min}$ post injection.

\section{Results}

Figure 13 shows the effect of MDMA pre-treatment on core body temperature and effects of 8-OHDPAT $(0.0,0.0315,0.0625,0.125,0.25$, $0.5 \mathrm{mg} / \mathrm{kg}, \mathrm{SC}$ ) injection. A 2-Way ANOVA (MDMA pre-treatment X 8OHDPAT dose) revealed a main effect of MDMA pre-treatment $(F(1,59)=20.15$, $\mathrm{p}<.01)$, and 8-OHDPAT dose $(\mathrm{F}(5,59)=72.52, \mathrm{p}<.01)$. Post hoc analysis showed that the $0.0625,0.125,0.25,0.5 \mathrm{mg} / \mathrm{kg}$ doses of 8 -OHDPAT significantly decreased body temperature. A 1-Way ANOVA revealed that MDMA pretreatment resulted in a significantly greater hypothermic response in MDMA pre- 
treated rats at 8-OHDPAT doses $0.0315(\mathrm{~F}(1,10)=18.175, \mathrm{p}<.05)$ and $0.0625 \mathrm{mg} / \mathrm{kg}(\mathrm{F}(1,10)=6.30, \mathrm{p}<.05)$.

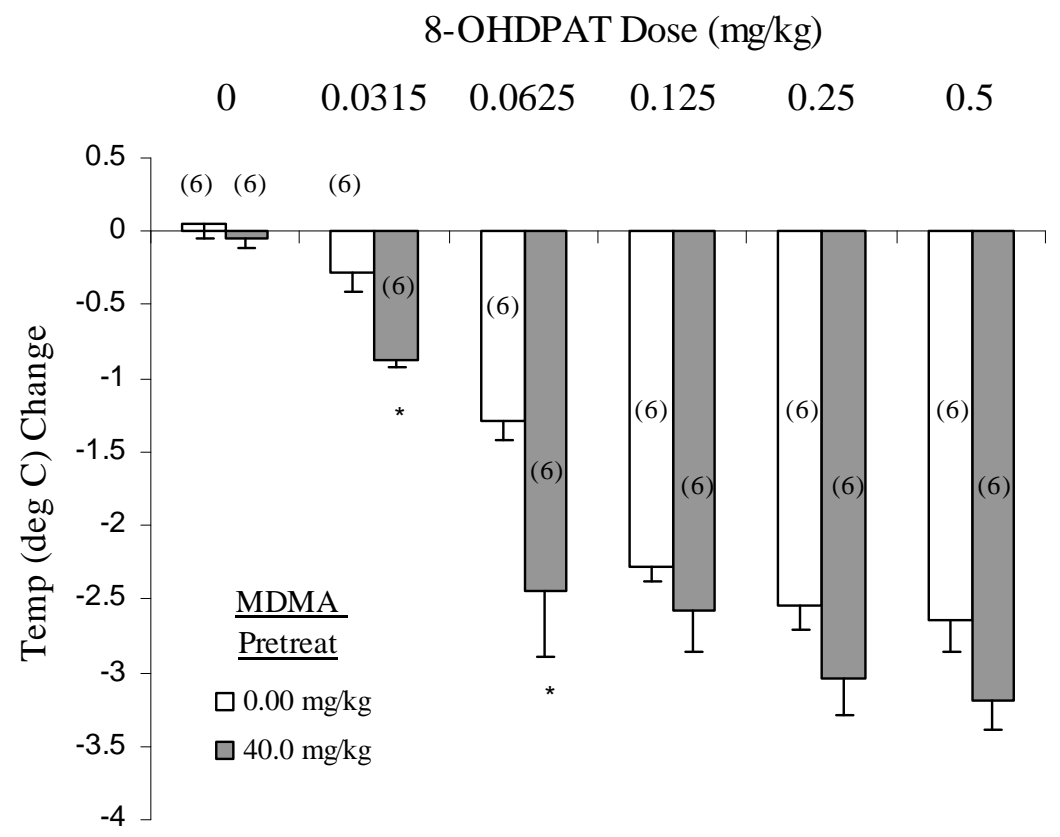

Fig 13 Temperature change (deg C) (+SEM) in saline and MDMA pretreated rats 30 minutes post acute 8-OHDPAT $(0.0,0.0315,0.0625,0.125$, $0.25,0.5 \mathrm{mg} / \mathrm{kg}, \mathrm{SC}$ ) administration. Significant difference relative to saline pre-treatment group * $\mathbf{p}<.05$.

\section{Discussion}

Results from the present study indicate that the hypothermic response induced by 8-OHDPAT administration was enhanced following MDMA pretreatment. Doses of 8-OHDPAT have been shown to distinguish pre and postsynaptic activation (Hillegaart, 1991) with low doses $(<0.05 \mathrm{mg} / \mathrm{kg})$ predominately presynaptic and higher doses postsynaptic. Most importantly, the potentiated response following MDMA pretreatment suggests an increased sensitivity of the $5-\mathrm{HT}_{1 \mathrm{a}}$ autoreceptor. This may indicate that $5-\mathrm{HT}_{1 \mathrm{a}}$ autoreceptor efficacy to negatively control 5-HT transmission is enhanced in MDMA pretreated rats. While the molecular mechanisms involved in the sensitisation 
process following MDMA exposure observed in the present study are unclear it is possible that the increased sensitivity of the $5-\mathrm{HT}_{1 \mathrm{a}}$ autoreceptor contributes to the deficits in synthesis and release of 5HT that results from MDMA exposure (Esteban, Moranta, Sastre-Coll, Miralles, \& Garcia-Sevilla, 2002; Shankaran \& Gudelsky, 1999). If so, the 5-HT $1 \mathrm{a}$ autoreceptor might be a potential target for reversing tolerance to MDMA-produced effects. 


\section{Section 4. Reversal of Tolerance to MDMA effects: Systemic Studies}

\section{Overview}

Section one of this thesis established the Emergence Test (ET) as a behavioural assay to examine the acute effects of MDMA. This paradigm was then used, in section two to show that tolerance to the behavioural effects of MDMA was most likely due to impaired 5-HT release. This section follows by examining the effects of MDMA on 5-HT $\mathrm{Ha}_{1 \mathrm{a}}$ autoreceptor function.

It is well documented that the 5-HT $\mathrm{Ha}_{1 \mathrm{a}}$ autoreceptor modulates 5-HT synthesis and release (Stamford et al., 2000). Regulation of 5-HT cell firing has also been attributed to the 5-HT $1 \mathrm{a}$ autoreceptors located in the dorsal raphe nuclei (DRN). Local or systemic activation of 5-HT 1a $_{\text {a }}$ atoreceptor by 5-HT (high affinity) or by administration of 5-HT 1 agonists which induce 5-HT release inhibited 5-HT release in the DRN and in forebrain regions innervated by DRN (Artigas, Romero, de Montigny, \& Blier, 1996; Blier, Serrano, \& Scatton, 1990; Hervas et al., 1998; Kreiss \& Lucki, 1994).

Section 3 showed a potentiated hypothermic response to low doses of the 5-HT $1 \mathrm{a}$ agonist 8-OHDPAT in MDMA pre-treated rats. It was suggested that repeated MDMA exposure rendered the 5-HT $\mathrm{H}_{1 \mathrm{a}}$ autoreceptor supersensitive. Indeed, there is evidence of 5- $\mathrm{HT}_{1 \mathrm{a}}$ autoreceptor supersensitivity following chronic administration of a number of drugs of abuse including ethanol, morphine, cocaine and MDMA (Cunningham, Paris, \& Goeders, 1992; Kelai et al., 2008; Kleven et al., 1995; Renoir et al., 2008; Sastre-Coll, Esteban, \& Garcia-Sevilla, 2002).MDMA pretreatment increased 8-OHDPAT -induced hypothermia in mice. In vitro, MDMA pretreatment potentiated the inhibition of DRN 5-HT cell firing following application of a 5-HT $1 \mathrm{a}$ agonist (Renoir et al., 2008). Chronic cocaine pretreatment also potentiated the inhibitory response of DRN 5-HT neurons to (-)cocaine, 8-OHDPAT, and a 5-HT reuptake inhibitor (Cunningham et al., 1992).

Enhanced behavioural 5- $\mathrm{HT}_{1 \mathrm{a}}$ mediated responses have also been reported. For example, chronic ethanol produced an increase in lower lip retraction in withdrawn rats, a response that is mediated by the $5-\mathrm{HT}_{1 \mathrm{a}}$ autoreceptor (Esteban et 
al., 2002).This hypersensitivity would be expected to enhance the inhibitory effects of the 5-HT $\mathrm{Ha}_{1 \mathrm{a}}$ autoreceptor on 5-HT synthesis and release.

MDMA pretreatment produces long lasting decreases in 5-HT neurotransmission (Stone, Hanson, \& Gibb, 1989a; White et al., 1996). Following pretreatment there is a persistent deficit in tissue levels of 5-HT and 5-HIAA, inactivation of tryptophan hydroxylase (TPH), loss of SERT binding and function, and alterations in 5-HT $1 \mathrm{a}$ density (Aguirre et al., 1995; Battaglia et al., 1988; Scanzello et al., 1993; White et al., 1996). These deficits, which are most pronounced after a short withdrawal period (Battaglia et al., 1987; Reneman et al., 2002) have been shown to persist for more than a year depending on MDMA dose and brain region assayed. In vitro, reactivation of central TPH through anaerobic incubation was dependent on MDMA dose and the period of time following exposure. Higher MDMA doses and longer periods post exposure decreased the ability to restore TPH activity and ultimately 5-HT synthesis (Stone, et al., 1989a; Stone et al., 1989b).

Many of the deficits in 5-HT function following MDMA exposure maybe due, in part, to the resulting supersensitivity of the 5-HT $\mathrm{Ha}_{1 \mathrm{a}}$ autoreceptor. A supersensitive $5-\mathrm{HT}_{1 \mathrm{a}}$ autoreceptor would result in enhanced inhibition of tryptophan hydroxylase thereby leading to persistent 5-HT and 5-HIAA depletions. This in turn would result in less 5-HT release when the system is challenged with a resultant reduction in the activation of 5-HT receptors that contribute to the effects of MDMA. Together, these may explain tolerance to some of MDMA-produced effects. If so, then a desensitisation of the 5-HT $1 \mathrm{a}$ autoreceptor would reduce its inhibitory actions leading to a recovery of 5-HT synthesis. One means of desensitising the autoreceptor is through the repeated administration of a highly selective $5-\mathrm{HT}_{1 \mathrm{a}}$ antagonist.

The selective 5- $\mathrm{HT}_{1 \mathrm{a}}$ antagonist, WAY100635, is classed as a silent agonist because it lacks any agonist properties at pre or post synaptic sites. In vivo, WAY100635 dose-dependently blocked the ability of 8-OHDPAT to inhibit the firing of dorsal raphe 5-HT neurons and to induce 5-HT postsynaptic receptor mediated behaviours including 5-HT syndrome and hyperphagia (Fletcher et al., 
1996).WAY100635 is $>100$-fold more selective for $5-\mathrm{HT}_{1 \mathrm{a}}$ than any other 5 -HTor DA receptors or reuptake sites (Fletcher et al., 1996).

Several studies have administered WAY100635 to ascertain that the effects of 5-HT $1 \mathrm{a}$ agonists are due to 5-HT $1 \mathrm{a}$ mechanisms. WAY100635 $(1.0 \mathrm{mg} / \mathrm{kg}$, SC) administered to guinea pigs alone produced no observable behaviours (Mundey, Fletcher, \& Marsden, 1996; Roberts, Boyd, Middlemiss, \& Routledge, 1999) but it fully blocked 8-OHDPAT induced behaviours. It was suggested that this was due to competitive antagonism by WAY100635 of somadendritic autoreceptors in the DRN via the negative feedback loop. When administered together with 8-OHDPAT, WAY100635 blocked 8-OHDPAT produced inhibition of cell firing, again suggesting that the DRN 5-HT tone is modulated by an inhibitory 5-HT $1 \mathrm{a}$ autoreceptor.

By repeatedly blocking the 5-HT $1 \mathrm{a}$ autoreceptor the inhibitory influence on neuronal firing and activity in the raphe would be reduced and consequently 5-HT synthesis and release may be enhanced. Indeed, WAY100635 (0.125-.5mg/kg, IV) increased the firing rate of DRN neurons. Of interest, WAY100635 alone restored DRN firing that was previously inhibited by 8-OHDPAT. These findings suggest that WAY100635 may be used to alter the sensitivity of the 5-HT $1 \mathrm{a}$ autoreceptor. An effect of WAY100635 on 5-HT release has also been shown using in vivo microdialysis. Roberts et al. (1999) found that WAY100635 elicited small increases in extracellular levels of 5-HT in the frontal cortex. Repeated 14 day WAY100635 pretreatment failed to alter basal levels of 5-HT in the hippocampus (Gurling, Ashworth-Preece, Dourish, \& Routledge, 1994) but a 7 day pretreatment increased 5-HT synthesis in the DRN (Tohyama, Yamane, Merid \& Diksic, 2001). These studies suggest that pretreatment period might be critical to the effects of WAY100635.

Section 4 tests the possibility that behavioural tolerance following repeated MDMA exposure can be reversed by repeated exposure to WAY100635. Because 5- $\mathrm{HT}_{1 \mathrm{a}}$ receptors have been implicated in feeding (Dourish et al., 1985; Fletcher et al., 1996) food consumption following the chronic 7 day 5-HT 1 a antagonist, WAY100635, administration was also measured. 
In order to measure the functional response following WAY100635 administration locomotor activity was chosen as the behavioural assay. Tolerance to MDMA-produced hyperactivity has consistently been reported (Brennan \& Schenk, 2006; Callaway \& Geyer, 1992) and this assay allows for the time-course of the behavioural effects of MDMA. The effect of MDMA pretreatment on MDMA-produced hyperactivity was established in the current study to determine the baselines from which $5-\mathrm{HT}_{1 \mathrm{a}}$ antagonist application could be investigated.

Tissue levels of 5-HT and 5-HIAA were measured in order to verify that the MDMA pretreatment regimen used in the present study produced deficits of 5HT as has previously been reported (Shankaran \& Gudelsky, 1999) and to determine any effects of WAY100635 pretreatment.

\section{Procedures: 5-HT 1 a antagonist WAY100635 7 day Chronic Subcutaneous Regime}

On day one rats were pre-treated as per the MDMA pre-treatment regime. Seven days later $71 \mathrm{x}$ daily injections of either WAY100635 (0.0, 0.01, 0.1, $1.0 \mathrm{mg} / \mathrm{kg}$ per injection, SC) or saline vehicle were administered. This pretreatment procedure was in line with Tohyama et al. (2001) who reported increases in DRN 5-HT synthesis following chronic WAY100635 administration as determined by autoradiography. Two weeks following the MDMA pretreatment rats were behaviourally assessed with an MDMA $(10.0 \mathrm{mg} / \mathrm{kg}$, IP) or vehicle challenge. Two days later animals were euthanized and brains removed (see Figure 3).

The schedule of the WAY100635 chronic subcutaneous administration experiments is shown in Figure 14. 


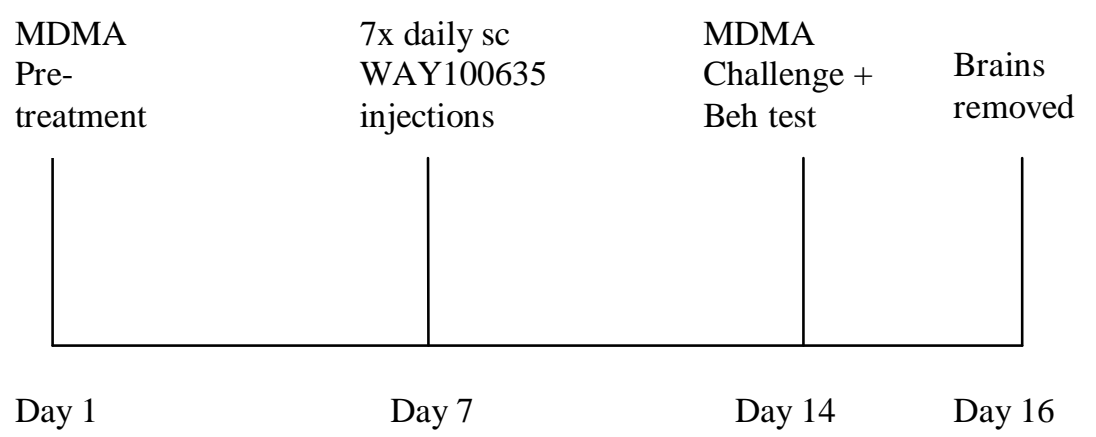

Fig 14 Schematic diagram of experiments outlining MDMA pretreatment, 5HT $_{1 \mathrm{a}}$ antagonist, WAY100635 $(0.00,0.01,0.10,1.0 \mathrm{mg} / \mathrm{kg}, \mathrm{SC})$ pretreatment, MDMA $(0.0,10.0 \mathrm{mg} / \mathrm{kg}$, IP) administration, behavioural testing and brain removal for 5-HT and 5-HIAA HPLC analysis.

\section{Food consumption}

Food consumption was measured following the first and last daily injection of WAY100635 administration.

\section{Effects of MDMA Pretreatment on MDMA -induced Hyperactivity}

Effects of MDMA Pre-treatment on MDMA-Produced Hyperactivity

MDMA and saline pretreated rats were administered the MDMA pretreatment regimen as in General Methods. On the test day, the rats were placed in the activity boxes for 30minutes after which they received an injection of MDMA $(0.0$ or $10.0 \mathrm{mg} / \mathrm{kg}, \mathrm{IP})$ and locomotor activity was recorded for a further 60minutes. 
Effects of WAY100635 pretreatment on MDMA-induced Hyperactivity

Effects of WAY100635 Treatment Following Saline and MDMA Pretreatment on MDMA-Induced Hyperactivity

Groups of saline and MDMA pre-treated rats were used to test the effects of 7 daily injections of WAY100635 $(0.0,0.01,0.1,1.0 \mathrm{mg} / \mathrm{kg}, \mathrm{SC})$ on MDMA $(0.0,10.0 \mathrm{mg} / \mathrm{kg} \mathrm{IP})$ produced hyperactivity. Activity was recorded, as above, 24 hr after the last WAY100635 injection. This withdrawal period was chosen so that any behavioural response assessed neuroadaptive changes rather than acute drug effects (Fletcher et al., 1996).

Table 2 Drug conditions defined by MDMA pretreatment, chronic WAY100635 and acute MDMA drug administration

\begin{tabular}{|l|l|l|l|}
\hline Conditions & Pretreat & $\begin{array}{l}\text { Chronic } \\
\text { Administration }\end{array}$ & $\begin{array}{l}\text { Acute } \\
\text { Administration }\end{array}$ \\
\hline SSS & Saline & Saline & Saline \\
\hline SWS & Saline & WAY100635 & Saline \\
\hline MSS & MDMA $(40 \mathrm{mg} / \mathrm{kg})$ & Saline & Saline \\
\hline MWS & MDMA $(40 \mathrm{mg} / \mathrm{kg})$ & WAY100635 & Saline \\
\hline
\end{tabular}




\section{Results}

\section{Food Consumption following WAY100635 Administration}

Figure 15 shows the food consumption of rats following the first and last day of WAY100635 (1.0mg/kg, SC) administration. A 2-Way ANOVA (days X WAY100635) with days as a repeated measure revealed no significant interaction between these factors $(F(1,46)=1.89, \mathrm{p}>.05)$. There was no main effect of day $(\mathrm{F}(1,46)=1.89, \mathrm{p}>.05)$ or WAY100635 pretreatment $(\mathrm{F}(1,46)=.01, \mathrm{p}>.05)$ indicating that WAY100635 had no influence on food consumption.

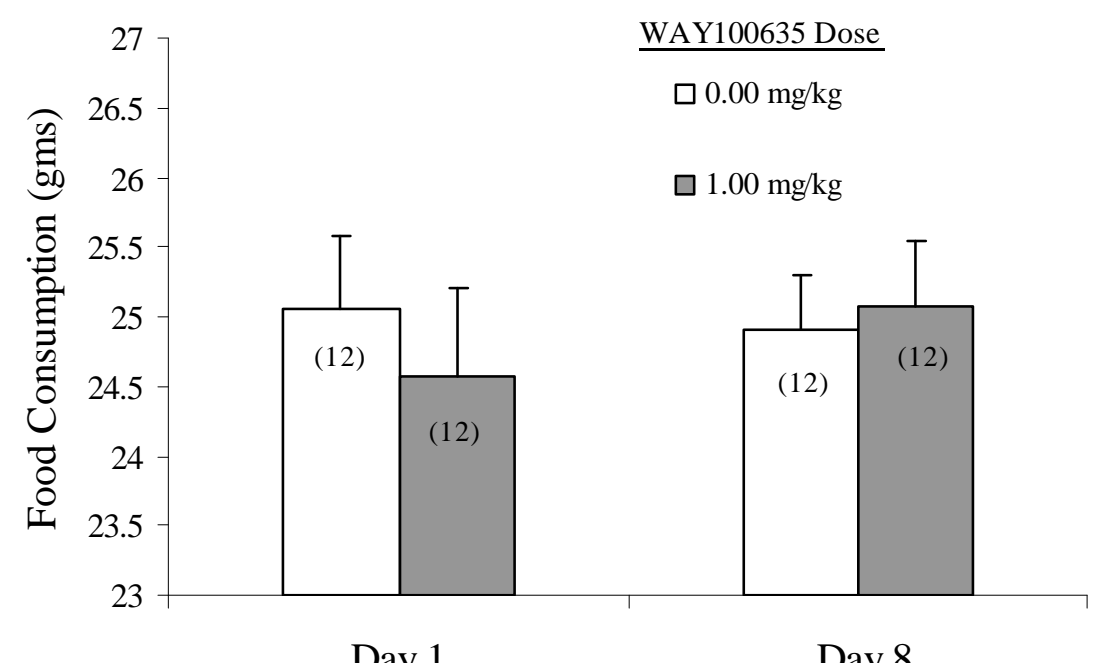

Figure 15 Mean food consumption (gms) following the first and last daily WAY100635 $(0.0,1.0 \mathrm{mg} / \mathrm{kg}, \mathrm{SC})$ injection in vehicle and MDMA Pre-treated rats $(+$ SEM).

Effect of MDMA Pre-treatment on MDMA-Produced Hyperactivity

Figure 16 shows the time course of activity counts in the 60 minute period post acute MDMA $(0.0,10.0 \mathrm{mg} / \mathrm{kg})$ in saline and MDMA-pre-treated rats (Figure 16A). A 3 -Way ANOVA (time X pre-treatment X MDMA dose) revealed no significant interaction between these factors $(F(11,275)=.67, \mathrm{p}>.05)$. There was a main effect of MDMA dose $(\mathrm{F}(1,25)=106.52, \mathrm{p}<.05)$ and pre-treatment $(\mathrm{F}(1,25)=$ 
$5.86, \mathrm{p}<.05)$. Figure $16 \mathrm{~B}$ shows the total number of activity counts in the 60 minute period post acute MDMA $(0.0,10.0 \mathrm{mg} / \mathrm{kg})$ in saline and MDMA-pretreated rats. A 2-Way ANOVA (MDMA dose X pre-treatment) revealed a significant interaction between these factors $(F(1,25)=5.56, \mathrm{p}<.05)$ as well as main effects of MDMA dose $(\mathrm{F}(1,25)=106.52, \mathrm{p}<.001)$ and pre-treatment $(\mathrm{F}(1,25)=5.861, \mathrm{p}<.05)$. A 1 -Way ANOVA for MDMA dose $(10.0 \mathrm{mg} / \mathrm{kg})$ in saline and pretreated animals revealed a significant difference $(\mathrm{F}(1,15)=8.13$, $\mathrm{p}<.05)$ with MDMA pretreatment reducing MDMA-produced hyperactivity. 

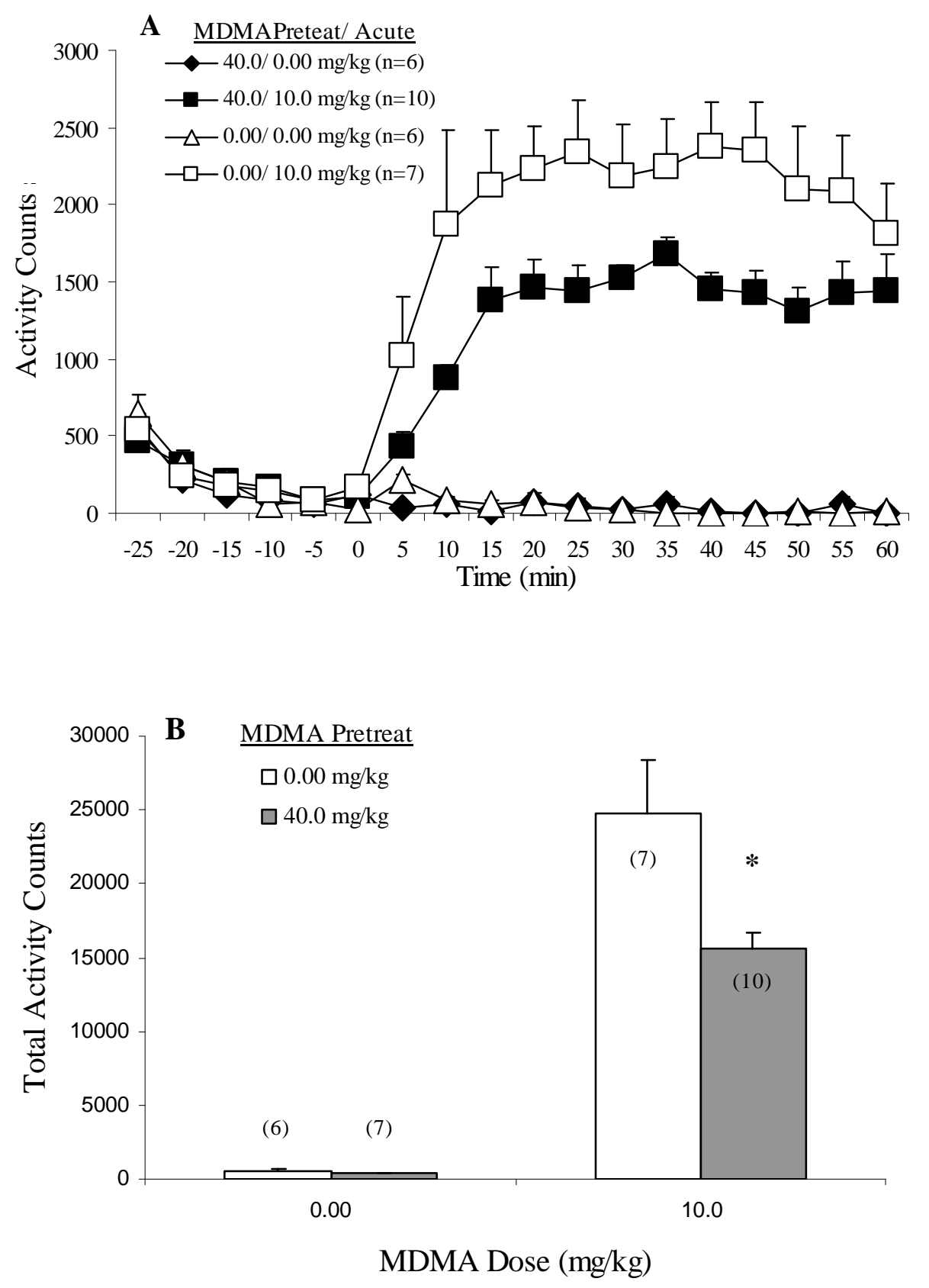

Figure 16 Activity counts produced following MDMA $(0.00,10.0 \mathrm{mg} / \mathrm{kg}, \mathrm{IP})$ administration in saline and MDMA pretreated rats. The top panel (Figure 16A) shows the time course of the mean activity counts produced following MDMA $(0.0,10.0 \mathrm{mg} / \mathrm{kg}$, IP at time =0) administration 2 weeks following saline or MDMA pretreatment (+SEM) while the bottom panel (Figure 16B) shows the total activity counts produced in the 60 minute period post MDMA $(0.0,10.0 \mathrm{mg} / \mathrm{kg}$, IP) administration following saline or MDMA pretreatment. Significant difference relative to saline pre-treatment group $* \mathbf{p}<.05$. 
Effects of WAY100635 administration on MDMA-induced Hyperactivity following Saline and MDMA pretreatment

Figure 17 shows the time course of MDMA -produced hyperactivity following WAY100635 $(0.0,0.01,0.1,1.0 \mathrm{mg} / \mathrm{kg}, \mathrm{SC}) 7$ day chronic administration in saline pretreated rats (Figure 17A).A 3-Way ANOVA (WAY pretreat $\mathrm{X}$ MDMA dose $\mathrm{X}$ time) with time as a repeated measure revealed no interaction between these factors $(\mathrm{F}(33,495)=.43, \mathrm{p}>.05)$. There was an interaction between WAY100635 and MDMA dose $(F(3,45)=3.89, \mathrm{p}<.05)$. 1Way ANOVAs (WAY dose X time) with time as repeated measure revealed a main effect of WAY100635 following MDMA (10.0mg/kg) administration $(F(3,25)=4.94, p<.05)$ but not following saline $(F(3,20)=.30, p>.05)$. Post hoc analysis revealed that WAY100635 doses 0.1 and $1.0 \mathrm{mg} / \mathrm{kg}$ significantly attenuated MDMA-induced hyperactivity.

Figure $17 \mathrm{~B}$ shows the total activity counts produced by acute MDMA (0.0, $10.0 \mathrm{mg} / \mathrm{kg})$ following various doses of the 7 day chronic WAY100635 $(0.0,0.01$, $0.1,1.0 \mathrm{mg} / \mathrm{kg}, \mathrm{SC}$ ) administration in saline pretreated rats. A 2-Way-ANOVA (MDMA X WAY100635) revealed a main interaction between these factors $(F(3,45)=3.89, \mathrm{p}<.05)$. There was a main effect of MDMA dose $(F(1,45)=110.99$, $\mathrm{p}<.05$ ) with MDMA $10.0 \mathrm{mg} / \mathrm{kg}$ significantly increasing locomotor activity above baseline. There was also a main effect of WAY100635 dose $(F(3,4.053)=p<.05)$. A 1-Way ANOVA of WAY100635 dose in MDMA challenged rats revealed a main effect of WAY100635 dose $(F(3,25)=4.396, \mathrm{p}<.05)$. Post hoc analysis showed that WAY100635 doses $1.0 \mathrm{mg} / \mathrm{kg}$ and $0.1 \mathrm{mg} / \mathrm{kg}$ significantly attenuated MDMA produced hyperactivity. 

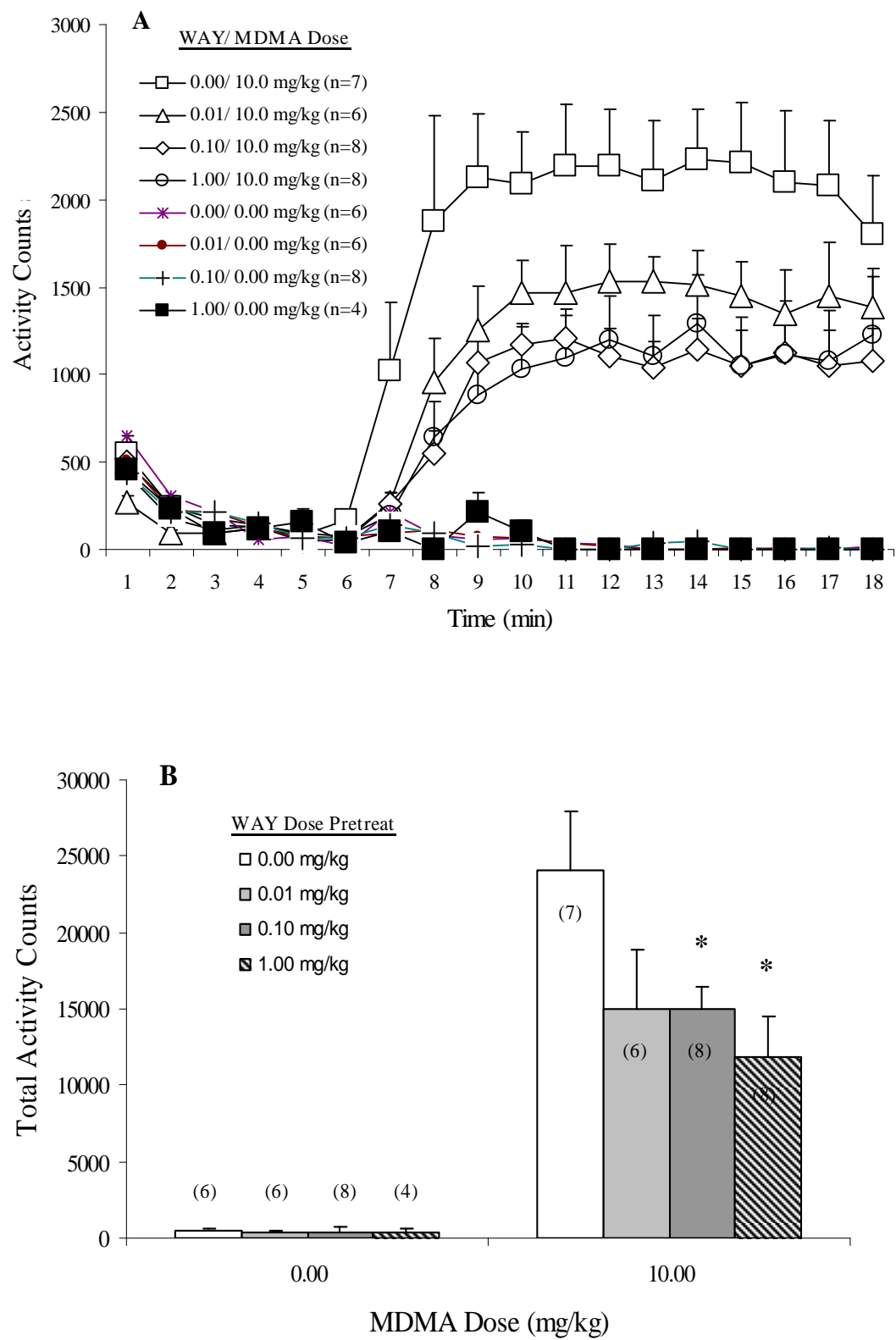

Figure 17 Activity counts produced following MDMA $(0.00,10.0 \mathrm{mg} / \mathrm{kg}$, IP $)$ administration in saline pretreated rats. The top panel (Figure 17A) shows the time course of the mean activity counts produced by MDMA (0.0, $10.0 \mathrm{mg} / \mathrm{kg}$, IP at time $=0$ ) administration following 7 days of chronic WAY100635 $(0.0,0.01,0.1,1.0 \mathrm{mg} / \mathrm{kg}, \mathrm{SC})$ pretreatment following saline pretreatment (+SEM) while the bottom panel (Figure 17B) shows the total activity counts produced in the 60 minute period post MDMA $(0.0,10.0 \mathrm{mg} / \mathrm{kg}$, IP) in saline pretreated rats following WAY100635 pretreatment. Significant difference relative to control group $* \mathbf{p}<.05$. 
Figure 18 shows the time course for MDMA $(0.0,10.0 \mathrm{mg} / \mathrm{kg}, \mathrm{IP})$ produced hyperactivity following WAY100635 (0.0, 0.01, 0.1, 1.0mg/kg, SC) 7 day chronic administration in MDMA pretreated rats (Figure 18A). A 3-Way ANOVA (WAY pretreat X MDMA dose $\mathrm{X}$ time) with time as a repeated measure revealed no interaction between these factors $(\mathrm{F}(22,473)=.58, \mathrm{p}>.05)$. There was no interaction between WAY100635 and MDMA dose $(F(3,43)=1.90, \mathrm{p}<.05)$. WAY100635 at any dose failed to significantly alter MDMA-induced hyperactivity. Figure 18B shows the total activity counts produced by MDMA $(0.0,10.0 \mathrm{mg} / \mathrm{kg})$ following various doses of the 7 day chronic WAY100635 (0.0, $0.01,0.1,1.0 \mathrm{mg} / \mathrm{kg}$ ) administration in MDMA pre-treated rats. A 1-Way ANOVA revealed no main effect of WAY100635 at any dose on MDMA-induced hyperactivity in MDMA pretreated rats challenged with MDMA $(10.0 \mathrm{mg} / \mathrm{kg}, \mathrm{IP})$ $(\mathrm{F}(3,28)=2.509, \mathrm{p}>.05)$. 

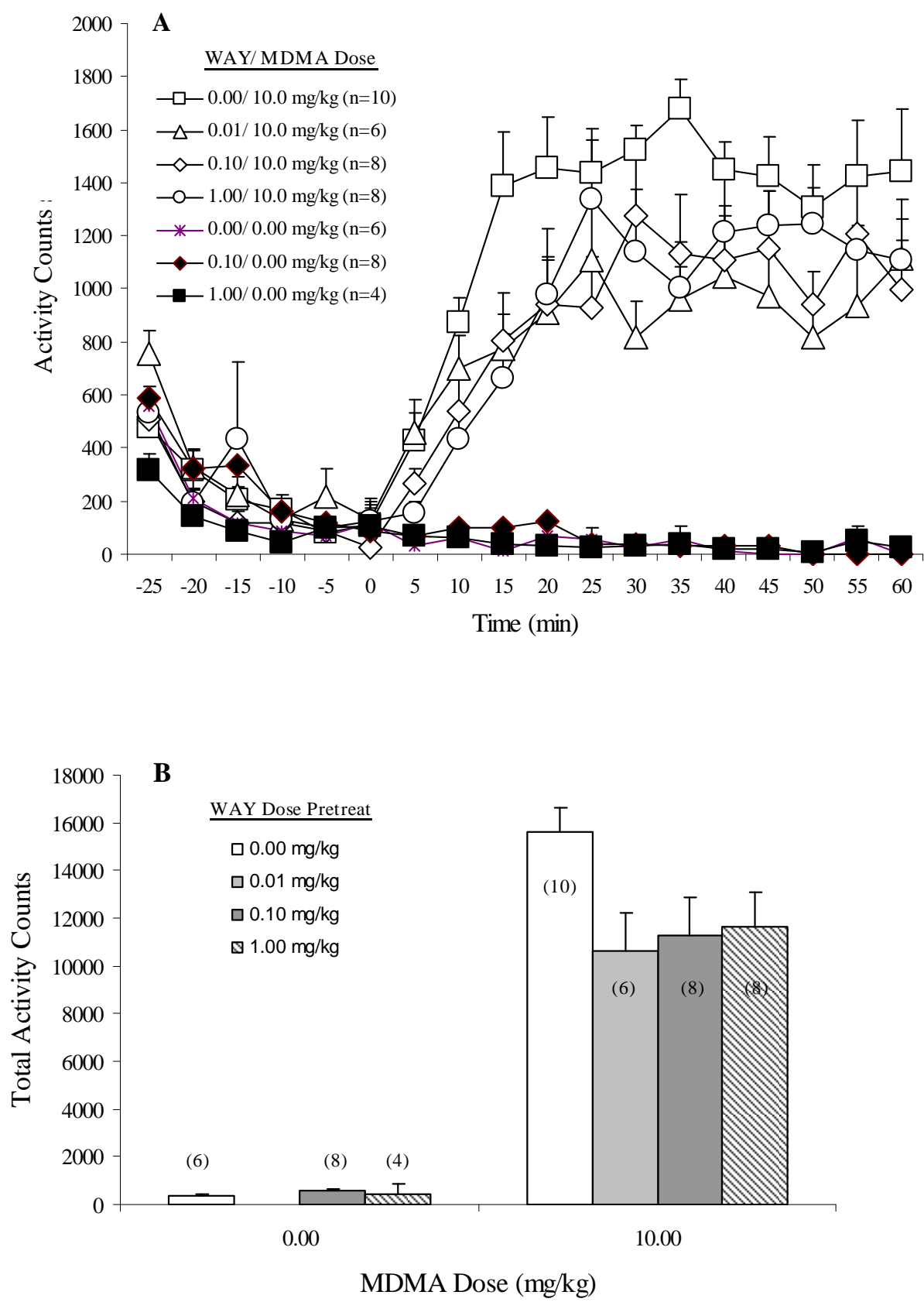

Figure 18 Activity counts produced following MDMA $(0.00,10.0 \mathrm{mg} / \mathrm{kg}$, IP) administration in MDMA pretreated rats. The top panel (Figure 18A) shows the time course of the mean activity counts produced by MDMA (0.0, $10.0 \mathrm{mg} / \mathrm{kg}$, IP at time =0) administration following 7 days of chronic WAY100635 $(0.0,0.01,0.1,1.0 \mathrm{mg} / \mathrm{kg}, \mathrm{SC})$ pretreatment following saline pretreatment (+SEM) while the bottom panel (Figure 18B) shows the total activity counts produced in the 60 minute period post MDMA $(0.0,10.0 \mathrm{mg} / \mathrm{kg}$, IP) in MDMA pretreated rats following WAY100635 pretreatment. 
Effect of WAY100635 and MDMA Pre-treatment on brain 5-HT and 5-HIAA tissue concentration

Tissue analysis of brain 5-HT and 5-HIAA concentration following 7 day chronic WAY100635 (1.0mg/kg, SC) administration

Table 3 show the effect of MDMA pre-treatment on brain 5-HT and 5HIAA tissue levels. 1-Way ANOVAs revealed a main effect of MDMA pretreatment on 5-HT levels in the frontal cortex $(\mathrm{F}(1,10)=5.78, \mathrm{p}<.05)$ and the striatum $(\mathrm{F}(1,10)=8.99, \mathrm{p}<.05)$. No significant 5-HIAA $(\mathrm{F}(1,10)=0.00 ; \mathrm{p}>.05)$; $(\mathrm{F}(1,10)=1.24), \mathrm{p}>.05)$ depletions were found in either region however there was a reduction in both regions. As expected in the dorsal raphe MDMA pretreatment failed to produce a main effect on 5-HT and 5-HIAA levels $(\mathrm{F}(1,10)=.01, \mathrm{p}>.05)$, $(\mathrm{F}(1,10)=1.19, \mathrm{p}>.05)$.

1-Way ANOVAs revealed that WAY100635 administration failed to alter 5-HT and 5-HIAA tissue concentrations in all brain regions (frontal cortex: $(\mathrm{F}(1,8)=1.995, \mathrm{p}>.05),(\mathrm{F}(1,8)=.10, \mathrm{p}>.05)$; striatum: $(\mathrm{F}(1,8)=.311, \mathrm{p}>.05)$, $(\mathrm{F}(1,8)=.05, \mathrm{p}>.05)$; dorsal raphe $(\mathrm{F}(1,8)=.021, \mathrm{p}>.05),(\mathrm{F}(1,8)=.52, \mathrm{p}>.05)$ and MDMA pretreated rats (frontal cortex: $(\mathrm{F}(1,8)=.512, \mathrm{p}>.05),(\mathrm{F}(1,8)=.148$, p>.05); striatum: $(\mathrm{F}(1,8)=.002, \mathrm{p}>.05),(\mathrm{F}(1,8)=.04, \mathrm{p}>.05)$; dorsal raphe $(F(1,8)=.353, p>.05),(F(1,8)=.49, p>.05)$. The effects of MDMA pretreatment on 5-HT levels were not significantly altered by WAY100635 administration. 
Table 3 HPLC analysis of the frontal cortex, striatum and dorsal raphe 5-HT and 5-HIAA tissue levels (ng/mg) following MDMA and WAY100635 pretreatment. * $\mathrm{p}<.05$ compared to SSS group

5-HT and 5-HIAA tissue concentration (ng/mg)

\begin{tabular}{lllllll}
\hline & \multicolumn{2}{l}{ Frontal Cortex } & \multicolumn{2}{l}{ Striatum } & \multicolumn{3}{l}{ Dorsal Raphe } \\
\hline & $5-\mathrm{HT}$ & 5-HIAA & 5-HT & 5-HIAA & 5-HT & 5-HIAA \\
\hline SSS & $.277 \pm .033$ & $.339 \pm .030$ & $.587 \pm .023$ & $.831 \pm .018$ & $1.184 \pm .455$ & $2.074 \pm .632$ \\
\hline SWS & $.211 \pm .010$ & $.325 \pm .024$ & $.538 \pm .084$ & $.936 \pm .089$ & $1.105 \pm .310$ & $2.711 \pm .612$ \\
\hline MSS & $.199 \pm .036 *$ & $.299 \pm .018$ & $.391 \pm .064 *$ & $.802 \pm .047$ & $1.196 \pm .277$ & $2.707 \pm .360$ \\
\hline MWS & $.157 \pm .021$ & $.318 \pm .049$ & $.379 \pm .034$ & $.812 \pm .069$ & $.890 \pm .434$ & $2.351 \pm .576$ \\
\hline
\end{tabular}

\section{Discussion}

In the current section chronic administration of WAY100635 did not affect feeding in saline or MDMA pretreated rats. An important role for the $5-\mathrm{HT}_{1 \mathrm{a}}$ autoreceptor in feeding has been suggested on the basis of agonist studies (Dourish et al., 1985; Fletcher et al., 1996). The antagonist, WAY100635, however, failed to alter feeding in this and other studies (Fletcher et al., 1996). The present results also suggest repeated $5-\mathrm{HT}_{1 \mathrm{a}}$ antagonist administration failed to influence food intake.

As previously reported MDMA produced a time dependent increase in locomotor activity (Brennan \& Schenk, 2006; Callaway \& Geyer, 1992).

Following MDMA pre-treatment, MDMA-induced hyperactivity was attenuated, suggesting behavioural tolerance. In line with previous findings, MDMA pretreatment significantly decreased 5-HT tissue levels in the frontal cortex and striatum. Although 5-HIAA levels reductions in MDMA pretreated rats was not significant there was evidence of a reduction in both regions.

It was reasoned that tolerance reflected a supersensitive $5-\mathrm{HT}_{1 \mathrm{a}}$ autoreceptor and that repeated administration of the antagonist, WAY100635, would reverse the deficits. In contrast to this hypothesis, chronic blockade of the 
5-HT ${ }_{1 \mathrm{a}}$ receptor significantly reduced_MDMA-induced hyperactivity in both saline and MDMA pretreated rats.

Activation of specific 5- $\mathrm{HT}_{1 \mathrm{a}}$ autoreceptors produced different responses that were dependent on brain region. For example, activation of DRN 5-HT 1 a autoreceptors by 8-OHDPAT potentiated cocaine-induced hyperlocomotion but MRN activation had no effect (Carey, Depalma, Damianopoulos, Muller, \& Huston, 2004).Other studies have also found opposite effects of the DRN and MRN receptor activation on 5-HT neurotransmission (Hervas et al., 1998; Higgins \& Elliot, 1991; Hopwood \& Stamford, 2001). Therefore, following systemic exposure to the antagonist, these region specific effects might serve to cancel or mask the other's response.

The repeated administration of WAY100635 failed to alter 5-HT tissue concentration in all brain regions examined. This is in contrast to Tohyama et al. (2001) who reported an increase in DRN 5-HT synthesis following chronic WAY100635 administration. This discrepancy may be explained by the varying methods of 5-HT measurement. Just as extracellular 5-HT levels measured by microdialysis are not directly correlated with 5-HT tissue content (Wang, Baumann, Dersch, \& Rothman, 2007), autoradiograpghy measurement may not correlate with 5-HT tissue levels. This suggests that tissue content does not necessarily exclude an increase in 5-HT synthesis or extracellular 5-HT levels following WAY100635 chronic administration.

The aim of the current study was to reverse tolerance to the motor activating effects of MDMA and deficits in 5-HT following MDMA pretreatment. The idea was that administration of the $5-\mathrm{HT}_{1 \mathrm{a}}$ antagonist, WAY100635, would desensitise the autoreceptor thereby restoring normal levels of synthesis and release. The treatment employed, however, failed to reverse the effects.

There are several possible explanations for the failure to reverse the effects of repeated MDMA exposure. Two of these possibilities concern the route of WAY100635 administration and the short period of withdrawal following WAY100635 pretreatment. Because systemic administration is not selective, WAY100635 may have blocked both pre and postsynaptic 5-HT ${ }_{1 \mathrm{a}}$ receptors. 5$\mathrm{HT}_{1 \mathrm{a}}$ receptors are located extensively throughout the CNS and therefore it is 
likely that many receptors in different brain areas were impacted by the chronic treatment. If so, it might not be surprising that the manipulation was ineffective. The short withdrawal period following WAY100635 administration does not preclude the possibility that the results reflect an acute WAY100635 effect or alternatively any reversal or neuroadaptations may only be evident following a longer withdrawal period. These possibilities will be addressed in the following section.

Subsequent data from our laboratory has determined that extending the withdrawal following subcutaneous administration of WAY1000635 to 7 days also failed to impact on tolerance to MDMA-produced hyperactivity. Therefore, the next section examined effects of local application of WAY100635 directly into the DRN. 


\section{Section 5: Reversal of Tolerance to MDMA effects: Intracranial Studies}

\section{Overview}

The inhibitory $5-\mathrm{HT}_{1 \mathrm{a}}$ autoreceptors are located in the somatodendritic region of 5-HT neurons in the raphe nuclei (Gozlan et al., 1983; Verge et al., 1986). These receptors in the dorsal raphe nucleus (DRN) play a major role in the autoregulation of 5-HT synthesis and cell firing (Blier et al., 1990; Casanovas \& Artigas, 1996). Additionally, the DRN neurons innervate a wide range of cortical regions including the striatum and frontal cortex (Hillegaart, 1991). Consequently, the DRN has been extensively targeted when investigating 5-HT $1 \mathrm{a}$ autoreceptor modulation.

As the DRN 5- $\mathrm{HT}_{1 \mathrm{a}}$ autoreceptor modulates CNS 5-HT activity section 5 will administer WAY100635 directly into the DRN. Preliminary studies suggested that a maximum of 4 injections into tissue could be made reliably. The period following the last WAY100635 injection will be extended to 3 days as opposed to the 24 hour withdrawal period used in the previous experiments. This period may better allow the development of neuroadaptive changes. In the literature there is a wide range of WAY100635 doses $(100 \mathrm{ng}-1 \mu \mathrm{g})$ used for local injections (Cheeta, Kenny, \& File, 2000; Herges \& Taylor, 1999; Marco, Moreno, \& de Pablo, 1999). The present study used a dose (500ng) for DRN injections that was mid range of those previously reported. Levels of 5-HT and 5-HIAA in striatum and frontal cortex will be measured to determine any reversal of MDMA-induced deficits by WAY100635 pretreatment.

\section{Procedures: WAY100635 4 day Chronic Intracranial-DRN Regime}

On day one intracranial DRN surgery was performed and the animals allowed a minimum of 5 days recovery. Rats were then administered the MDMA pre-treatment regime. Seven days following the MDMA pre-treatment regime, rats were administered 4 1xdaily intracranial-DRN micro-injections of either WAY100635 (at a concentration of $0.5 \mu \mathrm{g} / 0.5 \mu 1$ per injection; 500ng) or saline vehicle. Two weeks following the MDMA pre-treatment rats were behaviourally 
assessed with an MDMA $(10.0 \mathrm{mg} / \mathrm{kg})$ or vehicle challenge. Animals were euthanized two days later and brains removed (see Figure 19).

$\begin{array}{lllll}\begin{array}{l}\text { Intra-DR } \\ \text { Surgery }\end{array} & \begin{array}{l}\text { MDMA } \\ \text { Pre- } \\ \text { treatment }\end{array} & \begin{array}{l}\text { 4x daily } \\ \text { WAY100635 } \\ \text { Intra-DR } \\ \text { iniection }\end{array} & \begin{array}{l}\text { MDMA } \\ \text { Challenge }+ \\ \text { Beh test }\end{array} & \begin{array}{l}\text { Brains } \\ \text { removed }\end{array} \\ & & \mid & \mid & \\ \text { Day 1 } & \text { Day 7 } & \text { Day } & \text { Day 21 } & \text { Day 23 } \\ & & 14-17 & & \end{array}$

Figure 19 Schematic diagram of experimental timetable of intracranial surgery, MDMA pretreatment, DRN microinjections of WAY100635 (0.00, 500ng), MDMA (0.0, 10.0mg/kg, IP) administration, behavioural testing and brain removal for 5-HT and 5-HIAA HPLC tissue analysis

Intracranial-Dorsal Raphe Nucleus (DRN) Surgery

For intracranial-DRN surgery rats were anaesthetized intraperitoneally (IP) with ketamine/xylazine (90/9 mg/kg) (Phoenix Pharmaceuticals).After visually observing that the anaesthesia had taken effect, the rats were given a subcutaneous (SC) injection of Carprofen (Pfizer NZ Ltd) $(5 \mathrm{mg} / \mathrm{kg}$ ) for pain relief and their eyes swabbed with an eye ointment Lacri- Lube (Allergan), to ensure that the eyes remained moisturised. To ensure that the rats were deeply anaesthetized, a tail pinch was used to illicit a pain reflex. Once the anaesthetic was effective the rats were placed in a stereotaxic frame (David Kopf Instruments, South Natick, MA, USA) with the incisor bar at $3.3 \mathrm{~mm}$ (flat skull position) below the interaural line. The skull was exposed by retracting the skin and clearing the area so that the bregma and lambda were clearly visible. The stereotaxic instrument was aligned above the dorsal raphe nucleus (AP $-7.4 \mathrm{~mm}, \mathrm{~L}$ 0mm from the Bregma) according 
to the stereotaxic atlas Paxinos and Watson (2005). A hole (2mm i.d) was drilled to expose the dura. The meninges was then scratched with a hooked needle to reduce resistance against the guide cannula. A stainless-steel guide cannula (22 gauge) was implanted, $\mathrm{V}-4.8 \mathrm{~mm}$ from brain surface, so that the tip of the cannula was located $1 \mathrm{~mm}$ above the DRN (see Figure 20). This was held in place by three stainless steel screws and dental acrylic cement. Guide cannulae were sealed by removable dummy stainless-steel probes to prevent occlusions. Figure 2 shows the location of the DRN injector. Rats were then injected with $12 \mathrm{mls}$ of sodium lactate subcutaneously and the pain reliever Carprofen $(5 \mathrm{mg} / \mathrm{kg})$ to aid postoperative recovery. Following the surgical procedure animals were placed on a homeothermic heated blanket (Argus Heating Ltd, NZ) until they regained consciousness then placed in individual cages to recover. Animals were allowed a minimum of 5-7 days to recover, or until they had regained their pre-operative body weight, before any further experimental procedures.

\section{Intracranial-DRN Micro-injections}

For intracranial-DRN drug injections, an injector (30-gauge) was introduced through the guide cannula until its tip extended $1 \mathrm{~mm}$ beyond the cannula tip. A volume of $0.5 \mu 1$ was injected over a period of 1 minute using a 50 $\mu 1$ microsyringe with a diameter of $1.46 \mathrm{~mm}$ (701-LT, Hamilton, USA) attached to a Harvard Apparatus PHD 2000 micro-infusion pump (South Natick, MA, USA). The displacement of an air bubble inside the polyethylene catheter connecting the syringe needle to the intracranial needle was used to monitor the microinjection. At the end of the infusion the injector was left in place for a further 1 minute to allow diffusion.

\section{Histology}

At the completion of the DR micro-injection experiments an intracranial injector was inserted through each guide cannula and $0.5 \mu 1$ of Evans blue was injected and the injector removed 1 minute after the injection was finished. This was to allow the injection sites to be easily identifiable.

The animals were asphyxiated by $\mathrm{CO}^{2}$, decapitated and the brains rapidly removed. The brain was cut on the coronal plane at the level of the optic chiasm. 
The anterior portion was used for neurochemical analysis. The posterior portion was stored at $-80^{\circ} \mathrm{C}$ and cryostat sectioned at $70 \mu \mathrm{m}$. Slices were mounted and stained with neutral red. Placement of the cannulae was verified under a light microscope by an independent observer.

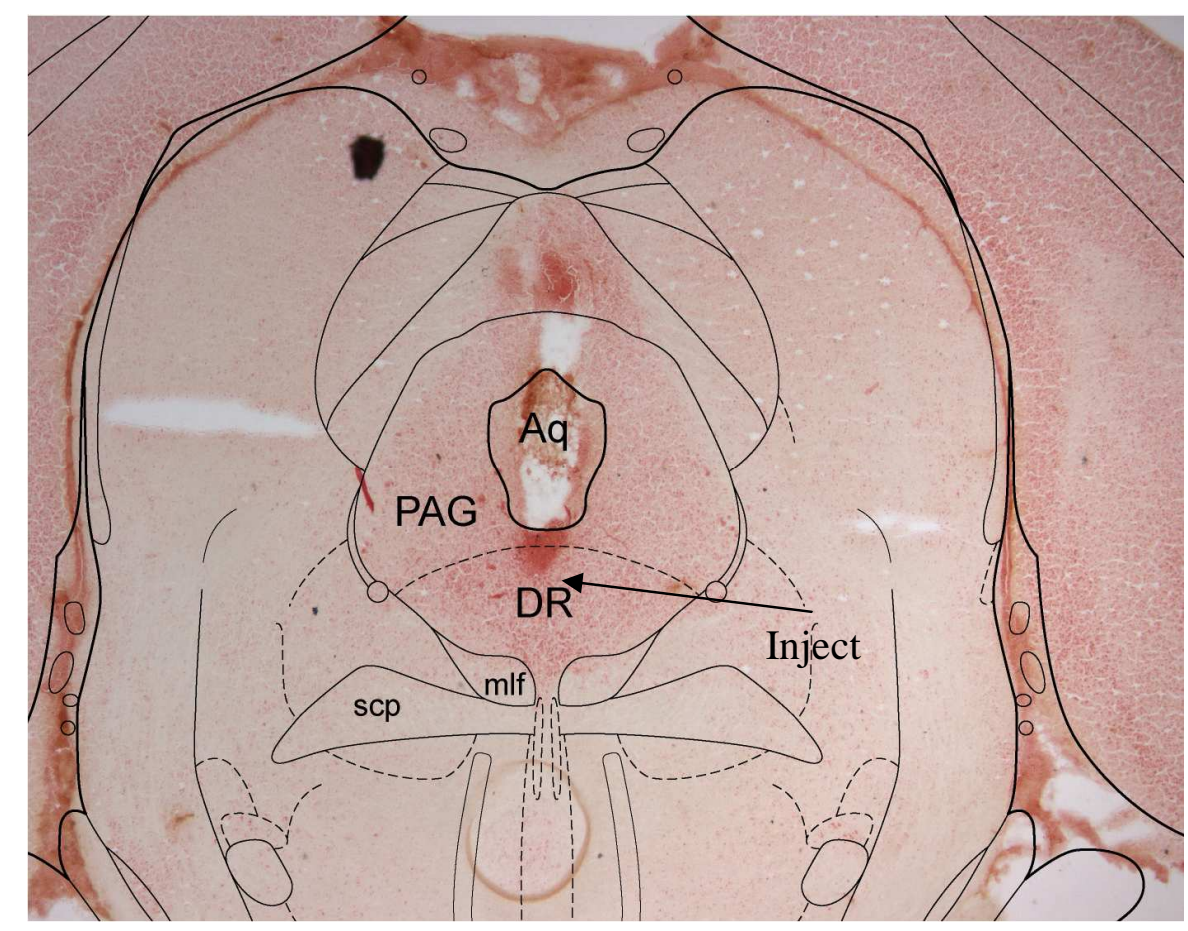

Figure 20 Coronal section of rat brain showing intracranial dorsal raphe injector site according to the stereotaxic atlas Paxinos and Watson (2005).

\section{Effects of MDMA Pre-treatment on MDMA-induced hyperactivity}

Separate groups of rats were pre-treated with saline or MDMA regimen as in general methods. Two weeks later rats were placed in the activity chambers, administered MDMA $(0.00,10.0 \mathrm{mg} / \mathrm{kg})$ and tested.

\section{Effects of WAY100635 on MDMA-induced hyperactivity}

Separate groups of rats were pre-treated with the saline or MDMA regimen. Seven days later WAY100635 (0.00, 500ng in $0.5 \mu 1$, IC) was administered daily for four days. Three days later they were placed in the activity chambers and effects on MDMA-produced induced hyperactivity were measured. 
Effect of MDMA pretreatment and WAY100635 4 day intra-DRN administration on brain 5-HT and 5-HIAA tissue concentrations

The effects of MDMA and WAY100635 pretreatment on 5-HT and 5HIAA brain tissue concentrations were determined by HPLC analysis 48 hours following behavioural testing.

\section{Results}

Effects of MDMA Pre-treatment on MDMA-induced hyperactivity

Figure 21 shows the time course of MDMA-produced hyperactivity in saline and MDMA pretreated rats (Figure 21A). A 3-Way-ANOVA (time X dose $\mathrm{X}$ pretreatment) with time as a repeated measure revealed no significant interaction between these factors $(\mathrm{F}(11,286)=.471, \mathrm{p}>.05)$. There was a main effect of pretreatment $(\mathrm{F}(1,26)=7.145, \mathrm{p}<.05)$ with MDMA pretreated rats showing reduced MDMA produced hyperactivity. Figure 21B shows the total activity counts in the 60 minute period post an acute MDMA $(0.0,10.0 \mathrm{mg} / \mathrm{kg})$ in saline and MDMA pre-treated rats. A 2-Way ANOVA (MDMA dose X MDMA pretreatment) revealed an interaction $(\mathrm{F}(1,20)=5.53, \mathrm{p}<0.05)$ with a main effect of MDMA dose $(\mathrm{F}(1,20)=125.05, \mathrm{p}<0.01)$ and pre-treatment $(\mathrm{F}(1,20)=5.48, \mathrm{p}<$ 0.05). MDMA pretreatment attenuated MDMA-induced hyperactivity indicating tolerance. 

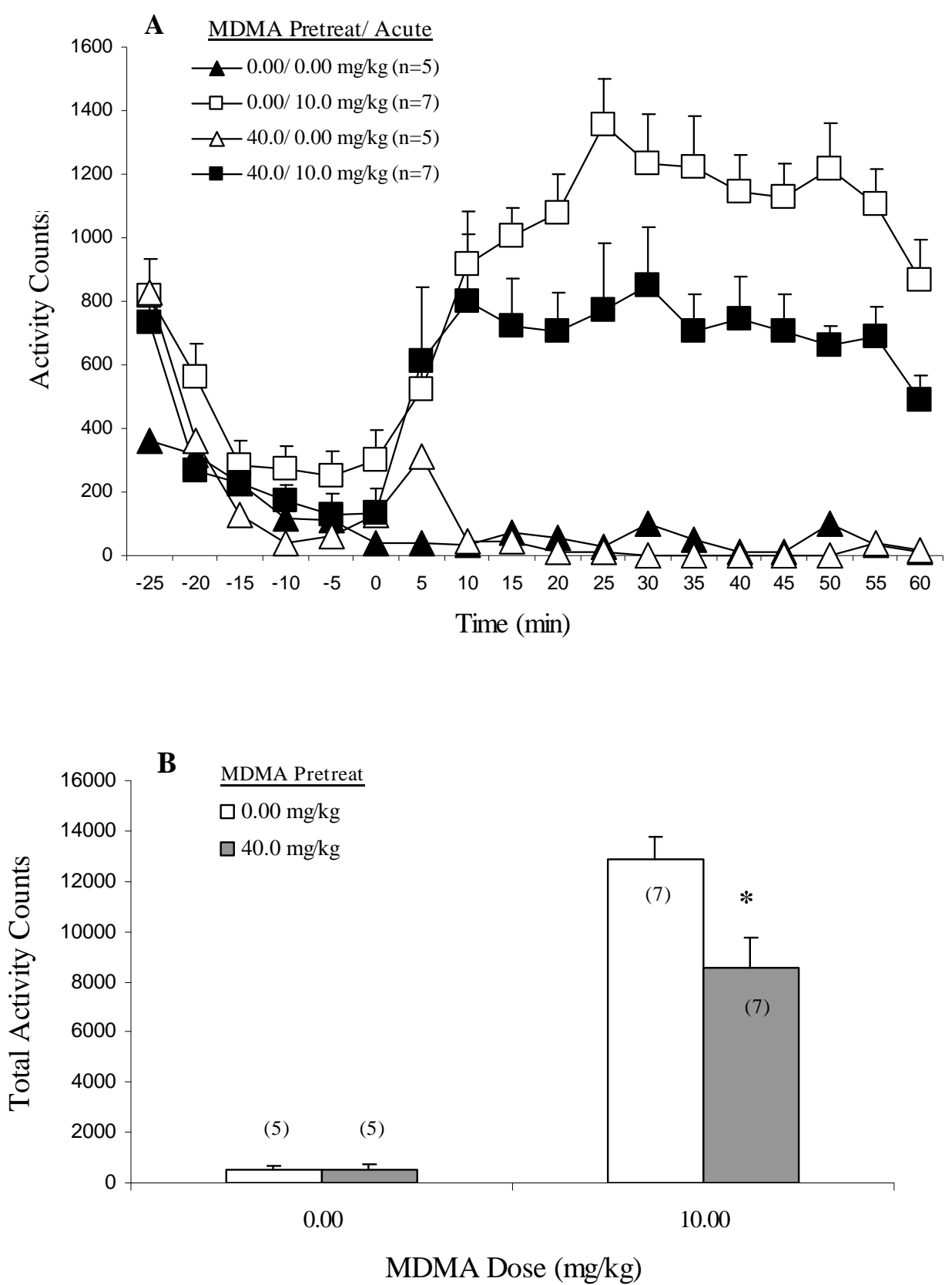

Figure 21 Activity counts produced following MDMA $(0.00,10.0 \mathrm{mg} / \mathrm{kg}, \mathrm{IP})$ administration in MDMA pretreated rats. The top panel (Figure 21A) shows the time course of the mean activity counts produced by MDMA (0.0, $10.0 \mathrm{mg} / \mathrm{kg}$, IP at time =0) administration following saline or MDMA pretreatment (+SEM) while the bottom panel (Figure 21B) shows the total activity counts produced in the 60 minute period post MDMA $(0.0,10.0 \mathrm{mg} / \mathrm{kg}$, IP) in saline and MDMA pretreated. Significant difference relative to MDMA pretreatment group * $\mathbf{p}<.05$. 
Effects of WAY100635 on MDMA-produced hyperactivity following MDMA pretreatment

Figure 22 shows the time course of MDMA produced locomotor activity in the $60 \mathrm{~min}$ period after an acute $\operatorname{MDMA}(0.00,10.0 \mathrm{mg} / \mathrm{kg})$ injection in saline (Figure 22A) and MDMA pre-treated (Figure 22B) rats that received WAY100635 (0.00, 500ng, IC) administration. A 4-Way ANOVA (time X MDMA pretreat X WAY100635 X MDMA dose) with time as a repeated measure revealed no interaction between these factors $(\mathrm{F}(11,451)=.52, \mathrm{p}>.05)$ nor between MDMA pretreatment, WAY pretreatment and MDMA dose $(\mathrm{F}(1,41)=2.71, \mathrm{p}>.05)$ and MDMA pretreatment and WAY pretreatment $(\mathrm{F}(1,41)=3.15, \mathrm{p}>.05)$. There were interactions between MDMA pretreatment and MDMA dose $((\mathrm{F}(1,41)=19.10, \mathrm{p}<.05)$ and WAY pretreatment and MDMA dose $(\mathrm{F}(1,41)=9.30$, $\mathrm{p}<.05$ ). A 2-Way ANOVA (time X WAY pretreat) with time as a repeated measure in saline pretreated rats revealed an interaction between these factors $(\mathrm{F}(11,110)=2.09, \mathrm{p}<.05)$ and a main effect of WAY pretreatment $(\mathrm{F}(1,10)=30.66$, $\mathrm{p}<.05)$. In saline pretreated rats WAY100635 pretreatment significantly potentiated MDMA-induced hyperactivity. A 2-Way ANOVA (time X WAY pretreat) with time as a repeated measure in MDMA pretreated rats revealed no interaction between these factors $(F(11,121)=1.68, p>.05)$ and no main effect of WAY pretreatment $(F(1,11)=1.00, \mathrm{p}>.05)$. In MDMA pretreated rats WAY100635 pretreatment did not alter MDMA-induced hyperactivity. 

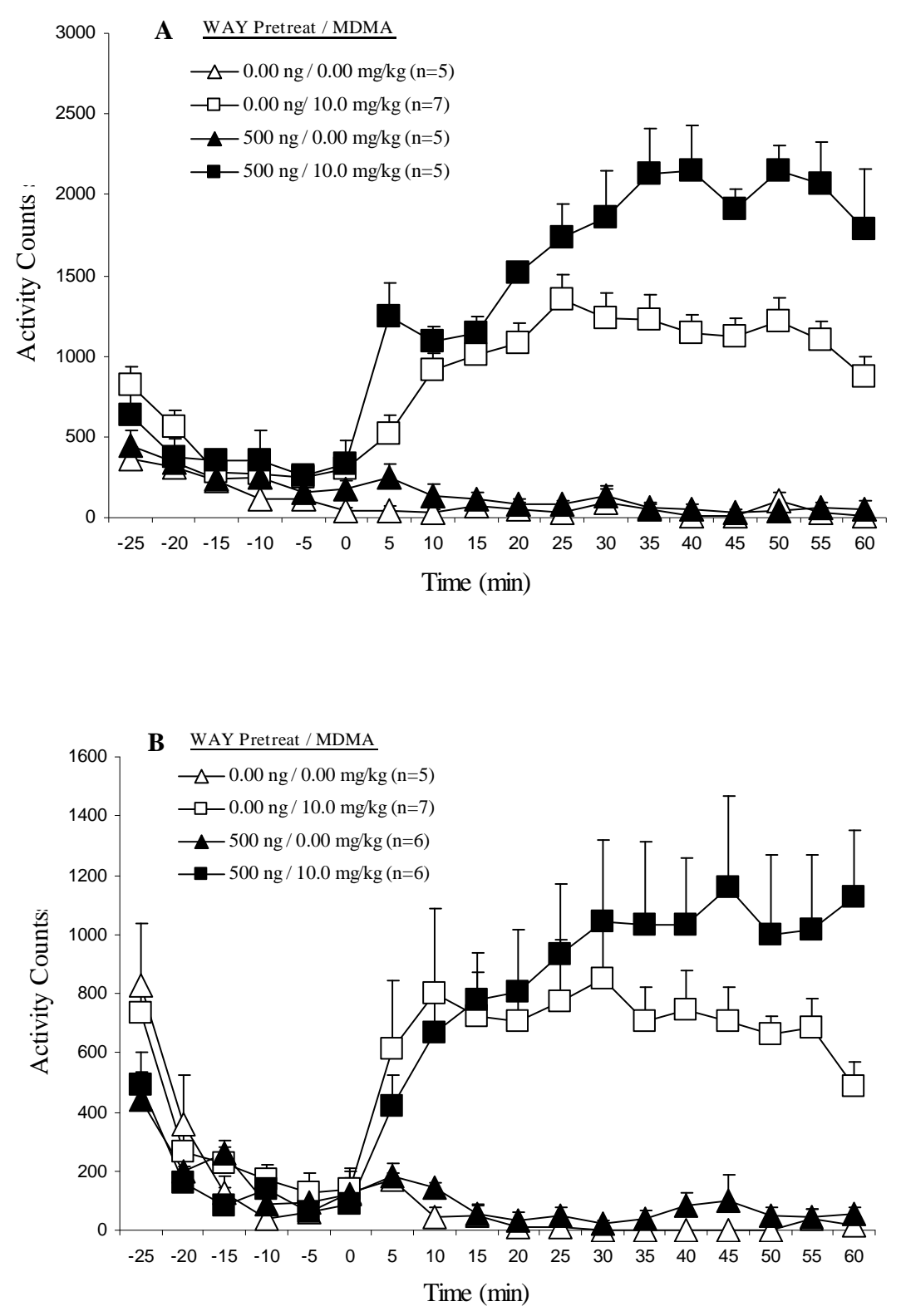

Figure 22 The time course of activity counts in saline (Figure 22A) and MDMA pretreated (Figure 22B) rats produced in the 60minute period post an acute MDMA(0.0, 10.0mg/ kg, IP) administration following 4 day WAY100635 (0.0, 500ng, IC) microinjections.

Figure 23 shows the total activity counts in the 60minute period post an acute MDMA $(0.0,10.0 \mathrm{mg} / \mathrm{kg}$ ) in saline (Figure 23A) and MDMA pretreated (Figure 23B) rats following a 4 day WAY100635 (0.0, 500ng, IC) administration. A 3-Way ANOVA (MDMA Pretreat X WAY100635 Pretreat X MDMA Dose) 
revealed no interaction between these factors $(F(1,41)=2.69, \mathrm{p}>.05)$ nor between MDMA pretreatment and WAY100635 pretreatment $(\mathrm{F}(1,41)=3.39, \mathrm{p}>.05)$. There were interactions between MDMA pretreatment and MDMA dose $(\mathrm{F}(1,41)=18.74$, $\mathrm{p}<.05)$ and WAY100635 pretreatment and MDMA dose $(\mathrm{F}(1,41)=8.78, \mathrm{p}<.05)$. Additionally, there was a main effect of MDMA pretreatment $(F(1,41)=20.44$, $\mathrm{p}<.05)$, WAY100635 pretreatment $(\mathrm{F}(1,41)=13.67, \mathrm{p}<.05)$ and MDMA dose $(\mathrm{F}(1,41)=248.27, \mathrm{p}<.05) .1$-Way ANOVAs revealed a main effect of WAY100635 pretreatment on MDMA-produced hyperactivity in saline pretreated rats $(\mathrm{F}(1,10)=32.05, \mathrm{p}<.05)$ but not in MDMA pretreated rats $(\mathrm{F}(1,11)=.95, \mathrm{p}>.05)$. 

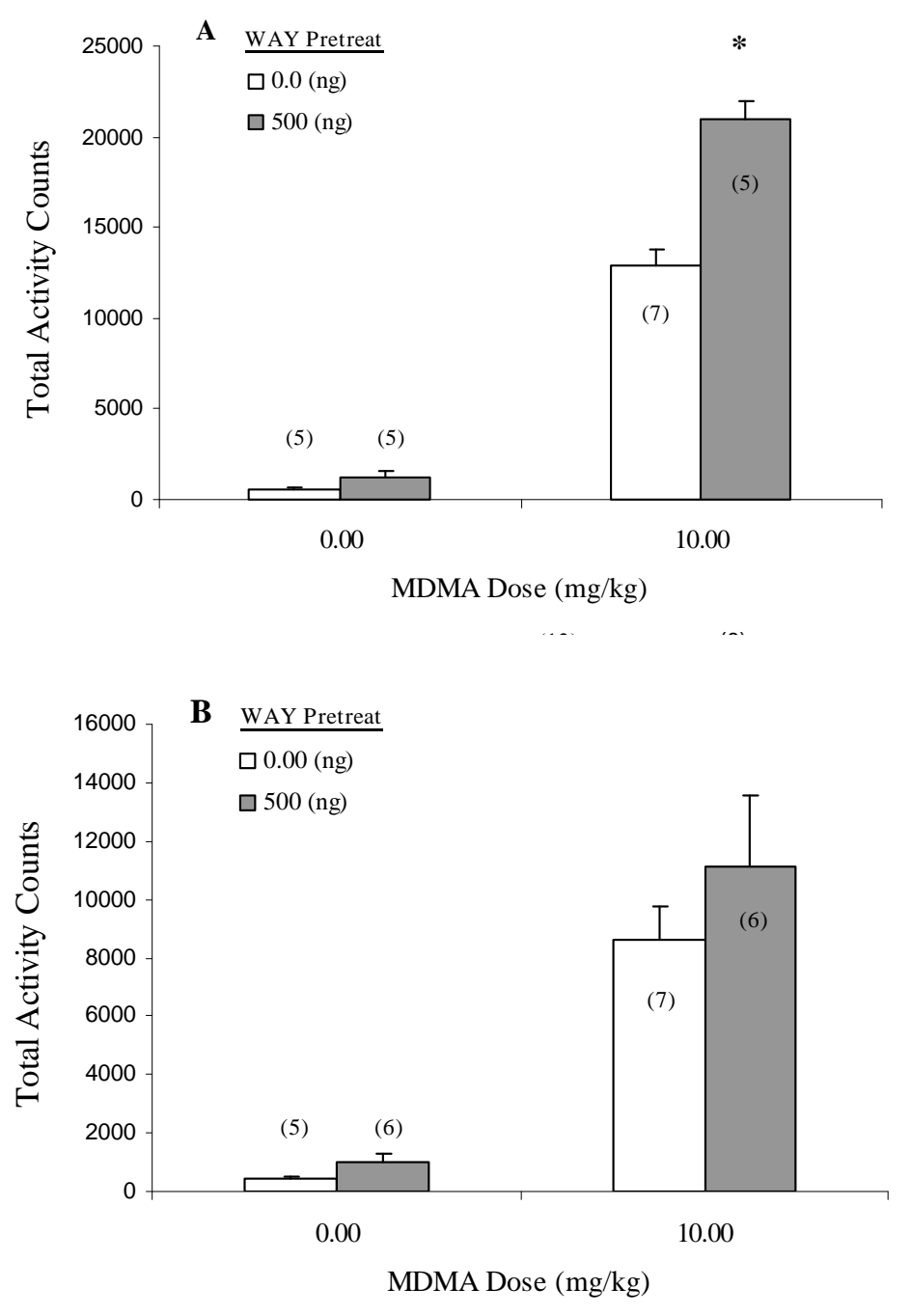

Figure 23 Total activity counts in saline (Figure 23A) and MDMA pretreated (Figure 23B) rats produced in the 60minute period post an acute MDMA(0.0, 10.0mg/kg, IP) administration following 4 day WAY100635 (0.0, 500ng, IC) microinjections. Significance relative to MDMA pretreatment group * $\mathbf{p}<.05$.

\section{Observations}

Following the $60 \mathrm{~min}$ period recorded in the activity chambers, animals were returned to their home cages. Informal observation of the MDMA pretreated animals following WAY100635 pretreatment was that these rats remained 
hyperactive for a prolonged period following acute MDMA administration. Some of these animals were extremely active. Stereotypic behaviour was also evident.

\section{Effect of MDMA and WAY100635 Pretreatment on brain 5-HT and 5-HIAA} tissue concentration.

Figure 24 shows a diagrammatic representation of coronal sections through the rat brain showing the location of correct injection sites (black circles) inside the DRN. Figures represent coordinates from Paxinos and Watson (2005) rat brain atlas. 


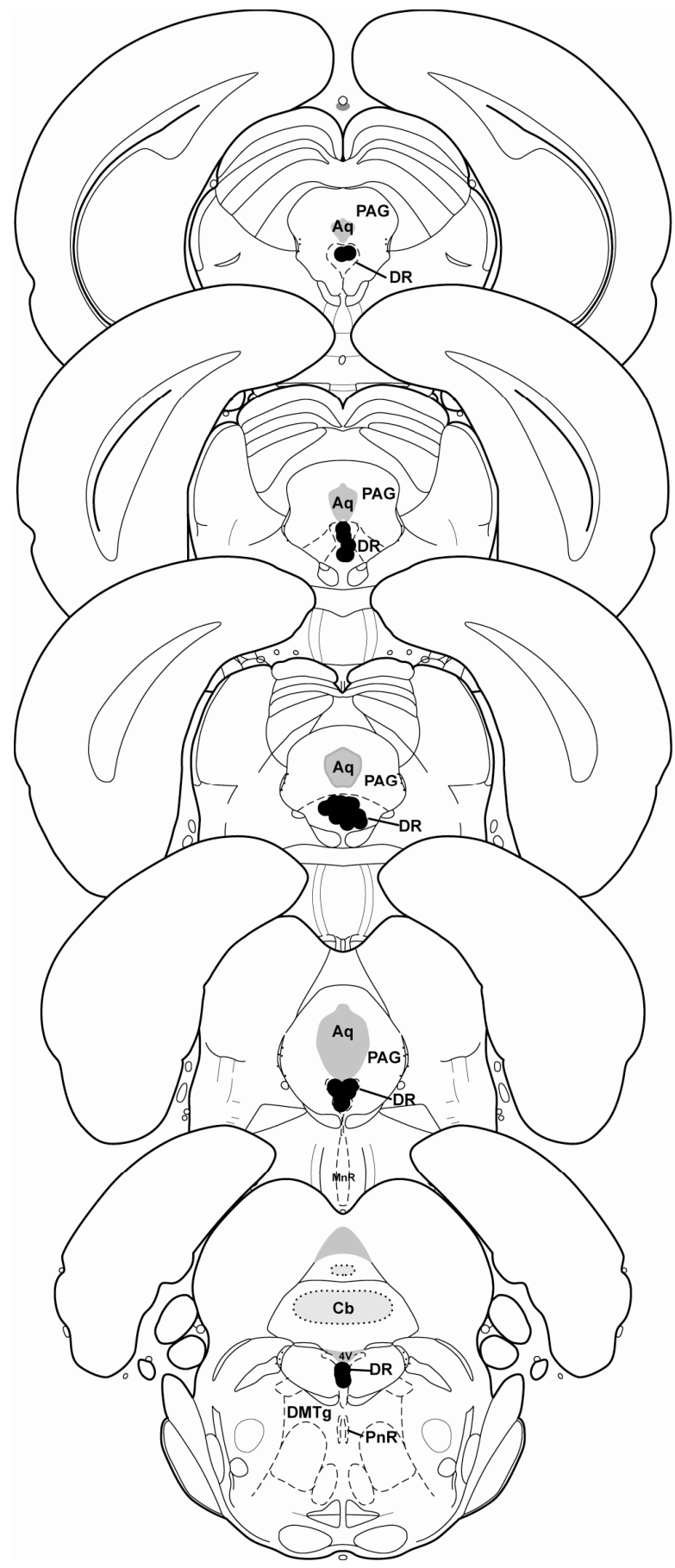

Bregma $-7.08 \mathrm{~mm}$

Bregma $-7.56 \mathrm{~mm}$

Bregma $-7.80 \mathrm{~mm}$

Bregma $-8.28 \mathrm{~mm}$

Bregma $-8.88 \mathrm{~mm}$

Figure 24 Diagrammatic representations of coronal sections through the rat brain showing the location of correct injection sites (black circles) inside the DRN. Figures represent coordinates from Paxinos and Watson (2005) rat brain atlas, with respect to bregma. Aq: aquaduct; Cb: cerebellum; DMTg: dorsomedial tegmental area; DR: dorsal raphe nucleus; $4 \mathrm{~V}$ : fourth ventricle; MnR: medial nucleus raphe; PAG: periaqueductal gray; PMnR: paramedical raphe. 
Table 4 show the effect of MDMA pre-treatment and WAY100635 administration on brain 5-HT and 5-HIAA tissue levels. In the frontal cortex 2Way ANOVA's (MDMA Pretreatment X WAY100635) on 5-HT and 5-HIAA tissue levels revealed no interactions between these factors $(F(1,19)=.005, p>.05)$ and $(\mathrm{F}(1,19)=.455, \mathrm{p}>.05)$ respectively (Table 4$)$. There was a main effect of MDMA pretreatment on 5-HT $(\mathrm{F}(1,19)=6.116, \mathrm{p}<.05)$ and 5-HIAA $(\mathrm{F}(1,19)=21.088, \mathrm{p}<.05)$ levels indicating that MDMA pretreatment significantly reduced 5-HT and 5-HIAA brain tissue levels. There was also a main effect of WAY100635 pretreatment on 5-HT $(\mathrm{F}(1,19)=6.493, \mathrm{p}<.05)$ and 5-HIAA $(\mathrm{F}(1,19)=4.345, \mathrm{p}<.05)$ indicating that in both MDMA and saline pretreated animals WAY100635 increased frontal cortex 5-HT and 5-HIAA tissue levels (Table 4).

In the striatum 2-Way ANOVA's (MDMA Pretreatment X WAY100635 ) on 5-HT and 5-HIAA tissue levels revealed no interactions between these factors $(\mathrm{F}(1,19)=.429, \mathrm{p}>.05)$ and $(\mathrm{F}(1,19)=.925, \mathrm{p}>.05)$ respectively (Table 4$)$. There was a main effect of MDMA pretreatment on 5-HT $(\mathrm{F}(1,19)=6.431, \mathrm{p}<.05)$ and 5HIAA $(\mathrm{F}(1,19)=20.220, \mathrm{p}<.05)$ levels indicating that MDMA pretreatment significantly reduced 5-HT and 5-HIAA brain tissue levels. There was also a main effect of WAY100635 pretreatment on 5-HT $(\mathrm{F}(1,19)=8.650, \mathrm{p}<.05)$ however 5HIAA $(\mathrm{F}(1,19)=1.122, \mathrm{p}<.05)$ levels failed to reach significance. Therefore, in MDMA and saline pretreated animals WAY100635 increased 5-HT tissue levels in both brain regions while only increasing 5-HIAA levels in the frontal cortex (Table 4). 
Table 4 HPLC analysis of frontal cortex and striatal 5-HT and 5-HIAA tissue levels (ng/mg) following MDMA and WAY100635 pretreatment, (a) p<.05 compared to SSS group: (b) $\mathrm{p}<.05$, compared to the relative saline or MDMA control group.

\begin{tabular}{|c|c|c|c|c|}
\hline \multicolumn{5}{|c|}{ 5-HT and 5-HIAA Tissue Levels (ng/mg) } \\
\hline & \multicolumn{2}{|c|}{ Frontal Cortex } & \multicolumn{2}{|l|}{ Striatum } \\
\hline & $5-\mathrm{HT}$ & 5-HIAA & $5-\mathrm{HT}$ & 5-HIAA \\
\hline SSS & $.320 \pm .03$ & $.460 \pm .04$ & $.270 \pm .03$ & $.710 \pm .06$ \\
\hline SWS & $.490 \pm .07_{b}$ & $.490 \pm .07$ & $.460 \pm .06_{b}$ & $.660 \pm .06$ \\
\hline MSS & $.210 \pm .02_{\mathrm{a}}$ & $.210 \pm .02_{\mathrm{a}}$ & $.160 \pm .0_{1 \mathrm{a}}$ & $.390 \pm .03_{\mathrm{a}}$ \\
\hline MWS & $.320 \pm .06_{b}$ & $.320 \pm .06_{b}$ & $.290 \pm .08_{b}$ & $.400 \pm .05$ \\
\hline
\end{tabular}

\section{Discussion}

In the present study MDMA produced a dose dependent increase in locomotor activity. This hyperactivity was attenuated by MDMA pretreatment, suggesting tolerance. As previously reported this behavioural tolerance was accompanied by MDMA-induced reductions in 5-HT and 5-HIAA levels in the striatum and frontal cortex (Shankaran \& Gudelsky, 1999).

In line with other studies there was no change in baseline locomotor activity following MDMA pretreatment (Bull et al., 2003; McNamara, Kelly, \& Leonard, 1995). This suggests that any deficits produced by MDMA pretreatment are not functionally evident under baseline conditions and require a pharmacological challenge to be observed. Additionally, no change in baseline activity was evident following the chronic 4 day intracranial administration of the 5-HT ${ }_{1 \mathrm{a}}$ antagonist, WAY100635. This is consistent with previous findings showing that lesions of the DRN did not alter spontaneous activity in rats (Geyer, Puerto, Menkes, Segal, \& Mandell, 1976; Jacobs, Wise, \& Taylor, 1974).

There are several major findings in this study related to the chronic administration of WAY100635. In saline pretreated rats WAY100635 
pretreatment potentiated MDMA-produced hyperactivity. This was accompanied by an increase in 5-HT and 5-HIAA tissue levels in the striatum and frontal cortex. MDMA induces locomotor activity through the release of monoamines and the subsequent activation of 5-HT and DA receptor subtypes (Bankson \& Cunningham, 2001; Green et al., 2003). The potentiation of activity in the current study may therefore be due to an increase in 5-HT availability as seen in the striatum and frontal cortex. As DRN 5-HT $1 \mathrm{a}$ autoreceptor activation inhibits 5-HT synthesis in forebrain regions (Hillegaart, Hjorth, \& Ahlenius, 1990) it is suggested that increases in 5-HT and 5-HIAA tissue levels in the present study may be attributed to blockade of the DRN 5- $\mathrm{HT}_{1 \mathrm{a}}$ autoreceptors.

A marked increase in MDMA-induced locomotor activity was also evident in MDMA pretreated animals but this effect failed to reach significance. This lack of effect may be partly due to small group numbers. There was high variability in MDMA pretreated rats with activity of one of the five animals $21 \%$ below the group mean. Alternatively, while the withdrawal period in the current experiments was extended compared to that in section 4 , a longer period may be required in order for reversal effects, as seen in saline pretreated animals, to be evident.

In MDMA pretreated animals WAY100635 administration produced an increase in 5-HT tissue concentrations in the frontal cortex and striatum. 5-HIAA levels were increased in the frontal cortex however the striatum was unaffected. This is in line with reports that MDMA-produced 5-HT depletions can be partially restored. Administration of the 5-HT precursor $\mathrm{L}_{\mathrm{L}}$-5-hydroxytryptophan (5-HTP) to MDMA pretreated rats partially restored 5-HT tissue levels 2 hours post administration (Wang et al., 2007). The lack of reversal of 5-HIAA in the striatum, as with the lack of effect on locomotor activity, suggests that MDMA pretreatment may render the 5-HT system less responsive to treatment. In line with the hypothesis of a supersensitive autoreceptor following MDMA pretreatment, this suggests that the efficacy $5-\mathrm{HT}_{1 \mathrm{a}}$ autoreceptor to negatively control 5-HT transmission is enhanced following MDMA pre-exposure. It is possible that a longer period of autoreceptor blockade or possibly a higher dose of WAY100635 may produce effects similar to those seen in controls. 
Future experiments may determine the efficacy of the 5- $\mathrm{HT}_{1 \mathrm{a}}$ autoreceptor to inhibit 5-HT transmission through direct measurement of 5-HT synthesis. Biochemical experiments which examine the accumulation of 5-HTP (Kelai et al., 2008) may further elucidate the functional status of the 5-HT1a autoreceptor following MDMA pretreatment and determine if the reversal of depletions as seen in the present study are due to a change in the functional status of the receptor by repeated receptor antagonism by WAY100635 and ultimately increased 5-HT synthesis.

Decreases in DRN 5-HT 1 a autoreceptor binding have been reported 7 days following high dose MDMA exposure (Aguirre et al., 1995; Aguirre et al., 1997). However, altered functional responses have been reported with no change in receptor binding (Richtand et al., 2003; Shuto et al., 2008). As the 5-HTa receptors are coupled to Gai and Gao proteins (Mannoury la Cour et al., 2001). Future studies examining the coupling efficacy of the receptors to the $G$ protein may also help elucidate the mechanism by which MDMA has altered the functional status of the 5-HT 1 a autoreceptor.

The mechanism responsible for the observation of a prolonged period of MDMA-produced hyperactivity in MDMA pretreated rats in the present study is not known. However, it is possible that the lack of a significant but marked increase in activity was due to an increase in other behaviours induced by MDMA and known to be 5-HT modulated. Stereotypic behaviour was evident when the animals were returned to their home cages. It is possible that a potentiated MDMA response could have resulted in behaviours associated with the 5-HT syndrome such as a flattening of the body resulting in impaired locomotor activity. Future studies may address this confound by administering various MDMA doses and measuring locomotor responses following WAY100635 administration.

It remains controversial whether MDMA is neurotoxic to 5-HT terminals or produces neuroadaptations (Baumann et al., 2007). Given recent findings that MDMA produces no reactive gliosis (Baumann et al., 2007) that MDMA-induced 5-HT depletions can be partially restored by administration of 5-HTP (Wang et al., 2007) and, as in the current study, by blockade of the inhibitory DRN 5-HT 1 a 
autoreceptor, support the idea that high dose MDMA produces a neuroadaptive response rather than neurotoxicity.

The results in the present study suggest that blockade of the DRN 5-HT $1 \mathrm{a}$ autoreceptor may offer an alternative mechanism to reverse the effects of repeated MDMA exposure and as a result may have a major implication for clinical use.

The 5-HT 1 a autoreceptor may be a viable target for restoring 5-HT concentrations in abstinent MDMA users who display ongoing cognitive and psychological impairments due to 5-HT deficits. However, as shown by the reduced effect of WAY100635 treatment in MDMA pretreated animals, it is suggested that the 5HT system may be severely compromised following MDMA exposure and that future MDMA use may induce irreversible deficits. 


\section{General Discussion}

The aim of the current thesis was to investigate the role of the 5- $\mathrm{HT}_{2 \mathrm{a}}, 5$ $\mathrm{HT}_{2 \mathrm{c}}$ and 5- $\mathrm{HT}_{1 \mathrm{a}}$ receptors in tolerance to the effects of MDMA following repeated MDMA exposure and to attempt to reverse tolerance through the local application of a 5-HT antagonist.

In section 1 the Emergence Test (ET) was developed as a behavioural assay that provided a reliable, sensitive measure of the effects of MDMA. Furthermore, the ET was developed an assay responsive to specific 5-HT pharmacological probes in order to investigate the contribution of specific 5-HT receptors to the effects of acute and repeated MDMA exposure. Experimental parameters including habituation periods, handling procedures, test exposure effects as well as MDMA dose and time course effects were determined. To date the number of studies examining the effect on neotic preferences in rats, as seen in the ET, by 5-HT agonists such as MDMA has been limited and those described often reported conflicting results (Cox \& Tye, 1975; Hughes \& Pither, 1987; McGregor et al., 2003; Morley et al., 2005). Many of the discrepancies have been attributed to methodological procedures or animal species/strain. The present study adds to the literature by providing a procedure for examining the effects of both acute and repeated MDMA administration in the ET. Future research may now add the ET to the battery of assays utilised to investigate the effects of MDMA administration by applying the parameters indicated within these findings.

Section 2 utilised the ET to investigate the contribution of the 5-HT $\mathrm{Ha}_{2 \mathrm{a}}$ and $5-\mathrm{HT}_{2 \mathrm{c}}$ receptors to the acute and repeated effects of MDMA. Tolerance has been shown to be one of the most reported effects of MDMA use in humans leading to increases in MDMA dose and frequency of consumption (Parrott, 2005). However, few animal studies have examined the functional consequence of repeated MDMA exposure (Baumann et al., 2008; Shankaran \& Gudelsky, 1999). Therefore, the present study adds to an area of research that is limited yet has major implications for humans who use and abuse MDMA. Three major findings resulted from Section 2. Previous studies have suggested that, following repeated MDMA exposure, tolerance to the effects of various 5-HT agonists was likely due to impaired 5-HT release (Baumann et al., 2008; Bull et al., 2003; Shankaran \& 
Gudelsky, 1999). While these findings elucidated the possible mechanisms underlying MDMA-induced tolerance it was not established whether this was relevant for MDMA produced effects. The present study was therefore the first to demonstrate tolerance to MDMA produced decreases in emergence latency in the Emergence Test. Secondly that the reduction in emergence latency was likely due to impaired 5-HT release. And thirdly, that the 5- $\mathrm{HT}_{2 \mathrm{c}}$ receptors associated with exploratory behaviour may not become desensitised following MDMA pretreatment, as previously suggested (Bull et al., 2003). This suggests that any changes in the response of the 5- $\mathrm{HT}_{2 \mathrm{c}}$ receptor following MDMA exposure may be secondary to alterations in 5-HT transmission. SERT-mediated 5-HT release has also previously been shown to be a predominant mechanism underlying the response to MDMA's decreased ability of MDMA to enhance synaptic 5-HT (Schenk et al., 2007, Rudnick \& Wall, 1992). However, given the significant depletions in 5-HT and 5-HIAA in the brain regions examined in the present study, impaired SERT-mediated 5-HT release was, as with possible inactivation of the 5$\mathrm{HT}_{2 \mathrm{c}}$ receptors, likely to be secondary to impaired 5-HT synthesis. Therefore, 5HT synthesis rather than 5-HT reuptake was targeted via the 5- $\mathrm{HT}_{1 \mathrm{a}}$ autoreceptor known to mediate 5-HT transmission.

In section 3 the potentiated response to low dose $5-\mathrm{HT}_{1 \mathrm{a}}$ agonist, as measured by hypothermia, led to the hypothesis that following MDMA pretreatment the $5-\mathrm{HT}_{1 \mathrm{a}}$ autoreceptor was rendered supersensitive. It was suggested that this heightened sensitivity enhanced the autoreceptor's inhibitory action on 5-HT release and synthesis and thereby contributed to tolerance. A supersensitivity of the 5-HT $1 \mathrm{a}$ autoreceptor has also been reported in wild-type mice following MDMA exposure (Renoir et al., 2008) as shown by a higher potency of a selective 5- $\mathrm{HT}_{1 \mathrm{a}}$ receptor agonist to inhibit cell discharge. Further, the hypothermic response in mice was enhanced following MDMA pre-treatment (Hedlund et al., 2004). In rats a 14 day pre-treatment with cocaine also resulted in 5-HT ${ }_{1 \mathrm{a}}$ autoreceptor supersensitivity (Cunningham et al., 1992), and chronic alcohol intake was found to induce the same effect in C57BL/6J mice (Kelai et al., 2005). Within these studies a variety of dosing regimens, from single day high dose regimens to daily exposure over a number of days, have all produced a 
supersensitivity of the 5-HT $\mathrm{Ha}_{1 \mathrm{a}}$ autoreceptor. However, varying MDMA pretreatment regimens have induced both increased and decreased responses to acute MDMA. An interesting question for future studies is whether the adaptive changes, as shown in the present study, occur under various MDMA dosing regimens. By administering a range of MDMA pre-treatment regimens that induce tolerance will help determine the parameters of MDMA exposure that elicit 5$\mathrm{HT}_{1 \mathrm{a}}$ receptor supersensitivity and therefore the possibility that the 5-HT $1 \mathrm{a}$ autoreceptor contributes to tolerance to MDMA-produced effects.

Previous studies have attempted to block the effects of repeated MDMA exposure on the 5-HT system. However, only one other study has attempted to reverse the effects of repeated MDMA exposure. Administration of the 5-HT precursor 5-HTP potentiated an MDMA-induced effect (Wang et al., 2007). The present study aimed at inducing potentially longer lasting neuroadaptive changes rather than the transient effect reported (Wang et al., 2007). Therefore, a 5-HT 1 a antagonist was chronically administered in an attempt to desensitise the receptor reducing its inhibitory actions and reverse the tolerance to MDMA produced effects. These effects were observed 3 days following $5-\mathrm{HT}_{1 \mathrm{a}}$ antagonist pretreatment. Previous literature has shown some MDMA-induced behavioural deficits may persist up to 12 months (Battaglia et al., 1988) while others have shown recovery after 12 weeks (Brennan \& Schenk, 2006). By examining various periods post pre-treatment the sustainability and therefore the therapeutic usefulness of the present reversal may be determined.

Previous literature has shown that administration of a 5- $\mathrm{HT}_{1 \mathrm{a}}$ agonist also desensitises the 5-HT 1 a receptor (Aguire et al., 1998). In contrast, the present study utilised the novel approach of administering a 5-HT antagonist pretreatment to desensitise the $5-\mathrm{HT}_{1 \mathrm{a}}$ autoreceptor. This approach was chosen as chronic application of the 5- $\mathrm{HT}_{1 \mathrm{a}}$ antagonist WAY100635 had previously been shown to increase 5-HT synthesis in various brain regions including the DRN (Tohyama et al., 2001). Both of these approaches have the potential to modify and possibly reverse tolerance to MDMA effects following high dose MDMA. Future studies may therefore attempt to replicate the present findings following an agonist pre- 
treatment. A combination of these approaches may help elucidate any differential mechanisms that each of these approaches may utilise.

One of the major findings of this thesis was a partial reversal of behavioural tolerance and complete reversal of the 5-HT deficits produced by MDMA pretreatment as a result of local DRN application of a 5- $\mathrm{HT}_{1 \mathrm{a}}$ antagonist. While systemic application failed to produce any reversal, the results highlight the DRN 5-HT $1 \mathrm{a}$ autoreceptor as a possible target for the development of pharmaceuticals relevant to MDMA use. While a potential therapeutic mechanism has been elucidated, local application inhibits its human application. Therefore, future studies examining various 5-HT $\mathrm{H}_{1 \mathrm{a}}$ antagonist doses and withdrawal times may allow systemic antagonist application to be successful. Additionally, future development of highly selective 5-HT 1 a autoreceptor agonists/antagonists may allow systemic rather than local application of the pre-treatment and therefore provide an approach to reducing the long term complications that arise from repeated human MDMA use. Further, the exact mechanism by which this approach was successful is yet to be determined. Future experiments such as biochemical experiments which examine the accumulation of the 5-HT precursor 5-hydroxytryptophan (5-HTP) following MDMA exposure may help elucidate these mechanisms.

Whether or not MDMA is neurotoxic to 5-HT nerve terminals remains controversial. Previous literature has examined a variety of end point measures of MDMA toxicity. A lack of reactive gliosis (Baumann et al., 2007) and an ability to top up intact nerve terminals following 5-HTP administration (Wang et al., 2007) would suggest a neuroadaptive response of the 5-HT system following MDMA rather than neurotoxicity. In the present study MDMA-induced depletions of 5-HT were reversed via the mechanism known to be responsible for 5-HT synthesis. Thus the present study supports a model of neuradaptation, as opposed to neurotoxicity, following repeated high dose MDMA administration on rat brain serotonergic systems. 


\section{References}

Adell, A., Celada, P., Abellan, M. T., \& Artigas, F. (2002). Origin and functional role of the extracellular serotonin in the midbrain raphe nuclei. Brain Res Brain Res Rev, 39(2-3), 154-180.

Aguirre, N., Ballaz, S., Lasheras, B., \& Del Rio, J. (1998). MDMA ('Ecstasy') enhances 5-HT1a receptor density and 8-OH-DPAT-induced hypothermia: blockade by drugs preventing 5-hydroxytryptamine depletion. Eur $J$ Pharmacol, 346, 181-188.

Aguirre, N., Frechilla, D., Garcia-Osta, A., Lasheras, B., \& Del Rio, J. (1997). Differential regulation by methylenedioxymethamphetamine of 5hydroxytryptamine1A receptor density and mRNA expression in rat hippocampus, frontal cortex, and brainstem: the role of corticosteroids. $J$ Neurochem, 68(3), 1099-1105.

Aguirre, N., Galbete, J. L., Lasheras, B., \& Del Rio, J. (1995).

Methylenedioxymethamphetamine induces opposite changes in central pre- and postsynaptic 5-HT1A receptors in rats. Eur J Pharmacol, 281(1), 101-105.

Albert, P. R., Lembo, P., Storring, J. M., Charest, A., \& Saucier, C. (1996). The 5HT1A receptor: signaling, desensitization, and gene transcription. Neuropsychopharmacology, 14(1), 19-25.

Artigas, F., Romero, L., de Montigny, C., \& Blier, P. (1996). Acceleration of the effect of selected antidepressant drugs in major depression by 5-HT1A antagonists. Trends Neurosci, 19(9), 378-383.

Bagdy, G., Graf, M., Anheuer, Z. E., Modos, E. A., \& Kantor, S. (2001). Anxietylike effects induced by acute fluoxetine, sertraline or m-CPP treatment are reversed by pretreatment with the 5-HT2C receptor antagonist SB-242084 but not the 5-HT1A receptor antagonist WAY-100635. Int J Neuropsychopharmacol, 4(4), 399-408.

Baker, K. G., Halliday, G. M., \& Tork, I. (1990). Cytoarchitecture of the human dorsal raphe nucleus. J Comp Neurol, 301(2), 147-161.

Ball, K. T., \& Rebec, G. V. (2005). Role of 5-HT2A and 5-HT2C/B receptors in the acute effects of 3,4-methylenedioxymethamphetamine (MDMA) on striatal single-unit activity and locomotion in freely moving rats. Psychopharmacology (Berl), 181(4), 676-687. 
Bankson, M. G., \& Cunningham, K. A. (2001). 3,4-

Methylenedioxymethamphetamine (MDMA) as a unique model of serotonin receptor function and serotonin-dopamine interactions. $J$ Pharmacol Exp Ther, 297(3), 846-852.

Bankson, M. G., \& Cunningham, K. A. (2002). Pharmacological studies of the acute effects of (+)-3,4-methylenedioxymethamphetamine on locomotor activity: role of 5-HT(1B/1D) and 5-HT(2) receptors.

Neuropsychopharmacology, 26(1), 40-52.

Barnes, N. M., \& Sharp, T. (1999). A review of central 5-HT receptors and their function. Neuropharmacology, 38(8), 1083-1152.

Battaglia, G., Brooks, B. P., Kulsakdinun, C., \& De Souza, E. B. (1988). Pharmacologic profile of MDMA (3,4-methylenedioxymethamphetamine) at various brain recognition sites. European Journal of Pharmacology, 149(1-2), 159-163.

Battaglia, G., Yeh, S. Y., O'Hearn, E., Molliver, M. E., Kuhar, M. J., \& De Souza, E. B. (1987). 3,4-Methylenedioxymethamphetamine and 3,4methylenedioxyamphetamine destroy serotonin terminals in rat brain: quantification of neurodegeneration by measurement of [3H]paroxetinelabeled serotonin uptake sites. J Pharmacol Exp Ther, 242(3), 911-916.

Baumann, M. H., Clark, R. D., Franken, F. H., Rutter, J. J., \& Rothman, R. B. (2008). Tolerance to 3,4-methylenedioxymethamphetamine in rats exposed to single high-dose binges. Neuroscience, 152(3), 773-784.

Baumann, M. H., Mash, D. C., \& Staley, J. K. (1995). The serotonin agonist mchlorophenylpiperazine (mCPP) binds to serotonin transporter sites in human brain. Neuroreport, 6(16), 2150-2152.

Baumann, M. H., Wang, X., \& Rothman, R. B. (2007). 3,4Methylenedioxymethamphetamine (MDMA) neurotoxicity in rats: a reappraisal of past and present findings. Psychopharmacology (Berl), 189(4), 407-424.

Berger, U. V., Gu, X. F., \& Azmitia, E. C. (1992). The substituted amphetamines 3,4-methylenedioxymethamphetamine, methamphetamine, $\mathrm{p}$ chloroamphetamine and fenfluramine induce 5-hydroxytryptamine release via a common mechanism blocked by fluoxetine and cocaine. Eur $J$ Pharmacol, 215(2-3), 153-160.

Bhattacharya, S., K., , Bhattacharya, A., \& Ghosal, G. (1998). Anxiogenic activity of methylenedioxymethamphetamine (Ecstatsy): and experimental study. Biogenic Amines, 14(3), 217-237. 
Biezonski, D. K., Courtemanche, A. B., Hong, S. B., Piper, B. J., \& Meyer, J. S. (2009). Repeated adolescent MDMA ("Ecstasy") exposure in rats increases behavioral and neuroendocrine responses to a 5-HT2A/2C agonist. Brain Research, 1252, 87-93.

Bilkei-Gorzo, A., Gyertyan, I., \& Levay, G. (1998). mCPP-induced anxiety in the light-dark box in rats--a new method for screening anxiolytic activity. Psychopharmacology (Berl), 136(3), 291-298.

Blier, P., \& de Montigny, C. (1998). Possible serotonergic mechanisms underlying the antidepressant and anti-obsessive-compulsive disorder responses. Biol Psychiatry, 44(5), 313-323.

Blier, P., Pineyro, G., el Mansari, M., Bergeron, R., \& de Montigny, C. (1998). Role of somatodendritic 5-HT autoreceptors in modulating 5-HT neurotransmission. Ann N Y Acad Sci, 861, 204-216.

Blier, P., Seletti, B., Gilbert, F., Young, S. N., \& Benkelfat, C. (2002). Serotonin 1A receptor activation and hypothermia in humans: lack of evidence for a presynaptic mediation. Neuropsychopharmacology, 27(2), 301-308.

Blier, P., Serrano, A., \& Scatton, B. (1990). Differential responsiveness of the rat dorsal and median raphe 5-HT systems to 5-HT1 receptor agonists and pchloroamphetamine. Synapse, 5(2), 120-133.

Blue, M. E., Yagaloff, K. A., Mamounas, L. A., Hartig, P. R., \& Molliver, M. E. (1988). Correspondence between 5-HT2 receptors and serotonergic axons in rat neocortex. Brain Res, 453(1-2), 315-328.

Bolla, K. I., McCann, U. D., \& Ricaurte, G. A. (1998). Memory impairment in abstinent MDMA ("Ecstasy") users. Neurology, 51(6), 1532-1537.

Bonhaus, D. W., Weinhardt, K.K., Taylor, M., Desouza, A., McNeeley, P.M., Szcepanski, K., Fontana, D.J., Trinh, J., Rocha, C.L., Dawson, M.W., Flippin, L.A., Eglen, R.M. (1997). RS-102221: a novel high affinity and selective, 5-HT2C receptor antagonist. Neuropharmacology, 36(4-5), 621629.

Bonvento, G., Scatton, B., Claustre, Y., \& Rouquier, L. (1992). Effect of local injection of 8-OH-DPAT into the dorsal or median raphe nuclei on extracellular levels of serotonin in serotonergic projection areas in the rat brain. Neurosci Lett, 137(1), 101-104.

Bosker, F. J., Donker, M. G., Klompmakers, A. A., Kurata, K., \& Westenberg, H. G. (1994). 5-Hydroxytryptamine release in dorsal hippocampus of freely moving rats: modulation by pindolol. Prog Neuropsychopharmacol Biol Psychiatry, 18(4), 765-778. 
Brennan, K. A., \& Schenk, S. (2006). Initial deficit and recovery of function after MDMA preexposure in rats. Psychopharmacology (Berl), 184(2), 239246.

Bull, E. J., Hutson, P. H., \& Fone, K. C. F. (2003). Reduced social interaction following 3,4-methylenedioxymethamphetamine is not associated with enhanced 5-HT 2C receptor responsivity. Neuropharmacology, 44(4), 439448 .

Bull, E. J., Hutson, P. H., \& Fone, K. C. F. (2004). Decreased social behaviour following 3,4-methylenedioxymethamphetamine (MDMA) is accompanied by changes in 5-HT(2A) receptor responsivity. (Publication.:

Callaway, C. W., \& Geyer, M. A. (1992). Tolerance and cross-tolerance to the activating effects of 3,4-methylenedioxymethamphetamine and a 5hydroxytryptamine1B agonist. J Pharmacol Exp Ther, 263(1), 318-326.

Callaway, C. W., Rempel, N., Peng, R. Y., \& Geyer, M. A. (1992). Serotonin 5HT1-like receptors mediate hyperactivity in rats induced by 3,4methylenedioxymethamphetamine. Neuropsychopharmacology, 7(2), 113127.

Callaway, C. W., Wing, L. L., \& Geyer, M. A. (1990). Serotonin release contributes to the locomotor stimulant effects of 3,4methylenedioxymethamphetamine in rats. J Pharmacol Exp Ther, 254(2), 456-464.

Carey, R. J., Depalma, G., Damianopoulos, E., Muller, C. P., \& Huston, J. P. (2004). The 5-HT1A receptor and behavioral stimulation in the rat: effects of 8-OHDPAT on spontaneous and cocaine-induced behavior. Psychopharmacology (Berl), 177(1-2), 46-54.

Carey, R. J., DePalma, G., Damianopoulos, E., Shanahan, A., Muller, C. P., \& Huston, J. P. (2005). Evidence that the 5-HT1A autoreceptor is an important pharmacological target for the modulation of cocaine behavioral stimulant effects. Brain Res, 1034(1-2), 162-171.

Carlson, R. G., Falck, R. S., McCaughan, J. A., \& Siegal, H. A. (2004). MDMA/Ecstasy use among young people in Ohio: perceived risk and barriers to intervention. J Psychoactive Drugs, 36(2), 181-189.

Casanovas, J. M., \& Artigas, F. (1996). Differential effects of ipsapirone on 5hydroxytryptamine release in the dorsal and median raphe neuronal pathways. J Neurochem, 67(5), 1945-1952.

Centre for Social and Health Outcomes Research and Evaluation. (2006). Recent Trends in Illegal Drug Use in New Zealand, : Massey University. 
Chadwick, I. S., Curry, P. D., Linsley, A., Freemont, A. J., \& Doran, B. (1991). Ecstasy, 3-4 methylenedioxymethamphetamine (MDMA), a fatality associated with coagulopathy and hyperthermia. J R Soc Med, 84(6), 371.

Chalmers, D. T., \& Watson, S. J. (1991). Comparative anatomical distribution of 5-HT1A receptor mRNA and 5-HT1 A binding in rat brain--a combined in situ hybridisation/in vitro receptor autoradiographic study. Brain Res, 561(1), 51-60.

Cheeta, S., Kenny, P. J., \& File, S. E. (2000). The role of 5-HT1A receptors in mediating the anxiogenic effects of nicotine following lateral septal administration. Eur J Neurosci, 12(10), 3797-3802.

Cohen, R. S. (1995). Subjective reports on the effects of the MDMA ('ecstasy') experience in humans. Prog Neuropsychopharmacol Biol Psychiatry, 19(7), 1137-1145.

Colado, M. I., Murray, T. K., \& Green, A. R. (1993). 5-HT loss in rat brain following 3,4-methylenedioxymethamphetamine (MDMA), pchloroamphetamine and fenfluramine administration and effects of chlormethiazole and dizocilpine. Br J Pharmacol, 108(3), 583-589.

Colado, M. I., O'Shea, E., \& Green, A. R. (2004). Acute and long-term effects of MDMA on cerebral dopamine biochemistry and function. Psychopharmacology (Berl), 173(3-4), 249-263.

Cole, J. C., Bailey, M., Sumnall, H. R., Wagstaff, G. F., \& King, L. A. (2002). The content of ecstasy tablets: implications for the study of their long-term effects. Addiction, 97(12), 1531-1536.

Cole, J. C., \& Sumnall, H. R. (2003a). Altered states: the clinical effects of Ecstasy. Pharmacol Ther, 98(1), 35-58.

Cole, J. C., \& Sumnall, H. R. (2003b). The pre-clinical behavioural pharmacology of 3,4-methylenedioxymethamphetamine (MDMA). Neurosci Biobehav Rev, 27(3), 199-217.

Commins, D. L., Vosmer, G., Virus, R. M., Woolverton, W. L., Schuster, C. R., \& Seiden, L. S. (1987). Biochemical and histological evidence that methylenedioxymethylamphetamine (MDMA) is toxic to neurons in the rat brain. J Pharmacol Exp Ther, 241(1), 338-345.

Conductier, G., Crosson, C., Hen, R., Bockaert, J., \& Compan, V. (2005). 3,4-Nmethlenedioxymethamphetamine-induced hypophagia is maintained in 5HT1B receptor knockout mice, but suppressed by the 5-HT2C receptor antagonist RS102221. Neuropsychopharmacology, 30(6), 1056-1063. 
Cowen, P. J., Power, A. C., Ware, C. J., \& Anderson, I. M. (1994). 5-HT1A receptor sensitivity in major depression. A neuroendocrine study with buspirone. Br J Psychiatry, 164(3), 372-379.

Cox, T., \& Tye, N. (1975). The effects of amphetamine, imipramine and ICI 58,834 (Vivalan), a potential antidepressant, on unconditioned behaviour in rats. Psychopharmacologia, 40(4), 297-304.

Crawley, J., \& Goodwin, F. K. (1980). Preliminary report of a simple animal behavior model for the anxiolytic effects of benzodiazepines. Pharmacol Biochem Behav, 13(2), 167-170.

Cunningham, K. A., Paris, J. M., \& Goeders, N. E. (1992). Chronic cocaine enhances serotonin autoregulation and serotonin uptake binding. Synapse, $11(2), 112-123$.

Dafters, R. I. (1994). Effect of ambient temperature on hyperthermia and hyperkinesis induced by 3,4-methylenedioxymethamphetamine (MDMA or "ecstasy") in rats. Psychopharmacology (Berl), 114(3), 505-508.

Dafters, R. I. (1995). Hyperthermia following MDMA administration in rats: effects of ambient temperature, water consumption, and chronic dosing. Physiol Behav, 58(5), 877-882.

Dalley, J. W., Laane, K., Theobald, D. E., Pena, Y., Bruce, C. C., Huszar, A. C., et al. (2007). Enduring deficits in sustained visual attention during withdrawal of intravenous methylenedioxymethamphetamine selfadministration in rats: results from a comparative study with damphetamine and methamphetamine. Neuropsychopharmacology, 32(5), 1195-1206.

Daniela, E., Brennan, K., Gittings, D., Hely, L., \& Schenk, S. (2004). Effect of SCH 23390 on (+/-)-3,4-methylenedioxymethamphetamine hyperactivity and self-administration in rats. Pharmacol Biochem Behav, 77(4), 745750 .

Davidson, C., \& Stamford, J. A. (1995). Evidence that 5-hydroxytryptamine release in rat dorsal raphe nucleus is controlled by 5-HT1A, 5-HT1B and 5-HT1D autoreceptors. Br J Pharmacol, 114(6), 1107-1109.

De Deurwaerdere, P., \& Spaminato, U. (1999). Role of serotonin2A and serotonin $2 \mathrm{~B} / 2 \mathrm{C}$ receptor subtypes in the control of accumbal and striatal dopamine release elicited in vivo by dorsal raphe nucleus electrical stimulation. J Neurochem, 73(3), 1033-1042.

De Deurwaerdere, P., Navailles, S., Berg, K. A., Clarke, W. P., \& Spampinato, U. (2004). Constitutive activity of the serotonin $2 \mathrm{C}$ receptor inhibits in vivo 
dopamine release in the rat striatum and nucleus accumbens. J Neurosci, 24(13), 3235-3241.

de la Torre, R., Farre, M., Ortuno, J., Mas, M., Brenneisen, R., Roset, P. N., et al. (2000a). Non-linear pharmacokinetics of MDMA ('ecstasy') in humans. $\mathrm{Br}$ J Clin Pharmacol, 49(2), 104-109.

de la Torre, R., Farre, M., Roset, P. N., Hernandez Lopez, C., Mas, M., Ortuno, J., et al. (2000b). Pharmacology of MDMA in humans. Ann N Y Acad Sci, 914, 225-237.

Dhonnchadha, B. A. N., Bourin, M.,. (2003). Anxiolytic-like effects of 5-HT2 ligands on three mouse models of anxiety. Behav Brain Res, 140(1-2), 203-214.

Di Matteo, V., Di Giovanni, G., Di Mascio, M., \& Esposito, E. (1999). SB 242084 , a selective serotonin $2 \mathrm{C}$ receptor antagonist, increases dopaminergic transmission in the mesolimbic system. Neuropharmacology, 38(8), 1195-1205.

Doherty, M. D., \& Pickel, V. M. (2000). Ultrastructural localization of the serotonin 2A receptor in dopaminergic neurons in the ventral tegmental area. Brain Res, 864(2), 176-185.

Dong, J., de Montigny, C., \& Blier, P. (1997). Effect of acute and repeated versus sustained administration of the 5-HT1A receptor agonist ipsapirone: electrophysiological studies in the rat hippocampus and dorsal raphe. Naunyn Schmiedebergs Arch Pharmacol, 356(3), 303-311.

Dourish, C. T., Hutson, P. H., \& Curzon, G. (1985). Low doses of the putative serotonin agonist 8-hydroxy-2-(di-n-propylamino) tetralin (8-OH-DPAT) elicit feeding in the rat. Psychopharmacology (Berl), 86(1-2), 197-204.

EACD, T. E. A. C. O. D. (2004). The Expert Advisory Committee on Drugs (EACD) Advice to the Minister on 3, 4 Methylenedioxymethamphetamine (MDMA).

Esteban, S., Moranta, D., Sastre-Coll, A., Miralles, A., \& Garcia-Sevilla, J. A. (2002). Withdrawal from chronic ethanol increases the sensitivity of presynaptic 5-HT(1A) receptors modulating serotonin and dopamine synthesis in rat brain in vivo. Neurosci Lett, 326(2), 121-124.

Evenden, J. L., \& Angeby-Moller, K. (1990). Effects of 8-hydroxy-2-(di-npropylamino)tetralin (8-OH-DPAT) on locomotor activity and rearing of mice and rats. Psychopharmacology (Berl), 102(4), 485-491.

Fallon, J. K., Kicman, A. T., Henry, J. A., Milligan, P. J., Cowan, D. A., \& Hutt, A. J. (1999). Stereospecific analysis and enantiomeric disposition of 3, 4- 
methylenedioxymethamphetamine (Ecstasy) in humans. Clin Chem, 45(7), 1058-1069.

Fantegrossi, W. E. (2007). Reinforcing effects of methylenedioxy amphetamine congeners in rhesus monkeys: are intravenous self-administration experiments relevant to MDMA neurotoxicity? Psychopharmacology (Berl), 189(4), 471-482.

Fantegrossi, W. E., Godlewski, T., Karabenick, R. L., Stephens, J. M., Ullrich, T., Rice, K. C., et al. (2003). Pharmacological characterization of the effects of 3,4-methylenedioxymethamphetamine ("ecstasy") and its enantiomers on lethality, core temperature, and locomotor activity in singly housed and crowded mice. Psychopharmacology (Berl), 166(3), 202-211.

Fantegrossi, W. E., Ullrich, T., Rice, K. C., Woods, J. H., \& Winger, G. (2002). 3,4-Methylenedioxymethamphetamine (MDMA, "ecstasy") and its stereoisomers as reinforcers in rhesus monkeys: serotonergic involvement. Psychopharmacology (Berl), 161(4), 356-364.

Fantegrossi, W. E., Woolverton, W. L., Kilbourn, M., Sherman, P., Yuan, J., Hatzidimitriou, G., et al. (2004). Behavioral and neurochemical consequences of long-term intravenous self-administration of MDMA and its enantiomers by rhesus monkeys. Neuropsychopharmacology, 29(7), 1270-1281.

Fehrer, E. (1956). The effects on hunger and familiarity of locale on exploration. $J$ Comp Physiol Psychol, 49(6), 549-552.

File, S. E. (1990). One-trial tolerance to the anxiolytic effects of chlordiazepoxide in the plus-maze. Psychopharmacology (Berl), 100(2), 281-282.

File, S. E. (1992). Usefulness of animal models with newer anxiolytics. Clin Neuropharmacol, 15 Suppl 1 Pt A, 525A-526A.

File, S. E., Mabbutt, P. S., \& Hitchcott, P. K. (1990). Characterisation of the phenomenon of "one-trial tolerance" to the anxiolytic effect of chlordiazepoxide in the elevated plus-maze. Psychopharmacology (Berl), 102(1), 98-101.

File, S. E., Zangrossi, H., Jr., Viana, M., \& Graeff, F. G. (1993). Trial 2 in the elevated plus-maze: a different form of fear? Psychopharmacology (Berl), 111(4), 491-494.

Fiorella, D., Rabin, R. A., \& Winter, J. C. (1995). The role of the 5-HT2A and 5HT2C receptors in the stimulus effects of $\mathrm{m}$-chlorophenylpiperazine. Psychopharmacology (Berl), 119(2), 222-230. 
Fischer, C., Hatzidimitriou, G., Wlos, J., Katz, J., \& Ricaurte, G. (1995).

Reorganization of ascending 5-HT axon projections in animals previously exposed to the recreational drug (+/-)3,4-

methylenedioxymethamphetamine (MDMA, "ecstasy"). J Neurosci, 15(8), 5476-5485.

Fitzgerald, J. L., \& Reid, J. J. (1990). Effects of methylenedioxymethamphetamine on the release of monoamines from rat brain slices. Eur J Pharmacol, 191(2), 217-220.

Fletcher, A., Forster, E. A., Bill, D. J., Brown, G., Cliffe, I. A., Hartley, J. E., et al. (1996). Electrophysical, biochemical, neurohormonal and behavioural studies with WAY-100635, a potent, selective and silent 5-HT1a receptor antagonist. Behavioural Brain Research(73), 337-353.

Fletcher, P. J., Korth, K. M., Robinson, S. R., \& Baker, G. B. (2002). Multiple 5HT receptors are involved in the effects of acute MDMA treatment: studies on locomotor activity and responding for conditioned reinforcement. Psychopharmacology (Berl), 162(3), 282-291.

Fletcher, P. J., Sinyard, J., \& Higgins, G. A. (2006). The effects of the 5-HT(2C) receptor antagonist SB242084 on locomotor activity induced by selective, or mixed, indirect serotonergic and dopaminergic agonists. Psychopharmacology (Berl), 187(4), 515-525.

Fone, K. C. F., Austin, R.H., Topham, I.A., Kennett, G.A., Punhani, T. (1998). Effect of chronic m-CPP on locomotion, hypophagia, plasma corticosterone and 5-HT2C receptor levels in the rat. Br J Pharmacol, 123(8), 1707-1715.

Forster, E. A., Cliffe, I. A., Bill, D. J., Dover, G. M., Jones, D., Reilly, Y., et al. (1995). A pharmacological profile of the selective silent 5-HT1A receptor antagonist, WAY-100635. Eur J Pharmacol, 281(1), 81-88.

Fox, H. C., Parrott, A. C., \& Turner, J. J. (2001). Ecstasy use: cognitive deficits related to dosage rather than self-reported problematic use of the drug. $J$ Psychopharmacol, 15(4), 273-281.

Frederick, D. L., \& Paule, M. G. (1997). Effects of MDMA on complex brain function in laboratory animals. Neurosci Biobehav Rev, 21(1), 67-78.

Fuxe, K., Farnebo, L. O., Hamberger, B., \& Ogren, S. O. (1975). On the in vivo and in vitro actions of fenfluramine and its derivatives on central monoamine neurons, especially 5-hydroxytryptamine neurons, and their relation to the anorectic activity of fenfluramine. Postgrad Med J, 51 Suppl 1, 35-45. 
Gamma, A., Buck, A., Berthold, T., Liechti, M. E., \& Vollenweider, F. X. (2000). 3,4-Methylenedioxymethamphetamine (MDMA) modulates cortical and limbic brain activity as measured by $[\mathrm{H}(2)(15) \mathrm{O}]-\mathrm{PET}$ in healthy humans. Neuropsychopharmacology, 23(4), 388-395.

Garattini, S., Buczko, W., Jori, A., \& Samanin, R. (1975). The mechanism of action of fenfluramine. Postgrad Med J, 51 Suppl 1, 27-35.

Gartside, S. E., McQuade, R., \& Sharp, T. (1996). Effects of repeated administration of 3,4-Methylenedioxymethamphetamine on 5Hydroxytryptamine neuronal activity and release in the rat brain in Vivo. Journal of Pharmacology And Experimental Therapeutics, 279, 277-283.

Gartside, S. E., McQuade, R., \& Sharp, T. (1997). Acute effects of 3,4Methylenedioxymethamphetamine (MDMA) on 5-HT cell firing and release: Comparison between dorsal and median raphe 5-HT systems. Neuropharmacology, 36(11/12), 1697-1703.

Gartside, S. E., Umbers, V., Hajos, M., \& Sharp, T. (1995). Interaction between a selective 5-HT1A receptor antagonist and an SSRI in vivo: effects on 5HT cell firing and extracellular 5-HT. Br J Pharmacol, 115(6), 1064-1070.

Gerra, G., Zaimovic, A., Giucastro, G., Maestri, D., Monica, C., Sartori, R., et al. (1998). Serotonergic function after (+/-)3,4-methylene-

dioxymethamphetamine ('Ecstasy') in humans. Int Clin Psychopharmacol, 13(1), 1-9.

Geyer, M. A., Puerto, A., Menkes, D. B., Segal, D. S., \& Mandell, A. J. (1976). Behavioral studies following lesions of the mesolimbic and mesostriatal serotonergic pathways. Brain Res, 106(2), 257-269.

Giorgetti, M., \& Tecott, L. H. (2004). Contributions of 5-HT(2C) receptors to multiple actions of central serotonin systems. Eur J Pharmacol, 488(1-3), $1-9$.

Gleason, S. D., Lucaites, V. L., Shannon, H. E., Nelson, D. L., \& Leander, J. D. (2001). m-CPP hypolocomotion is selectively antagonized by compounds with high affinity for 5-HT(2C) receptors but not 5-HT(2A) or 5-HT(2B) receptors. Behav Pharmacol, 12(8), 613-620.

Gobert, A., Rivet, J. M., Lejeune, F., Newman-Tancredi, A., Adhumeau-Auclair, A., Nicolas, J. P., et al. (2000). Serotonin(2C) receptors tonically suppress the activity of mesocortical dopaminergic and adrenergic, but not serotonergic, pathways: a combined dialysis and electrophysiological analysis in the rat. Synapse, 36(3), 205-221.

Godbout, R., Chaput, Y., Blier, P., \& de Montigny, C. (1991). Tandospirone and its metabolite, 1-(2-pyrimidinyl)-piperazine--I. Effects of acute and long- 
term administration of tandospirone on serotonin neurotransmission. Neuropharmacology, 30(7), 679-690.

Gozlan, H., El Mestikawy, S., Pichat, L., Glowinski, J., \& Hamon, M. (1983). Identification of presynaptic serotonin autoreceptors using a new ligand: 3H-PAT. Nature, 305(5930), 140-142.

Graeff, F. G., Netto, C. F., \& Zangrossi, H., Jr. (1998). The elevated T-maze as an experimental model of anxiety. Neurosci Biobehav Rev, 23(2), 237-246.

Granoff, M. I., \& Ashby, C. R., Jr. (2001). Effect of the repeated administration of (+/-)-3,4-methylenedioxymethamphetamine on the behavioral response of rats to the 5-HT1A receptor agonist (+/-)-8-hydroxy-(di-npropylamino)tetralin. Neuropsychobiology, 43(1), 42-48.

Green, A. R., Cross, A. J., \& Goodwin, G. M. (1995). Review of the pharmacology and clinical pharmacology of 3,4methylenedioxymethamphetamine (MDMA or "Ecstasy"). Psychopharmacology (Berl), 119(3), 247-260.

Green, A. R., Mechan, A. O., Elliott, J. M., O'Shea, E., \& Colado, M. I. (2003). The pharmacology and clinical pharmacology of 3,4methylenedioxymethamphetamine (MDMA, "ecstasy"). Pharmacol Rev, 55(3), 463-508.

Green, A. R., Sanchez, V., O'Shea, E., Saadat, K. S., Elliott, J. M., \& Colado, M. I. (2004). Effect of ambient temperature and a prior neurotoxic dose of 3,4-methylenedioxymethamphetamine (MDMA) on the hyperthermic response of rats to a single or repeated ('binge' ingestion) low dose of MDMA. Psychopharmacology (Berl), 173(3-4), 264-269.

Griebel, G. (1995). 5-Hydroxytryptamine-interacting drugs in animal models of anxiety disorders: more than 30 years of research. Pharmacol Ther, 65(3), 319-395.

Griebel, G., Perrault, G., \& Sanger, D. J. (1997). A comparative study of the effects of selective and non-selective 5-HT2 receptor subtype antagonists in rat and mouse models of anxiety. Neuropharmacology, 36(6), 793-802.

Grignaschi, G., Invernizzi, R. W., Fanelli, E., Fracasso, C., Caccia, S., \& Samanin, R. (1998). Citalopram-induced hypophagia is enhanced by blockade of 5-HT(1 A) receptors: role of 5-HT(2C) receptors. $\mathrm{Br} J$ Pharmacol, 124(8), 1781-1787.

Gudelsky, G. A., \& Nash, J. F. (1996). Carrier-mediated release of serotonin by 3,4-methylenedioxymethamphetamine: implications for serotonindopamine interactions. J Neurochem, 66(1), 243-249. 
Gudelsky, G. A., Yamamoto, B. K., \& Nash, J. F. (1994). Potentiation of 3,4methylenedioxymethamphetamine-induced dopamine release and serotonin neurotoxicity by 5-HT2 receptor agonists. Eur J Pharmacol, 264(3), 325-330.

Gurling, J., Ashworth-Preece, M. A., Dourish, C. T., \& Routledge, C. (1994). Effects of acute and chronic treatment with the selective 5-HT1A receptor antagonist WAY-100635 on hippocampal 5-HT release in vivo. British Journal of Pharmacology, 112, 299.

Halberstadt, A. L., van der Heijden, I., Ruderman, M. A., Risbrough, V. B., Gingrich, J. A., Geyer, M. A., et al. (2009). 5-HT2A and 5-HT2C Receptors Exert Opposing Effects on Locomotor Activity in Mice. Neuropsychopharmacology, 34(8), 1958-1967.

Hamik, A., \& Peroutka, S. J. (1989). 1-(m-chlorophenyl)piperazine (mCPP) interactions with neurotransmitter receptors in the human brain. Biol Psychiatry, 25(5), 569-575.

Harsing, L. G. (2006). The pharmacology of the neurochemical transmission in the midbrain raphe nuclei of the rat. Curr Neuropharmacol, 4(4), 313-339.

Hascoet, M., Bourin, M., \& Couetoux du Tertre, A. (1997). Influence of prior experience on mice behavior using the four-plate test. Pharmacol Biochem Behav, 58(4), 1131-1138.

Hascoet, M., Bourin, M., \& Dhonnchadha, B. A. (2001). The mouse light-dark paradigm: a review. Prog Neuropsychopharmacol Biol Psychiatry, 25(1), 141-166.

Heffner, T. G., Hartman, J. A., \& Seiden, L. S. (1980). A rapid method for the regional dissection of the rat brain. Pharmacol Biochem Behav, 13(3), 453-456.

Hedlund, P. B., Kelly, L., Mazur, C., Lovenberg, T., Sutcliffe, J. G., \& Bonaventure, P. (2004). 8-OH-DPAT acts on both 5-HT1A and 5-HT7 receptors to induce hypothermia in rodents. Eur J Pharmacol, 487(1-3), $125-132$.

Herges, S., \& Taylor, D. A. (1999). Modulation of cocaine-induced locomotor activity, rears and head bobs by application of WAY100635 into the dorsal and median raphe nuclei of the rat. Naunyn Schmiedebergs Arch Pharmacol, 360(2), 129-134.

Herin, D. V., Liu, S., Ullrich, T., Rice, K. C., \& Cunningham, K. A. (2005). Role of the serotonin 5-HT2A receptor in the hyperlocomotive and hyperthermic effects of (+)-3,4-methylenedioxymethamphetamine. Psychopharmacology (Berl), 178(4), 505-513. 
Hervas, I., Bel, N., Fernandez, A. G., Palacios, J. M., \& Artigas, F. (1998). In vivo control of 5-hydroxytryptamine release by terminal autoreceptors in rat brain areas differentially innervated by the dorsal and median raphe nuclei. Naunyn Schmiedebergs Arch Pharmacol, 358(3), 315-322.

Higgins, G. A., Bradbury, A. J., Jones, B. J., \& Oakley, N. R. (1988). Behavioural and biochemical consequences following activation of 5HT1-like and GABA receptors in the dorsal raphe nucleus of the rat. Neuropharmacology, 27(10), 993-1001.

Higgins, G. A., \& Elliott, P. J. (1991). Differential behavioural activation following intra-raphe infusion of 5-HT1A receptor agonists. Eur J Pharmacol, 193(3), 351-356.

Hillegaart, V. (1991). Effects of local application of 5-HT and 8-OH-DPAT into the dorsal and median raphe nuclei on core temperature in the rat. Psychopharmacology (Berl), 103(3), 291-296.

Hillegaart, V., Hjorth, S., \& Ahlenius, S. (1990). Effects of 5-HT and 8-OHDPAT on forebrain monoamine synthesis after local application into the median and dorsal raphe nuclei of the rat. J Neural Transm Gen Sect, 81(2), 131-145.

Hiramatsu, M., \& Cho, A. K. (1990). Enantiomeric differences in the effects of 3,4-methylenedioxymethamphetamine on extracellular monoamines and metabolites in the striatum of freely-moving rats: an in vivo microdialysis study. Neuropharmacology, 29(3), 269-275.

Hjorth, S. (1985). Hypothermia in the rat induced by the potent serotoninergic agent 8-OH-DPAT. J Neural Transm, 61(1-2), 131-135.

Ho, Y. J., Pawlak, C. R., Guo, L., \& Schwarting, R. K. (2004). Acute and longterm consequences of single MDMA administration in relation to individual anxiety levels in the rat. Behav Brain Res, 149(2), 135-144.

Hopwood, S. E., \& Stamford, J. A. (2001). Multiple 5-HT(1) autoreceptor subtypes govern serotonin release in dorsal and median raphe nuclei. Neuropharmacology, 40(4), 508-519.

Hornung, J. P. (2003). The human raphe nuclei and the serotonergic system. J Chem Neuroanat, 26(4), 331-343.

Howell, L. L., \& Kimmel, H. L. (2008). Monoamine transporters and psychostimulant addiction. Biochem Pharmacol, 75(1), 196-217.

Hoyer, D., Clarke, D. E., Fozard, J. R., Hartig, P. R., Martin, G. R., Mylecharane, E. J., et al. (1994). International Union of Pharmacology classification of 
receptors for 5-hydroxytryptamine (Serotonin). Pharmacol Rev, 46(2), 157-203.

Hoyer, D., Hannon, J. P., \& Martin, G. R. (2002). Molecular, pharmacological and functional diversity of 5-HT receptors. Pharmacol Biochem Behav, 71(4), 533-554.

Hughes, R. N. (2007). Neotic preferences in laboratory rodents: issues, assessment and substrates. Neurosci Biobehav Rev, 31(3), 441-464.

Hughes, R. N., \& Pither, J. M. (1987). Chronic imipramine effects on exploratory behavior in rats. Pharmacol Biochem Behav, 27(2), 359-362.

Ikemoto, K., Nishimura, A., Okado, N., Mikuni, M., Nishi, K., \& Nagatsu, I. (2000). Human midbrain dopamine neurons express serotonin 2A receptor: an immunohistochemical demonstration. Brain Res, 853(2), 377380.

Jacobs, B. L., Wise, W. D., \& Taylor, K. M. (1974). Differential behavioral and neurochemical effects following lesions of the dorsal or median raphe nuclei in rats. Brain Res, 79(3), 353-361.

Jensen, K. F., Olin, J., Haykal-Coates, N., O'Callaghan, J., Miller, D. B., \& de Olmos, J. S. (1993). Mapping toxicant-induced nervous system damage with a cupric silver stain: a quantitative analysis of neural degeneration induced by 3,4-methylenedioxymethamphetamine. NIDA Res Monogr, 136, 133-149; discussion 150-134.

Johnson, M. P., Conarty, P. F., \& Nichols, D. E. (1991). [3H]monoamine releasing and uptake inhibition properties of 3,4methylenedioxymethamphetamine and p-chloroamphetamine analogues. Eur J Pharmacol, 200(1), 9-16.

Johnson, M. P., Hoffman, A. J., \& Nichols, D. E. (1986). Effects of the enantiomers of MDA, MDMA and related analogues on $[3 \mathrm{H}]$ serotonin and $[3 \mathrm{H}]$ dopamine release from superfused rat brain slices. Eur J Pharmacol, 132(2-3), 269-276.

Jones, K., Brennan, K., Schenk, S. (2009). Tolerance to 3,4methylenedioxymethamphetamine is associated with impaired transporter mediated serotonin release. (Unpublished).

Kehne, J. H., Ketteler, H. J., McCloskey, T. C., Sullivan, C. K., Dudley, M. W., \& Schmidt, C. J. (1996). Effects of the selective 5-HT2A receptor antagonist MDL 100,907 on MDMA-induced locomotor stimulation in rats. Neuropsychopharmacology, 15(2), 116-124. 
Kelai, S., Renoir, T., Chouchana, L., Saurini, F., Hanoun, N., Hamon, M., et al. (2008). Chronic voluntary ethanol intake hypersensitizes 5-HT(1A) autoreceptors in C57BL/6J mice. J Neurochem, 107(6), 1660-1670.

Kennett, G. A., \& Curzon, G. (1988). Evidence that mCPP may have behavioural effects mediated by central 5-HT1C receptors. Br J Pharmacol, 94(1), 137-147.

Kennett, G. A., Marcou, M., Dourish, C. T., \& Curzon, G. (1987). Single administration of 5-HT1A agonists decreases 5-HT1A presynaptic, but not postsynaptic receptor-mediated responses: relationship to antidepressantlike action. Eur J Pharmacol, 138(1), 53-60.

Kennett, G. A., Wood, M. D., Bright, F., Cilia, J., Piper, D. C., Gager, T., et al. (1996). In vitro and in vivo profile of SB 206553, a potent 5-HT2C/5HT2B receptor antagonist with anxiolytic-like properties. Br J Pharmacol, $117(3), 427-434$.

Kennett, G. A., Wood, M. D., Bright, F., Trail, B., Riley, G., Holland, V., et al. (1997). SB 242084, a selective and brain penetrant 5-HT2C receptor antagonist. Neuropharmacology, 36(4-5), 609-620.

Kennett, G. A., Wood, M. D., Glen, A., Grewal, S., Forbes, I., Gadre, A., et al. (1994). In vivo properties of SB 200646A, a 5-HT2C/2B receptor antagonist. Br J Pharmacol, 111(3), 797-802.

Kitamura, Y., Kitagawa, K., Fujitani, Y., Shibata, K., Araki, H., Sendou, T., et al. (2007). The 5-HT1A receptor full agonist, 8-OH-DPAT inhibits ACTHinduced 5-HT2A receptor hyperfunction in rats: involvement of 5-HT1 A receptors in the DOI-induced wet-dog shakes in ACTH-treated rats. Biol Pharm Bull, 30(1), 117-120.

Kleven, M.S., Assie, M. B., \& Koek, W. (1997). Pharmacological characterization of in vivo properties of putative mixed 5-HT1 A agonist/5-HT(2A/2C) antagonist anxiolytics. II. Drug discrimination and behavioral observation studies in rats. J Pharmacol Exp Ther, 282(2), 747-759.

Kleven, M., Ybema, C., Carilla, E., Hamon, M., \& Koek, W. (1995). Modification of behavioral effects of 8-hydroxy-2-(di-n-propylamino)tetralin following chronic ethanol consumption in the rat: evidence for the involvement of 5HT1A receptors in ethanol dependence. Eur J Pharmacol, 281(3), 219228.

Kreiss, D. S., \& Lucki, I. (1994). Differential regulation of serotonin (5-HT) release in the striatum and hippocampus by 5-HT1A autoreceptors of the dorsal and median raphe nuclei. J Pharmacol Exp Ther, 269(3), 12681279. 
Lester, S. J., Baggott, M., Welm, S., Schiller, N. B., Jones, R. T., Foster, E., et al. (2000). Cardiovascular effects of 3,4-methylenedioxymethamphetamine. A double-blind, placebo-controlled trial. Ann Intern Med, 133(12), 969973.

Lew, R., Sabol, K. E., Chou, C., Vosmer, G. L., Richards, J., \& Seiden, L. S. (1996). Methylenedioxymethamphetamine-induced serotonin deficits are followed by partial recovery over a 52-week period. Part II: Radioligand binding and autoradiography studies. J Pharmacol Exp Ther, 276(2), 855865.

Liechti, M. E., Baumann, C., Gamma, A., \& Vollenweider, F. X. (2000a). Acute psychological effects of 3,4-methylenedioxymethamphetamine (MDMA, "Ecstasy") are attenuated by the serotonin uptake inhibitor citalopram. Neuropsychopharmacology, 22(5), 513-521.

Liechti, M. E., Saur, M. R., Gamma, A., Hell, D., \& Vollenweider, F. X. (2000b). Psychological and physiological effects of MDMA ("Ecstasy") after pretreatment with the 5-HT(2) antagonist ketanserin in healthy humans. Neuropsychopharmacology, 23(4), 396-404.

Lin, H. Q., Burden, P. M., Christie, M. J., \& Johnston, G. A. (1999). The anxiogenic-like and anxiolytic-like effects of MDMA on mice in the elevated plus-maze: a comparison with amphetamine. Pharmacol Biochem Behav, 62(3), 403-408.

Lopez-Gimenez, J. F., Mengod, G., Palacios, J. M., \& Vilaro, M. T. (1997). Selective visualization of rat brain 5-HT2A receptors by autoradiography with [3H]MDL 100,907. Naunyn Schmiedebergs Arch Pharmacol, 356(4), 446-454.

Lopez-Gimenez, J. F., Mengod, G., Palacios, J. M., \& Vilaro, M. T. (2001). Regional distribution and cellular localization of 5-HT2C receptor mRNA in monkey brain: comparison with $[3 \mathrm{H}]$ mesulergine binding sites and choline acetyltransferase mRNA. Synapse, 42(1), 12-26.

Lucas, G., \& Spampinato, U. (2000). Role of striatal serotonin2A and serotonin2C receptor subtypes in the control of in vivo dopamine outflow in the rat striatum. J Neurochem, 74(2), 693-701.

Lucki, I., Ward, H. R., \& Frazer, A. (1989). Effect of 1-(mchlorophenyl)piperazine and 1-(m-trifluoromethylphenyl)piperazine on locomotor activity. J Pharmacol Exp Ther, 249(1), 155-164.

Lyles, J., \& Cadet, J. L. (2003). Methylenedioxymethamphetamine (MDMA, Ecstasy) neurotoxicity: cellular and molecular mechanisms. Brain Res Brain Res Rev, 42(2), 155-168. 
Mannoury la Cour, C., Boni, C., Hanoun, N., Lesch, K. P., Hamon, M., \& Lanfumey, L. (2001). Functional consequences of 5-HT transporter gene disruption on 5-HT(1a) receptor-mediated regulation of dorsal raphe and hippocampal cell activity. J Neurosci, 21(6), 2178-2185.

Marco, E. J., Moreno, M. J., \& de Pablo, A. L. (1999). Local treatments of dorsal raphe nucleus induce changes in serotonergic activity in rat major cerebral arteries. Stroke, 30(8), 1695-1701.

Marston, H. M., Reid, M. E., Lawrence, J. A., Olverman, H. J., \& Butcher, S. P. (1999). Behavioural analysis of the acute and chronic effects of MDMA treatment in the rat. Psychopharmacology (Berl), 144(1), 67-76.

Martin, J. R., Bos, M., Jenck, F., Moreau, J., Mutel, V., Sleight, A. J., et al. (1998). 5-HT2C receptor agonists: pharmacological characteristics and therapeutic potential. J Pharmacol Exp Ther, 286(2), 913-924.

Mas, M., Farre, M., de la Torre, R., Roset, P. N., Ortuno, J., Segura, J., et al. (1999). Cardiovascular and neuroendocrine effects and pharmacokinetics of 3, 4-methylenedioxymethamphetamine in humans. J Pharmacol Exp Ther, 290(1), 136-145.

Matuszewich, L., Filon, M. E., Finn, D. A., \& Yamamoto, B. K. (2002). Altered forebrain neurotransmitter responses to immobilization stress following 3,4-methylenedioxymethamphetamine. Neuroscience, 110(1), 41-48.

McCann, U. D., Mertl, M., Eligulashvili, V., \& Ricaurte, G. A. (1999). Cognitive performance in (+/-) 3,4-methylenedioxymethamphetamine (MDMA, "ecstasy") users: a controlled study. Psychopharmacology (Berl), 143(4), 417-425.

McCann, U. D., Szabo, Z., Scheffel, U., Dannals, R. F., \& Ricaurte, G. A. (1998). Positron emission tomographic evidence of toxic effect of MDMA ("Ecstasy") on brain serotonin neurons in human beings. Lancet, 352(9138), 1433-1437.

McCardle, K., Luebbers, S., Carter, J. D., Croft, R. J., \& Stough, C. (2004). Chronic MDMA (ecstasy) use, cognition and mood. Psychopharmacology (Berl), 173(3-4), 434-439.

McCreary, A. C., Bankson, M. G., \& Cunningham, K. A. (1999).

Pharmacological studies of the acute and chronic effects of (+)-3, 4methylenedioxymethamphetamine on locomotor activity: role of 5hydroxytryptamine(1A) and 5-hydroxytryptamine(1B/1D) receptors. $J$ Pharmacol Exp Ther, 290(3), 965-973.

McGregor, I. S., Clemens, K. J., Van der Plasse, G., Li, K. M., Hunt, G. E., Chen, F., et al. (2003). Increased anxiety 3 months after brief exposure to 
MDMA ("Ecstasy") in rats: association with altered 5-HT transporter and receptor density. Neuropsychopharmacology, 28(8), 1472-1484.

McNamara, M. G., Kelly, J. P., \& Leonard, B. E. (1995). Some behavioural and neurochemical aspects of subacute $(+/-) 3,4-$ methylenedioxymethamphetamine administration in rats. Pharmacol Biochem Behav, 52(3), 479-484.

McQuade, R., \& Sharp, T. (1995). Release of cerebral 5-hydroxytryptamine evoked by electrical stimulation of the dorsal and median raphe nuclei: effect of a neurotoxic amphetamine. Neuroscience, 68(4), 1079-1088.

Mechan, A. O., Esteban, B., O'Shea, E., Elliott, J. M., Colado, M. I., \& Green, A. R. (2002a). The pharmacology of the acute hyperthermic response that follows administration of 3,4-methylenedioxymethamphetamine (MDMA, 'ecstasy') to rats. Br J Pharmacol, 135(1), 170-180.

Mechan, A. O., Moran, P. M., Elliott, M., Young, A. J., Joseph, M. H., \& Green, R. (2002b). A study of the effect of a single neurotoxic dose of 3,4methylenedioxymethamphetamine (MDMA; "ecstasy") on the subsequent long-term behaviour of rats in the plus maze and open field. Psychopharmacology (Berl), 159(2), 167-175.

Mechan, A. O., O'Shea, E., Elliott, J. M., Colado, M. I., \& Green, A. R. (2001). A neurotoxic dose of 3,4-methylenedioxymethamphetamine (MDMA; ecstasy) to rats results in a long-term defect in thermoregulation. Psychopharmacology (Berl), 155(4), 413-418.

Meltzer, H. Y., \& Nash, J. F. (1991). Effects of antipsychotic drugs on serotonin receptors. Pharmacol Rev, 43(4), 587-604.

Merrill, J. (1996). Ecstasy and neurodegeneration. Advice is that "less is more". Bmj, 313(7054), 423.

Mlinar, B., \& Corradetti, R. (2003). Endogenous 5-HT, released by MDMA through serotonin transporter- and secretory vesicle-dependent mechanisms, reduces hippocampal excitatory synaptic transmission by preferential activation of 5-HT1B receptors located on CA1 pyramidal neurons. Eur J Neurosci, 18(6), 1559-1571.

Molliver, M. E., Berger, U. V., Mamounas, L. A., Molliver, D. C., O'Hearn, E., \& Wilson, M. A. (1990). Neurotoxicity of MDMA and related compounds: anatomic studies. Ann N Y Acad Sci, 600, 649-661; discussion 661-644.

Morgan, M. J. (2000). Ecstasy (MDMA): a review of its possible persistent psychological effects. Psychopharmacology (Berl), 152(3), 230-248. 
Morgan, M. J., McFie, L., Fleetwood, H., \& Robinson, J. A. (2002). Ecstasy (MDMA): are the psychological problems associated with its use reversed by prolonged abstinence? Psychopharmacology (Berl), 159(3), 294-303.

Morley, K. C., Arnold, J. C., \& McGregor, I. S. (2005). Serotonin (1A) receptor involvement in acute 3,4-methylenedioxymethamphetamine (MDMA) facilitation of social interaction in the rat. Prog Neuropsychopharmacol Biol Psychiatry, 29(5), 648-657.

Morley, K. C., Gallate, J. E., Hunt, G. E., Mallet, P. E., \& McGregor, I. S. (2001). Increased anxiety and impaired memory in rats 3 months after administration of 3,4-methylenedioxymethamphetamine ("ecstasy"). Eur $J$ Pharmacol, 433(1), 91-99.

Morley, K. C., \& McGregor, I. S. (2000). (+/-)-3,4methylenedioxymethamphetamine (MDMA, 'Ecstasy') increases social interaction in rats. Eur J Pharmacol, 408(1), 41-49.

Moser, P. C. (1991). The effect of putative 5-HT1A receptor antagonists on 8OH-DPAT-induced hypothermia in rats and mice. Eur J Pharmacol, 193(2), 165-172.

Mundey, M. K., Fletcher, A., \& Marsden, C. A. (1996). Effects of 8-OHDPAT and 5-HT1A antagonists WAY100135 and WAY100635, on guinea-pig behaviour and dorsal raphe 5-HT neurone firing. Br J Pharmacol, 117(4), 750-756.

Nair, S. G., \& Gudelsky, G. A. (2006). Effect of a serotonin depleting regimen of 3,4-methylenedioxymethamphetamine (MDMA) on the subsequent stimulation of acetylcholine release in the rat prefrontal cortex. Brain Res Bull, 69(4), 382-387.

Nash, J. F., Arora, R. C., Schreiber, M. A., \& Meltzer, H. Y. (1991). Effect of 3,4methylenedioxymethamphetamine on $[3 \mathrm{H}]$ paroxetine binding in the frontal cortex and blood platelets of rats. Biochem Pharmacol, 41(1), 7984.

Nichols, D. E., \& Oberlender, R. (1990). Structure-activity relationships of MDMA and related compounds: a new class of psychoactive drugs? Ann N Y Acad Sci, 600, 613-623; discussion 623-615.

Nocjar, C., Roth, B. L., \& Pehek, E. A. (2002). Localization of 5-HT(2A) receptors on dopamine cells in subnuclei of the midbrain A10 cell group. Neuroscience, 111(1), 163-176.

O'Callaghan, J. P., \& Miller, D. B. (1993). Quantification of reactive gliosis as an approach to neurotoxicity assessment. NIDA Res Monogr, 136, 188-212. 
O'Hearn, E., Battaglia, G., De Souza, E.B., Kuhar, M.J., Molliver, M.E. (1988). Methylenedioxyamphetamine (MDA) and methylenedioxymethamphetamine (MDMA) cause selective ablation of serotonergic axon terminals in forebrain: immunocytochemical evidence for neurotoxicity. J Neurosci, 8(8), 2788-2803.

Pare, W. P., Tejani-Butt, S., \& Kluczynski, J. (2001). The emergence test: effects of psychotropic drugs on neophobic disposition in Wistar Kyoto (WKY) and Sprague Dawley rats. Prog Neuropsychopharmacol Biol Psychiatry, 25(8), 1615-1628.

Parrott, A. C. (2001). Human psychopharmacology of Ecstasy (MDMA): a review of 15 years of empirical research. Hum Psychopharmacol, 16(8), 557-577.

Parrott, A. C. (2002). Recreational Ecstasy/MDMA, the serotonin syndrome, and serotonergic neurotoxicity. Pharmacol Biochem Behav, 71(4), 837-844.

Parrott, A. C. (2004a). Is ecstasy MDMA? A review of the proportion of ecstasy tablets containing MDMA, their dosage levels, and the changing perceptions of purity. Psychopharmacology (Berl), 173(3-4), 234-241.

Parrott, A. C. (2004b). Is ecstasy MDMA? A review of the proportion of ecstasy tablets containing MDMA, their dosage levels, and the changing perceptions of purity. Psychopharmacology (Berl), 173(3-4), 234-241.

Parrott, A. C. (2005). Chronic tolerance to recreational MDMA (3,4methylenedioxymethamphetamine or Ecstasy). Journal of Psychopharmacology, 19(1), 71-83.

Parrott, A. C., Buchanan, T., Scholey, A. B., Heffernan, T., Ling, J., \& Rodgers, J. (2002). Ecstasy/MDMA attributed problems reported by novice, moderate and heavy recreational users. Hum Psychopharmacol, 17(6), 309-312.

Parrott, A. C., \& Lasky, J. (1998). Ecstasy (MDMA) effects upon mood and cognition: before, during and after a Saturday night dance. Psychopharmacology (Berl), 139(3), 261-268.

Parrott, A. C., Milani, R. M., Parmar, R., \& Turner, J. D. (2001). Recreational ecstasy/MDMA and other drug users from the UK and Italy: psychiatric symptoms and psychobiological problems. Psychopharmacology (Berl), 159(1), 77-82.

Paulus, M. P., \& Geyer, M. A. (1992). The effects of MDMA and other methylenedioxy-substituted phenylalkylamines on the structure of rat locomotor activity. Neuropsychopharmacology, 7(1), 15-31. 
Paxinos G, Watson, C (2005). The Rat Brain in Stereotaxic Coordinates. San Diego: Academic Press

Pazos, A., Cortes, R., \& Palacios, J. M. (1985). Quantitative autoradiographic mapping of serotonin receptors in the rat brain. II. Serotonin-2 receptors. Brain Res, 346(2), 231-249.

Pazos, A., \& Palacios, J. M. (1985). Quantitative autoradiographic mapping of serotonin receptors in the rat brain. I. Serotonin-1 receptors. Brain Res, 346(2), 205-230.

Pedigo, N. W., Yamamura, H. I., \& Nelson, D. L. (1981). Discrimination of multiple $[3 \mathrm{H}] 5$-hydroxytryptamine binding sites by the neuroleptics spiperone in the rat brain. Journal of Neurochemistry, 36, 205-230.

Penington, N. J., Kelly, J. S., \& Fox, A. P. (1993a). Unitary properties of potassium channels activated by 5 -HT in acutely isolated rat dorsal raphe neurones. J Physiol, 469, 407-426.

Penington, N. J., Kelly, J. S., \& Fox, A. P. (1993b). Whole-cell recordings of inwardly rectifying $\mathrm{K}+$ currents activated by 5 -HT1A receptors on dorsal raphe neurones of the adult rat. J Physiol, 469, 387-405.

Peroutka, S. J., Lebovitz, R. M., \& Snyder, S. H. (1981). Two distinct central serotonin receptors with different physiological functions. Science, 212(4496), 827-829.

Peroutka, S. J., Newman, H., \& Harris, H. (1988). Subjective effects of 3,4methylenedioxymethamphetamine in recreational users. Neuropsychopharmacology, 1(4), 273-277.

Peroutka, S. J., \& Snyder, S. H. (1980). Regulation of serotonin2 (5-HT2) receptors labeled with $[3 \mathrm{H}]$ spiroperidol by chronic treatment with the antidepressant amitriptyline. J Pharmacol Exp Ther, 215(3), 582-587.

Pettibone, D. J., \& Williams, M. (1984). Serotonin-releasing effects of substituted piperazines in vitro. Biochem Pharmacol, 33(9), 1531-1535.

Pineyro, G., \& Blier, P. (1999). Autoregulation of serotonin neurons: role in antidepressant drug action. Pharmacol Rev, 51(3), 533-591.

Piper, B. J., Fraiman, J. B., \& Meyer, J. S. (2005). Repeated MDMA ("Ecstasy") exposure in adolescent male rats alters temperature regulation, spontaneous motor activity, attention, and serotonin transporter binding. Dev Psychobiol, 47(2), 145-157. 
Piper, B. J., \& Meyer, J. S. (2004). Memory deficit and reduced anxiety in young adult rats given repeated intermittent MDMA treatment during the periadolescent period. Pharmacol Biochem Behav, 79(4), 723-731.

Piper, B. J., \& Meyer, J. S. (2006). Increased responsiveness to MDMA in adult rats treated neonatally with MDMA. Neurotoxicol Teratol, 28(1), 95-102.

Pompeiano, M., Palacios, J. M., \& Mengod, G. (1994). Distribution of the serotonin 5-HT2 receptor family mRNAs: comparison between 5-HT2A and 5-HT2C receptors. Brain Res Mol Brain Res, 23(1-2), 163-178.

Price, L. H., Ricaurte, G. A., Krystal, J. H., \& Heninger, G. R. (1989).

Neuroendocrine and mood responses to intravenous L-tryptophan in 3,4methylenedioxymethamphetamine (MDMA) users. Preliminary observations. Arch Gen Psychiatry, 46(1), 20-22.

Pubill, D., Canudas, A. M., Pallas, M., Camins, A., Camarasa, J., \& Escubedo, E. (2003). Different glial response to methamphetamine- and methylenedioxymethamphetamine-induced neurotoxicity. Naunyn Schmiedebergs Arch Pharmacol, 367(5), 490-499.

Pucadyil, T. J., Kalipatnapu, S., \& Chattopadhyay, A. (2005). The Serotonin1A Receptor: A Representative Member of the Serotonin Receptor Family. Cellular and Molecular Neurobiology, 25(3/4), 553-580.

Reneman, L., Booij, J., Majoie, C. B., Van Den Brink, W., \& Den Heeten, G. J. (2001). Investigating the potential neurotoxicity of Ecstasy (MDMA): an imaging approach. Hum Psychopharmacol, 16(8), 579-588.

Reneman, L., Booij, J., Schmand, B., van den Brink, W., \& Gunning, B. (2000). Memory disturbances in "Ecstasy" users are correlated with an altered brain serotonin neurotransmission. Psychopharmacology (Berl), 148(3), 322-324.

Reneman, L., Endert, E., de Bruin, K., Lavalaye, J., Feenstra, M. G., de Wolff, F. A., et al. (2002). The acute and chronic effects of MDMA ("ecstasy") on cortical 5-HT2A receptors in rat and human brain.

Neuropsychopharmacology, 26(3), 387-396.

Renoir, T., Paizanis, E., Yacoubi, M. E., Saurini, F., Hanoun, N., Melfort, M., et al. (2008). Differential long-term effects of MDMA on the serotoninergic system and hippocampal cell proliferation in 5-HTT knock-out vs. wildtype mice. Int J Neuropsychopharmacol, 11(8), 1149-1162.

Riad, M., Garcia, S., Watkins, K. C., Jodoin, N., Doucet, E., Langlois, X., et al. (2000). Somatodendritic localization of 5-HT1A and preterminal axonal localization of 5-HT1B serotonin receptors in adult rat brain. J Comp Neurol, 417(2), 181-194. 
Riad, M., Watkins, K. C., Doucet, E., Hamon, M., \& Descarries, L. (2001). Agonist-induced internalization of serotonin-1a receptors in the dorsal raphe nucleus (autoreceptors) but not hippocampus (heteroreceptors). $J$ Neurosci, 21(21), 8378-8386.

Ricaurte, G. A., Forno, L. S., Wilson, M. A., DeLanney, L. E., Irwin, I., Molliver, M. E., et al. (1988). (+/-)3,4-Methylenedioxymethamphetamine selectively damages central serotonergic neurons in nonhuman primates. Jama, 260(1), 51-55.

Richtand, N. M., Welge, J. A., Levant, B., Logue, A. D., Hayes, S., Pritchard, L. M., et al. (2003). Altered behavioral response to dopamine D3 receptor agonists 7-OH-DPAT and PD 128907 following repetitive amphetamine administration. Neuropsychopharmacology, 28(8), 1422-1432.

Roberts, C., Boyd, D. F., Middlemiss, D. N., \& Routledge, C. (1999). Enhancement of 5-HT1B and 5-HT1D receptor antagonist effects on extracellular 5-HT levels in the guinea-pig brain following concurrent 5HT1A or 5-HT re-uptake site blockade. Neuropharmacology, 38(9), 14091419.

Ross, J. D., Herin, D. V., Frankel, P. S., Thomas, M. L., \& Cunningham, K. A. (2006). Chronic treatment with a serotonin(2) receptor (5-HT(2)R) agonist modulates the behavioral and cellular response to (+)-3,4methylenedioxymethamphetamine [(+)-MDMA]. Drug Alcohol Depend, 81(2), 117-127.

Rothman, R. B., \& Baumann, M. H. (2002). Serotonin releasing agents. Neurochemical, therapeutic and adverse effects. Pharmacol Biochem Behav, 71(4), 825-836.

Rudnick, G., \& Wall, S. C. (1992). The molecular mechanism of "ecstasy" [3,4methylenedioxy-methamphetamine (MDMA)]: serotonin transporters are targets for MDMA-induced serotonin release. Proc Natl Acad Sci U S A, 89(5), 1817-1821.

Rusyniak, D. E., Zaretskaia, M. V., Zaretsky, D. V., \& DiMicco, J. A. (2007). 3,4Methylenedioxymethamphetamine- and 8-hydroxy-2-di-n-propylaminotetralin-induced hypothermia: role and location of 5-hydroxytryptamine 1A receptors. J Pharmacol Exp Ther, 323(2), 477-487.

Sastre-Coll, A., Esteban, S., \& Garcia-Sevilla, J. A. (2002). Supersensitivity of 5HT1A autoreceptors and alpha2-adrenoceptors regulating monoamine synthesis in the brain of morphine-dependent rats. Naunyn Schmiedebergs Arch Pharmacol, 365(3), 210-219. 
Scanzello, C. R., Hatzidimitriou, G., Martello, A. L., Katz, J. L., \& Ricaurte, G. A. (1993). Serotonergic recovery after (+/-)3,4-(methylenedioxy) methamphetamine injury: observations in rats. $J$ Pharmacol Exp Ther, 264(3), 1484-1491.

Schechter, M. D. (1991). Effect of MDMA neurotoxicity upon its conditioned place preference and discrimination. Pharmacol Biochem Behav, 38(3), 539-544.

Schenk, S., Hely, L., Lake, B., Daniela, E., Gittings, D., \& Mash, D. C. (2007). MDMA self-administration in rats: acquisition, progressive ratio responding and serotonin transporter binding. Eur J Neurosci, 26(11), 3229-3236.

Schmidt, C. J. (1987). Neurotoxicity of the psychedelic amphetamine, methylenedioxymethamphetamine. J Pharmacol Exp Ther, 240(1), 1-7.

Schmidt, C. J., Abbate, G. M., Black, C. K., \& Taylor, V. L. (1990). Selective 5hydroxytryptamine 2 receptor antagonists protect against the neurotoxicity of methylenedioxymethamphetamine in rats. $J$ Pharmacol Exp Ther, 255(2), 478-483.

Schmidt, C. J., Levin, J. A., \& Lovenberg, W. (1987). In vitro and in vivo neurochemical effects of methylenedioxymethamphetamine on striatal monoaminergic systems in the rat brain. Biochem Pharmacol, 36(5), 747755.

Schmitt, U., \& Hiemke, C. (1998). Strain differences in open-field and elevated plus-maze behavior of rats without and with pretest handling. Pharmacol Biochem Behav, 59(4), 807-811.

Scholey, A. B., Parrott, A. C., Buchanan, T., Heffernan, T. M., Ling, J., \& Rodgers, J. (2004). Increased intensity of Ecstasy and polydrug usage in the more experienced recreational Ecstasy/MDMA users: A WWW study. Addictive Behaviors, 29(4), 743-752.

Schreiber, R., Brocco, M., Audinot, V., Gobert, A., Veiga, S., \& Millan, M. J. (1995). (1-(2,5-dimethoxy-4 iodophenyl)-2-aminopropane)-induced headtwitches in the rat are mediated by 5-hydroxytryptamine (5-HT) $2 \mathrm{~A}$ receptors: modulation by novel 5-HT2A/2C antagonists, D1 antagonists and 5-HT1A agonists. J Pharmacol Exp Ther, 273(1), 101-112.

Schreiber, R., Melon, C., \& De Vry, J. (1998). The role of 5-HT receptor subtypes in the anxiolytic effects of selective serotonin reuptake inhibitors in the rat ultrasonic vocalization test. Psychopharmacology (Berl), 135(4), 383-391.

Seiden, L. S., Woolverton, W. L., Lorens, S. A., Williams, J. E., Corwin, R. L., Hata, N., et al. (1993). Behavioral consequences of partial monoamine 
depletion in the CNS after methamphetamine-like drugs: the conflict between pharmacology and toxicology. NIDA Res Monogr, 136, 34-46; discussion 46-52.

Semple, D. M., Ebmeier, K. P., Glabus, M. F., O'Carroll, R. E., \& Johnstone, E. C. (1999). Reduced in vivo binding to the serotonin transporter in the cerebral cortex of MDMA ('ecstasy') users. Br J Psychiatry, 175, 63-69.

Series, H. G., Cowen, P. J., \& Sharp, T. (1994). p-Chloroamphetamine (PCA), 3,4-methylenedioxy-methamphetamine (MDMA) and d-fenfluramine pretreatment attenuates d-fenfluramine-evoked release of 5-HT in vivo. Psychopharmacology (Berl), 116(4), 508-514.

Shankaran, M., \& Gudelsky, G. A. (1999). A neurotoxic regimen of MDMA suppresses behavioral, thermal and neurochemical responses to subsequent MDMA administration. Psychopharmacology (Berl), 147(1), 66-72.

Sharp, T., Umbers, V., \& Hjorth, S. (1996). The role of 5-HT1A autoreceptors and alpha 1-adrenoceptors in the inhibition of 5-HT release--II NAN-190 and SDZ 216-525. Neuropharmacology, 35(6), 735-741.

Shioda, K., Nisijima, K., Yoshino, T., Kuboshima, K., Iwamura, T., Yui, K., et al. (2008). Risperidone attenuates and reverses hyperthermia induced by 3,4methylenedioxymethamphetamine (MDMA) in rats. Neurotoxicology, 29(6), 1030-1036.

SHORE, Centre for Social and Health Outcomes Research and Evaluation \& Te Ropu Whariki. Recent Trends in Illegal Drug Use in New Zealand, 2006: Massey University.

Shuto, T., Seeman, P., Kuroiwa, M., \& Nishi, A. (2008). Repeated administration of a dopamine D1 receptor agonist reverses the increased proportions of striatal dopamine D1High and D2High receptors in methamphetaminesensitized rats. Eur J Neurosci, 27(10), 2551-2557.

Slikker, W., Jr., Holson, R. R., Ali, S. F., Kolta, M. G., Paule, M. G., Scallet, A. C., et al. (1989). Behavioral and neurochemical effects of orally administered MDMA in the rodent and nonhuman primate. Neurotoxicology, 10(3), 529-542.

Solowij, N., Hall, W., \& Lee, N. (1992). Recreational MDMA use in Sydney: a profile of 'Ecstacy' users and their experiences with the drug. Br J Addict, 87(8), 1161-1172.

Spanos, L. J., \& Yamamoto, B. K. (1989). Acute and subchronic effects of methylenedioxymethamphetamine [(+/-)MDMA] on locomotion and serotonin syndrome behavior in the rat. Pharmacol Biochem Behav, 32(4), 835-840. 
Sprouse, J. S., Bradberry, C. W., Roth, R. H., \& Aghajanian, G. K. (1989). MDMA (3,4-methylenedioxymethamphetamine) inhibits cell firing of dorsal praphe neurons in brain slices via release of serotonin. European Journal of Pharmacology, 167, 375-383.

Stamford, J. A., Davidson, C., McLaughlin, D. P., \& Hopwood, S. E. (2000). Control of dorsal raphe 5-HT function by multiple 5-HT(1) autoreceptors: parallel purposes or pointless plurality? Trends Neurosci, 23(10), 459-465.

Steele, T. D., McCann, U. D., \& Ricaurte, G. A. (1994). 3,4Methylenedioxymethamphetamine (MDMA, "Ecstasy"): pharmacology and toxicology in animals and humans. Addiction, 89(5), 539-551.

Stone, D. M., Hanson, G. R., \& Gibb, J. W. (1989a). In vitro reactivation of rat cortical tryptophan hydroxylase following in vivo inactivation by methylenedioxymethamphetamine. J Neurochem, 53(2), 572-581.

Stone, D. M., Johnson, M., Hanson, G. R., \& Gibb, J. W. (1989b). Acute inactivation of tryptophan hydroxylase by amphetamine analogs involves the oxidation of sulfhydryl sites. Eur J Pharmacol, 172(1), 93-97.

Stone, D. M., Stahl, D. C., Hanson, G. R., \& Gibb, J. W. (1986). The effects of 3,4-methylenedioxymethamphetamine (MDMA) and 3,4methylenedioxyamphetamine (MDA) on monoaminergic systems in the rat brain. Eur J Pharmacol, 128(1-2), 41-48.

Sumnall, H. R., O'Shea, E., Marsden, C. A., \& Cole, J. C. (2004). The effects of MDMA pretreatment on the behavioural effects of other drugs of abuse in the rat elevated plus-maze test. Pharmacol Biochem Behav, 77(4), 805814.

Tohyama, Y., Yamane, F., Merid, M. F., \& Diksic, M. (2001). Effects of selective 5-HT1A receptor antagonists on regional serotonin synthesis in the rat brain: an autoradiographic study with alpha-[14C]methyl-L-tryptophan. Eur Neuropsychopharmacol, 11(3), 193-202.

Topp, L., Hando, J., Dillon, P., Roche, A., \& Solowij, N. (1999). Ecstasy use in Australia: patterns of use and associated harm. Drug Alcohol Depend, 55(1-2), 105-115.

Tricklebank, M. D., Forler, C., \& Fozard, J. R. (1984). The involvement of subtypes of the 5-HT1 receptor and of catecholaminergic systems in the behavioural response to 8-hydroxy-2-(di-n-propylamino)tetralin in the rat. Eur J Pharmacol, 106(2), 271-282. 
Underwood, M. D., Arango, V., Bakalian, M. J., Ruggiero, D. A., \& Mann, J. J. (1999). Dorsal raphe nucleus serotonergic neurons innervate the rostral ventrolateral medulla in rat. Brain Res, 824(1), 45-55.

United Nations Office on Drugs and Crime. (2004). World Drug Report. New York: United Nations Press Conference.

van Driel, K. S., \& Talling, J. C. (2005). Familiarity increases consistency in animal tests. Behav Brain Res, 159(2), 243-245.

Verge, D., Daval, G., Marcinkiewicz, M., Patey, A., el Mestikawy, S., Gozlan, H., et al. (1986). Quantitative autoradiography of multiple 5-HT1 receptor subtypes in the brain of control or 5,7-dihydroxytryptamine-treated rats. $J$ Neurosci, 6(12), 3474-3482.

Verheyden, S. L., Henry, J. A., \& Curran, H. V. (2003). Acute, sub-acute and long-term subjective consequences of 'ecstasy' (MDMA) consumption in 430 regular users. Hum Psychopharmacol, 18(7), 507-517.

Verkes, R. J., Gijsman, H. J., Pieters, M. S., Schoemaker, R. C., de Visser, S., Kuijpers, M., et al. (2001). Cognitive performance and serotonergic function in users of ecstasy. Psychopharmacology (Berl), 153(2), 196-202.

Vollenweider, F. X., Gamma, A., Liechti, M., \& Huber, T. (1998). Psychological and cardiovascular effects and short-term sequelae of MDMA ("ecstasy") in MDMA-naive healthy volunteers. Neuropsychopharmacology, 19(4), 241-251.

Wallace, T. L., Gudelsky, G. A., \& Vorhees, C. V. (2001). Alterations in diurnal and nocturnal locomotor activity in rats treated with a monoaminedepleting regimen of methamphetamine or 3,4methylenedioxymethamphetamine. Psychopharmacology (Berl), 153(3), 321-326.

Wang, X., Baumann, M. H., Dersch, C. M., \& Rothman, R. B. (2007). Restoration of 3,4-methylenedioxymethamphetamine-induced 5-HT depletion by the administration of L-5-hydroxytryptophan. Neuroscience, 148(1), 212-220.

Wang, X., Baumann, M. H., Xu, H., Morales, M., \& Rothman, R. B. (2005). (+/-)3,4-Methylenedioxymethamphetamine administration to rats does not decrease levels of the serotonin transporter protein or alter its distribution between endosomes and the plasma membrane. J Pharmacol Exp Ther, 314(3), 1002-1012.

Wang, X., Baumann, M. H., Xu, H., \& Rothman, R. B. (2004). 3,4methylenedioxymethamphetamine (MDMA) administration to rats decreases brain tissue serotonin but not serotonin transporter protein and glial fibrillary acidic protein. Synapse, 53(4), 240-248. 
White, S. R., Duffy, P., \& Kalivas, P. W. (1994).

Methylenedioxymethamphetamine depresses glutamate-evoked neuronal firing and increases extracellular levels of dopamine and serotonin in the nucleus accumbens in vivo. Neuroscience, 62(1), 41-50.

White, S. R., Obradovic, T., Imel, K. M., \& Wheaton, M. J. (1996). The effects of methylenedioxymethamphetamine (MDMA, "Ecstasy") on monoaminergic neurotransmission in the central nervous system. Progress in Neurobiology, 49(5), 455-479.

WHO, World Health Organisation Geneva. Ecstasy, MDMA and other ringsubstituted amphetamines. A global review. 2001.

Wilkins, C., Bhatta, K., Pledger, M., \& Casswell, S. (2003). Ecstasy use in New Zealand: findings from the 1998 and 2001 National Drug Surveys. $N Z$ Med J, 116(1171), U383.

Wilkins, C., Sweetsur, P., \& Casswell, S. (2006). Recent population trends in amphetamine use in New Zealand: comparisons of findings from national household drug surveying in 1998, 2001, and 2003. N Z Med J, 119(1244), U2285.

Willins, D. L., \& Meltzer, H. Y. (1997). Direct injection of 5-HT2A receptor agonists into the medial prefrontal cortex produces a head-twitch response in rats. J Pharmacol Exp Ther, 282(2), 699-706.

Yamamoto, B. K., Nash, J. F., \& Gudelsky, G. A. (1995). Modulation of methylenedioxymethamphetamine-induced striatal dopamine release by the interaction between serotonin and gamma-aminobutyric acid in the substantia nigra. J Pharmacol Exp Ther, 273(3), 1063-1070.

Young, A. H., MacDonald, L. M., St John, H., Dick, H., \& Goodwin, G. M. (1992). The effects of corticosterone on 5-HT receptor function in rodents. Neuropharmacology, 31(5), 433-438.

Zacny, J. P., Virus, R. M., \& Woolverton, W. L. (1990). Tolerance and crosstolerance to 3,4-methylenedioxymethamphetamine (MDMA), methamphetamine and methylenedioxyamphetamine. Pharmacol Biochem Behav, 35(3), 637-642.

Zifa, E., \& Fillion, G. (1992). 5-Hydroxytryptamine receptors. Pharmacol Rev, 44(3), 401-458. 